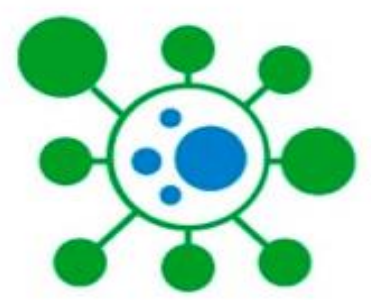

I SIMPÓSIO CLÍNICO

UNIVERSIDADE Nilton Lins MULTIPROFISSIONAL DE INFECTOLOGIA

Iocal: Auditório Vânia Pimentel - Universidade Nilton Lins

$$
16,17 \text { e } 18 \text { de outubro }
$$

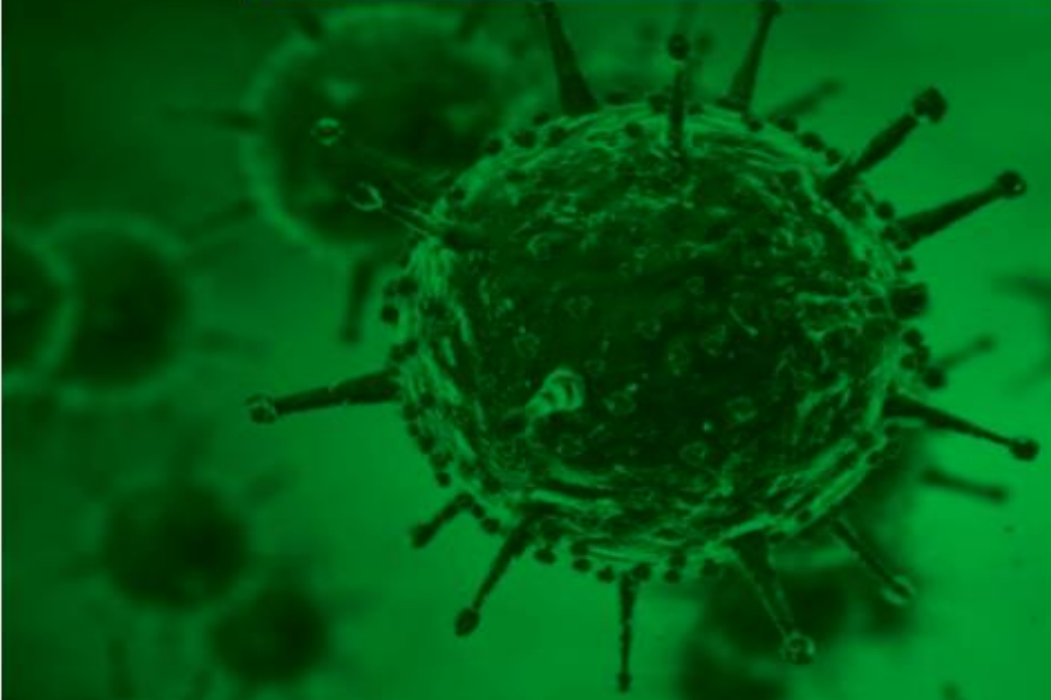

ÂpOI0:

\section{ACERVO Malis ioviscas}

As publicações mais rápidas do país!

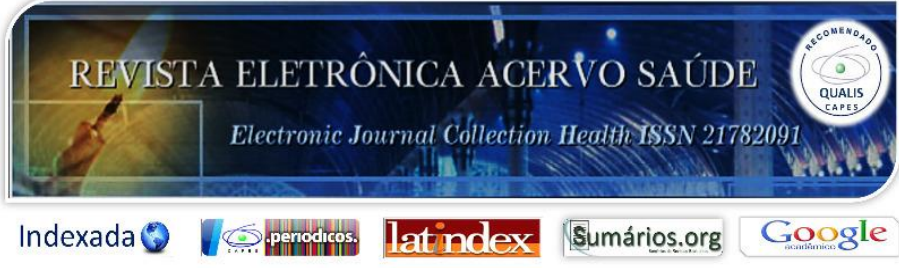




\section{APRESENTAÇÃO}

O $1^{\circ}$ Simpósio Clínico Multiprofissional de Infectologia foi realizado entre os dias 16,17 e 18 de outubro de 2019, no Auditório Vânia Pimentel, Universidade Nilton Lins; Manaus, Am.

O tema foi: Infectologia no contexto multiprofissional, destinado as áreas de enfermagem, medicina, farmácia, fisioterapia, nutrição, fonoaudiologia e biomedicina.

Este congresso teve como Presidente e Diretor Geral, o Prof. Enf. Esp. Railton da Silva Miranda, juntamente à Coordenação Organizadora nas pessoas de: Prof. Mestre Ana Carolina Moraes, Prof. Esp. Maria Gracimar Fecury e Prof. Esp. Michelli Domingos, sendo este os responsáveis pela produção do evento em consonância com a comissão científica e promovida pela Universidade Nilton Lins.

O evento contou com a participação de 320 ouvintes, 23 palestrantes e mais de 25 membros da comissão organizadora. Os principais temas abordados no Simpósio foram: HIV/AIDS, HTLV-1, Doença de chagas, leishmaniose tegumentar americana, infecção hospitalar, nutrição enteral e parenteral, fonoterapia em pacientes de UTI - Infectologia e animais peçonhentos. Houveram minicursos sobre Exame dermartoneurológico em pacientes suspeitos de hanseníase, processo de enfermagem em paciente com sepse, avaliação semiológica respiratória em pacientes com Pneumonia e Tuberculose.

O I Simpósio Clínico Multiprofissional de Infectologia, se consolidou como o único no contexto multiprofissional a ser realizado no Estado do Amazonas, nossa estimativa é de crescimento e desenvolvimento científico.

Enf. Esp. Railton da Silva Miranda Presidente do I Simpósio Clínico Multiprofissional de Infectologia. 


\title{
PRESIDENTE DO I SIMPÓSIO CLÍNICO MULTIPROFISSIONAL DE INFECTOLOGIA
}

RAILTON DA SILVA MIRANDA

\section{COMISSÃO ORGANIZADORA}

\author{
ANA CAROLINA DE MORAES CRUZ \\ MARIA GRACIMAR OLIVEIRA FECURY DA GAMA \\ MICHELLI DOMINGOS DA SILVA
}

BANCA AVALIADORA

Andreia Lábrea Pereira

Antônia Evilânnia Cavalcante Maciel Brandão

Cynthia Costa Guimarães

Débora Fortes de Oliveira

Fábio Batista Miranda

Janaína dos Santos Dias

Leonardo Barbosa Rolim

Ricardo Bezerra de Freitas 


\section{Sumário}

DIAGNÓSTICOS DA LEUCEMIA LINFÓIDE AGUDA: UMA REVISÃO DE

LITERATURA

MANEJO CLIINICO DE PACIENTES ACOMETIDOS POR PÊNFIGO VULGAR: UM

RELATO DE EXPERIÊNCIA.

ESTUDO EPIDEMIOLÓGICO DA TRANSMISSÃO DE SÍFILIS CONGÊNITA NO

ESTADO DO AMAZONAS

ATUAÇÃO DO ENFERMEIRO NA TESTAGEM RÁPIDA PARA IST'S NO PRÉ

NATAL: RELATO DE EXPERIÊNCIA.

FATORES QUE INTERFEREM NO DESEMPENHO DA UTILIZAÇÃO DE

LEITOS DE UMA UTI PARA ADULTOS EM UM HOSPITAL REFERÊNCIA EM

INFECTOLOGIA DO AMAZONAS

RESIDÊNCIA MULTIPROFISSIONAL EM SAÚDE: UM RELATO DE

EXPERIÊNCIA.

SENSIBILIZAÇÃO SOBRE O TEMA "SEXUALIDADE E HIV/AIDS" COM OS

DISCENTES DO LABORATÓRIO LECC-UFAM.

IMPORTÂNCIA DA EQUIPE DE ENFERMAGEM NA ACOLHIDA DE

GESTANTE COM ISTS: UM RELATO DE EXPERIÊNCIA.

RELATO DE EXPERIÊNCIA DOS ACADÊMICOS DE ENFERMAGEM NA

ASSISTÊNCIA AO PÊNFIGO FOLIÁCEO.

PROMOVENDO SAÚDE NO AMBIENTE ESCOLAR - IMUNIZAÇÃO AO

PAPILOMA VÍRUS HUMANO (HPV): UM RELATO DE

EXPERIÊNCIA.

PERCEPÇÃO DE ACOMPANHANTES DE PACIENTES DE UM HOSPITAL

SOBRE MEDIDAS DE PREVENÇÃO PARA TUBERCULOSE: RELATO DE

EXPERIÊNCIA.

EDUCAÇÃO EM SAUDE: ABORDAGEM DAS IST`s ESCOLARES PARA

MAIORES DE 18 ANOS - RELATO DE EXPERIÊNCIA

APRESENTAÇÃO DOS CASOS DE SARAMPO NO ESTADO DO AMAZONAS,

NO PERÍODO DE 2018 E 2019.

PERCEPÇÃO ACADÊMICA DE ENFERMAGEM - ASPECTOS CLÍNICOS DE

PACIENTES COM ALOPECIA SIFILÍTICA: RELATO DE

EXPERIÊNCIA...

RELATO DE EXPERIÊNCIA: PERCEPÇÃO DOS ACADÊMICOS DE

ENFERMAGEM FRENTE AO PACIENTE TUBERCULOSO NA ATENÇÃO

PRIMÁRIA.

MONITORIA ACADÊMICA DE AGENTES INFECTOPARASITÁRIOS PARA OS

ACADÊMICOS DE MEDICINA: UM RELATO DE EXPERIÊNCIA......................25

DIFICULDADES DO ACADÊMICO DE ENFERMAGEM NA REALIZAÇÃO DO

DIAGNÓSTICOS DAS IST'S - RELATO DE EXPERIÊNCIA.

ADESÃO A HIGIENE DAS MÃOS ENTRE A EQUIPE DE ENFERMAGEM DAS

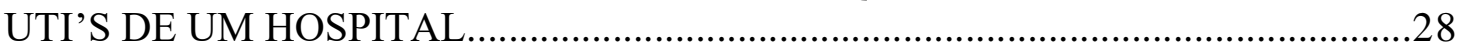

PROJETO DE EXTENSÃO SOBRE IST'S/AIDS PARA ADOLESCENTES:

RELATO DE EXPERIÊNCIA. 
A PERCEPÇÃO DOS ACADÊMICOS DE ENFERMAGEM FRENTE AO SURTO DO SARAMPO EM MANAUS - RELATO DE EXPERIÊNCIA.

CUIDADOS DE ENFERMAGEM NO TRATAMENTO DE PACIENTES COM HANSENÍASE: RELATO DE EXPERIÊNCIA..............................................................32 A IMPORTÂNCIA DA FISIOTERAPIA NO PROCESSO DE DECANULAÇÃO DE PACIENTES HOSPITALIZADOS NO SERVIÇO PÚBLICO DE SAÚDE: RELATO DE EXPERIÊNCIA

LEVANTAMENTO DA PREVALÊNCIA DA INFECÇÃO PELO PAPILOMA VÍRUS HUMANO (HPV) E O CÂNCER DE COLO DE ÙTERO NO BRASIL: REVISÃO SISTEMÁTICA

OCORRÊNCIA DE RELATOS DE TABAGISMO, ALCOOLISMO E USO DE DROGAS ILÍCITAS ENTRE PACIENTES COM TUBERCULOSE. 35 SÍNDROME DE GUILLAIN-BARRÉ ASSOCIADA AO HIV SOB OS CUIDADOS DE ENFERMAGEM: RELATO DE EXPERIÊNCIA. 37

RELATO DE EXPERIÊNCIA: ENFERMAGEM NA PREVENCÃO DAS INFECÇÕES URINARIAS RELACINADO A CATETER VESICAL DE DEMORA.................................38 RELATO DE EXPERIÊNCIA NA TERAPIA EMPIRICA DAS INFECÇÕES DO TRATO URINARIO NO IDOSO.

PERFIL SOCIODEMOGRÁFICO DE PACIENTES COM LESÃO POR PRESSÃO

DE UM HOSPITAL REFERÊNCIA EM INFECTOLOGIA/AM...................................40

CUIDADOS AO NEONATO COM MÃE PORTADORA DE SÍFILIS: UM RELATO

DE EXPERIÊNCIA

ASPECTOS CLÍNICOS DA MALÁRIA EM UMA UNIDADE HOSPITALAR DA

ZONA OESTE DE MANAUS .42

DIFICULDADES QUANTO A ABORDAGEM DE ENFERMAGEM SOBRE IST'S AO PÚBLICO ADOLESCENTE - RELATO DE EXPERIÊNCIA.

LIGA ACADÊMICA DE DOENÇAS TRANSMISSÍVEIS: A IMPORTÂNCIA DA EXTENSÃO UNIVERSITÁRIA NA FORMAÇÃO DO ENFERMEIRO... .44

DIALOGANDO COM O ADOLESCENTE SOBRE IST'S-AIDS EM ESCOLAS

PUBLICAS EM MANAUS: RELATO DE EXPERIÊNCIA 45

RELATO DE EXPERIÊNCIA DE ACADÊMICOS DE ENFERMAGEM NA

ASSISTÊNCIA DE ENFERMAGEM NA LEISMANIOSE VISCERAL.......47

ESTIGMAS EM PACIENTES COM HANSENÍASE: A MELHOR SOLUÇÃO É A

INFORMAÇÃO - RELATO DE EXPERIÊNCIA.. 48

ASSISTÊNCIA DE ENFERMAGEM A PACIENTES PORTADORES DE HIV/AIDS

INTERNADOS NA UNIDADE DE TERAPIA INTENSIVA (UTI).

RELATO DE EXPERIÊNCIA: A IMPORTÂNCIA DO CCIH FRENTE AO

PACIENTE COM DOENÇAS INFECTOCONTAGIOSAS.

IMPACTO DO TABACO AOS MORADORES DA ÁREA RIBEIRINHA DE

MANAUS RELACIONADO À TUBERCULOSE

BIOSSEGURANÇA E O USO DO JALECO EM AMBIENTE NÃO HOSPITALAR:

RELATO DE EXPERIÊNCIA

VIVÊNCIA NO CAMPO DE ESTÁGIO EM DOENÇAS INFECTOCONTAGIOSAS:

RELATO DE EXPERIÊNCIA. 54

RELATO DE EXPERIÊNCIA DOS ACADÊMICOS DE ENFERMAGEM FRENTE AO PACIENTE COM DOENÇA DE CHAGAS. .55 
MEDIDAS DE CONTROLE APLICADAS PARA A PREVENÇÃO DA TRANSMISSÃO DO MYCOBACTERIUM TUBERCULOSIS: RELATO DE EXPERIÊNCIA. .56

RELATO DE EXPERIÊNCIA SOBRE DOENÇAS INFECTOCONTAGIOSAS:

PROMOÇÃO E PREVENÇÃO A SAÚDE EM NO CENTRO

SOCIOEDUCATIVO .58

AÇÕES DE EDUCAÇÃO EM SAÚDE NO COMBATE AO ZIKA VÍRUS EM UMA ESCOLA DE MANAUS. 59

IDENTIFICAÇÃO DOS RISCOS DE INFECÇÃO DO VÍRUS HIV POR ACIDENTES DE TRABALHO ENTRE PROFISSIONAIS DE SAÚDE 60

ESTRATÉGIAS DE AÇÃO PARA CONTENÇÃO DO SURTO DE SARAMPO EM MANAUS: UM RELATO DE EXPERIÊNCIA 61

CUIDADOS DE ENFERMAGEM EM UM AMBULATÓRIO DE PÉ DIABÉTICO:

RELATO DE EXPERIÊNCIA 62

COBERTURA VACINAL DE H1N1 POR GRUPOS PRIORITÁRIOS EM MANAUS

$-\mathrm{AM}$. .64

ATUAÇÃO DA ENFERMAGEM NO SERVIÇO DE ASSISTÊNCIA

ESPECIALIZADA EM HIV/AIDS SOB A PERSPECTIVA DISCENTE .65

PROJETO "INFECTO NA ESCOLA" - O USO NA DISCIPLINA ENFERMAGEM

EM DOENÇAS INFECTOCONTAGIOSAS - RELATO DE

EXPERIÊNCIA. 66

LEISHMANIOSE MUCOSA: ASPECTOS CLÍNICOS, EPIDEMIOLÓGICOS E

EVOLUTIVOS DE PACIENTES ATENDIDOS EM UM CENTRO DE REFERÊNCIA EM MANAUS DE JANEIRO DE 2007 A DEZEMBRO DE

2016. 68

ASSISTÊNCIA À SAÚDE DA MULHER TRANSGÊNERO PORTADORA

DE HIV/AIDS NO BRASIL. 69

COINFECÇÃO DE CRIPTOCOCOSE E HISTOPLASMOSE EM IMUNOCOMPETENTES - REVISÃO DE LITERATURA 70

ATUAÇÃO DE ACADÊMICOS DE ENFERMAGEM NA CAMPANHA NACIONAL DE VACINAÇÃO CONTRA O SARAMPO 71 ATUAÇÃO DE ACADÊMICOS NA PROMOÇÃO DA SAÚDE A MULHERES ATRAVÉS DA EDUCAÇ̃̃O EM SAÚDE .72

ADMISSÃO DA PACIENTE NO PRÉ- PARTO E AVALIAÇÃO

SINTOMATOLÓGICA DE DOENÇAS INFECCIOSAS: RELATO DE EXPERIÊNCIA.................................................73

ATITUDES E PRÁTICAS DOS SERVIDORES DE UNIDADE DE PROCESSAMENTO DE ROUPAS DE SERVIÇOS DE SAÚDE SOBRE COMPORTAMENTO EM AMBIENTE DE LAVANDERIA HOSPITAR DE MANAUS/AM...........................................................74

RELATO DE EXPERIÊNCIA: PERCEPÇÃO E CONHECIMENTO DOS ACADÊMICOS DE ENFERMAGEM QUANTO À EXPOSIÇÃO AOS RISCOS BIOLÓGICOS. .75 
ATENÇÃO FARMACÊUTICA NA DISPENSAÇÃO DA PROFILAXIA PÓSEXPOSIÇÃO NUMA FUNDAÇÃO DE REFERÊNICA - RELATO DE EXPERIÊNCIA. 77

SOFRIMENTO MORAL DURANTE A RESIDÊNCIA EM ENFERMAGEM NUMA UNIDADE DE SAÚDE - RELATO DE EXPERIÊNCIA. 
ANAIS DO I SIMPÓSIO CLÍNICO MULTIPROFISSIONAL DE

INFECTOLOGIA, 2019; 08-78

\title{
DIAGNÓSTICOS DA LEUCEMIA LINFÓIDE AGUDA: UMA REVISÃO DE LITERATURA
}

\author{
Josué Nélio Brutus'; Geraldo Majela Soares ${ }^{2}$ \\ ${ }^{1}$ Farmacêutico, Residente do Programa de Residência Multiprofissional em Saúde de Apoio \\ Diagnóstico e terapêutico, Fundação de Medicina Tropical Doutor Heitor Dourado. \\ ${ }^{2}$ Farmacêutico-Bioquímico, Fundação de Medicina Tropical Doutor Heitor Dourado
}

\section{RESUMO}

Introdução: A leucemia é uma propagação neoplásica generalizada ou um acúmulo de células hematopoiéticas, envolvendo ou não o sangue periférico. As leucemias são definidas conforme o tipo célula envolvido e o nível de maturação das células. De acordo com o Instituto Nacional de Câncer (INCA), a estimativa de casos novos de leucemia para o ano de 2018 e 2019 no Brasil foi de 5.940 casos em homens e4.860 em mulheres para cada biênio. Objetivo: Mostrar através de uma revisão de literatura os diagnósticos da leucemia linfóide aguda (LLA). Metodologia: Este estudo é uma pesquisa qualitativa, realizada através de uma revisão sistemática da literatura literária. Como critérios de seleção foram considerados artigos que abordavam o diagnóstico de leucemia linfoide aguda e outras informações específicas relacionadas ao assunto. Resultado: A LLA é caracterizada pelo diagnóstico de mais de $25 \%$ de linfoblastos na medula. O diagnóstico laboratorial é geralmente baseado no exame morfológico da extensão sanguínea e medula óssea, com uma alta porcentagem de linfoblastos mais ou menos anômalos. Na maioriados casos, há leucocitose, porem em alguns pacientes o numero de leucócitos pode estar normal ou diminuído, com blastos linfóides. Nos casos com leucocitose, os linfoblastos são as células predominantes e são observadas também sobras nucleares ou manchas de Gumprecth. Esse exame deve sempre ser complementado com a observação das células através de testes citoquímicos e imunofenotipagem. A imunofenotipagem é sugerida para definição da sublinhagem B ou T e estágio de maturação. Conclusão: Vários exames podem ser feitos para diagnosticar a leucemia, o hemograma que pode ser um exame sugestivo, mielograma, citogenética, imunofenotipagem. Contudo, os testes imunofenotípicos são muito importantes e são considerados indispensáveis para o resultado diagnóstico da leucemia linfóide aguda.

Descritores: Leucemia linfóide, diagnósticos, imunofenotípica 


\section{MANEJO CLÍNICO DE PACIENTES ACOMETIDOS POR PÊNFIGO VULGAR: UM RELATO DE EXPERIÊNCIA}

Anderson Lima Cordeiro da Silva ${ }^{1}$; Heriederson Sávio Dias Moura ${ }^{2}$; Diorges Boone da Silva $^{2}$;Daniella Souza Gama ${ }^{2}$; Eurides Souza de Lima ${ }^{3}$.

${ }^{1}$ Graduando Relator em Bacharelado em Enfermagem, CEUNI-FAMETRO, ManausAmazonas- Brasil. E-mail: enfandersoncordeiro@gmail.com.

${ }^{2}$ Graduandos em Bacharelado em Enfermagem, CEUNI-FAMETRO, ManausAmazonas-Brasil.

${ }^{3}$ Enfermeira, Mestra em Enfermagem pela Universidade Federal do Amazonas - UFAM.

\section{RESUMO}

Introdução: O pênfigo vulgar é uma doença autoimune rara, caracterizada pela formação de bolhas flácidas e erosões na pele ou na mucosa oral, cuja causa está relacionada à presença de anticorpos contra componentes epidérmicos, entre os quais estão as desmogleínas (DSG). A infecção pode acometer o ser humano por toda vida, porém tornase frequente em pessoas entre 40 a 50 anos (CARVALHO et al., 2018). Objetivo: Relatar a experiência vivenciada por acadêmicos de enfermagem frente ao manejo clínico de pacientes acometidos por pênfigo vulgar em Manaus. Metodologia: Trata-se um estudo do tipo relato de experiência, vivenciado por um período de seis meses em um Serviço de Atendimento Especializado em Medicina Tropical situada na cidade de Manaus/Amazonas. Resultado: A vivência frente ao manejo clínico do pênfigo vulgar proporcionou uma melhor compreensão da patologia, corroborando para a interatividade com a equipe multiprofissional para uma melhor assistência. A princípio foi realizado o diagnóstico do paciente que se deu pela combinação dos achados clínicos, somados com o resultado da biópsia da pele acometida e com ensaio de imunoabsorção enzimática. Após a confirmação do diagnóstico, foi realizado o acompanhamento psicológico, a fim de garantir a adesão ao tratamento que se deu pela hospitalização do mesmo, sendo realizado uso de corticoides em alta dosagem somado com imunossupressores, após 13 semanas com a evolução eficaz do tratamento medicamentoso do paciente, o mesmo teve alta hospitalar. Conclusão: A experiência possibilitou a agregar conhecimentos de uma patologia não tão conhecida por acadêmicos e profissionais da saúde. Na busca pela melhor forma de cuidar do paciente acometido pela patologia citado no estudo, faz-se necessário a difusão mais ampla, de maneira a ter um olhar criterioso desde a etiologia, como também na fomentação de novas análises e estudos para a melhoria da qualidade assistencial.

Descritores: Pênfigo, Acantólise, Epiderme.

\section{Referências}

CARVALHO, A. A. et al. Pênfigo neonatal em filho de mãe com pênfigo vulgar: relato de caso. Rev. paul. pediatr. vol.37, n.1, pp.130-134, 2018.

FUERTES, I.; GUILABERT, A.; MASCARÓ, Jr. J. M.; IRANZO, P. Rituximabe no pênfigo vulgar na infância: Um caso de acompanhamento a longo prazo e revisão da literatura. Dermatology; 221:13-6, 2010. 


\section{ESTUDO EPIDEMIOLÓGICO DA TRANSMISSÃO DE SÍFILIS CONGÊNITA NO ESTADO DO AMAZONAS}

Anderson Lima Cordeiro da Silva ${ }^{1}$; Heriederson Sávio Dias Moura ${ }^{2}$; Diorges Boone da Silva $^{2}$;Daniella Souza Gama ${ }^{2}$; Eurides Souza de Lima ${ }^{3}$.

${ }^{1}$ Graduando Relator em Bacharelado em Enfermagem, CEUNI-FAMETRO, ManausAmazonas- Brasil. E-mail: enfandersoncordeiro@gmail.com.

${ }^{2}$ Graduandos em Bacharelado em Enfermagem, CEUNI-FAMETRO, ManausAmazonas-Brasil.

${ }^{3}$ Enfermeira, Mestra em Enfermagem pela Universidade Federal do Amazonas - UFAM

\section{RESUMO}

Introdução: A Sífilis é uma doença infecto-contagiosa, causada pela bactéria Treponema pallidum. Transmitida comumente por práticas sexuais, transfusão de sangue infectado, contato com lesões mucocutâneas ricas em treponemas, como também por via transplacentária ou pelo canal do parto, estes últimos caracterizando a sífilis congênita (SOEIRO, 2012). Objetivo: Descrever o perfil epidemiológico da transmissão de sífilis congênita no Amazonas. Metodologia: Trata-se de um estudo descritivo retrospectivo, de 2010 a 2018, com levantamento de dados a partir do Departamento de Informática do SUS DATASUS) e, utilização de embasamento através de literaturas das bases Biblioteca Virtual em Saúde (BVS), Biblioteca Cientifica Eletrônica Online (SciELO), Literatura Latino-Americano e do Caribe (LILACS), utilizando critérios para inclusão e exclusão das publicações acerca da temática. Resultado: A sífilis congênita correspondeu a um total de 231.905 novos casos entre os anos analisados, sendo de notificação pelo estado do Amazonas 6.238 novos casos da doença. Analisando o número em recém-nascidos menores de 28 dias em território nacional no mesmo período, observou-se uma notificação de 133.619 casos, correspondendo 2.654 casos de incidência no Amazonas. Conclusão: Tendo em vista o grande número de novos casos de sífilis congênita, faz-se necessário ter um olhar mais criterioso quanto ao diagnóstico das possíveis falhas na identificação das mulheres acometidas pelas infecções, uma vez essas estratégias podem reverter o grande número de casos notificados pelo Amazonas, bem como permitirá realizar ações e investimentos pontuais nas políticas de saúde do Estado.

Descritores: Transmissão vertical, Sífilis Congênita, Sífilis.

\section{Referências}

SOEIRO, C. M. O. Estudo epidemiológico da Transmissão Vertical de Sífilis e HIV no

Amazonas. Manaus: Universidade do Estado do Amazonas, Fundação de Medicina Tropical,2012.

AVELLEIRA, J. C. R.; BOTTINO, G. Sífilis: diagnóstico, tratamento e controle. An. Bras. Dermatol. 2006; 81(2): 111-126. 


\title{
ANAIS DO I SIMPÓSIO CLÍNICO MULTIPROFISSIONAL DE
}

INFECTOLOGIA, 2019; 08-78

\section{ATUAÇÃO DO ENFERMEIRO NA TESTAGEM RÁPIDA PARA IST'S NO PRÉ NATAL: RELATO DE EXPERIÊNCIA}

\author{
Ana Carolina Moraes Cruz ${ }^{1}$, Alessandro Barbosa de Andrade ${ }^{2}$ \\ ${ }^{1}$ Enfermeira Mestre em Doenças Infecciosas e Parasitárias pela FMT/HDV, Manaus, \\ Amazonas, Brasil. \\ ${ }^{2}$ Graduando de Enfermagem da Universidade Nilton Lins, Manaus, Amazonas, Brasil.
}

\section{RESUMO}

Introdução: A consulta de pré-natal é utilizada para avaliação da saúde da mulher e do bebê, sendo uma estratégia para a prevenção das complicações e ISTs relacionada á gestação; dentre elas destaca se a sífilis, que se detectada no teste rápido feito pelo profissional enfermeiro, terá o tratamento baseado na portaria do Ministério da Saúde que instituiu a rede cegonha por meio da portaria número 1459, de 24 de junho de 2011, que assegura a mulher o direito de planejamento familiar e bem como a criança o nascimento seguro, crescimento e desenvolvimento saudável. Criando assim uma relação de confiança e confidencialidade entre profissional/paciente. Objetivo: Relatar a experiência da prática na consulta de Enfermagem e testagem rápida no Pré-Natal. Metodologia: Relato de experiência do discente do $9^{\circ}$ semestre de Enfermagem do componente curricular Estágio Curricular I, da Universidade Nilton Lins, durante a prática Curricular em Unidade Básica de Saúde (UBS), localizados no município de Manaus- AM. Após as práticas foram efetivadas debates do aluno com a docente responsável nas quais foram escolhidas as experiências mais relevantes. Resultados: Preliminarmente, foram realizadas entrevistas necessárias (anamnese, antecedentes pessoais e familiares, além das queixas) para identificar possíveis problemas de saúde. Logo em seguida, o teste rápido e se necessário prescrições. $\mathrm{O}$ acolhimento torna-se uma excepcional estratégia para minimizar a ansiedade e medos das mulheres, perante a realização do teste. Conclusão: A experiência diária no consultório de Enfermagem tornou explicito a importância do vínculo entre a Enfermagem e a mulher, executando sempre um atendimento humanizado, através de uma consulta acolhedora, tornando possível a troca de informações, na qual as mulheres manifestam participação durante todo o processo da consulta e se mostram confiantes.

Descritores: Pré-natal, relatos, enfermeiro. 
ANAIS DO I SIMPÓSIO CLÍNICO MULTIPROFISSIONAL DE

INFECTOLOGIA, 2019; 08-78

\title{
FATORES QUE INTERFEREM NO DESEMPENHO DA UTILIZAÇÃO DE LEITOS DE UMA UTI PARA ADULTOS EM UM HOSPITAL REFERÊNCIA EM INFECTOLOGIA DO AMAZONAS
}

\author{
Arimatéia Portela de Azevedo ${ }^{1}$, Geissa Paula Trindade Nobre ${ }^{2}$, Maria Lucivane Felix \\ da Silva ${ }^{3}$, Roberta Lima de Oliveira ${ }^{4}$ \\ ${ }^{1}$ Enfermeiro. Mestre. Fundação de Medicina Tropical Dr. Heitor Vieira Dourado. \\ Manaus/AM. Brasil.E-mail:arimateia@fmt.am.gov.br \\ ${ }^{2}$ Discentes. Curso de Enfermagem do Centro Universitário Nilton Lins - \\ UNINILTONLINS. Manaus/AM.Brasil. E-mail: geissa.paula@gmail.com
}

\section{RESUMO}

Introdução: A Taxa de ocupação operacional da Unidade de Terapia Intensiva (UTI) serve para avaliar o grau de utilização dos leitos operacionais do hospital como um todo. Mede o perfil de utilização e gestão do leito operacional no hospital. Está relacionado ao intervalo de substituição e a media de permanência. Objetivo: Realizar avaliação dos indicadores de desempenho na utilização de leitos em uma UTI para pacientes adultos em um hospital referência em infectologia de Manaus, Amazonas. Metodologia: Estudo do tipo retrospectivo, descritivo e quantitativo onde realizou-se o registro de informações existentes no banco de dados da CCIH referentes ao desempenho na utilização de leitos da Fundação de Medicina Tropical Dr. Heitor Vieira Dourado. Resultados: Em 2018 foram registradas 205 saídas e 1.921 pacientes/dias, com uma media de permanência de 45 dias, com um aumento anual no índice de giro de 6,84\%e uma taxa de mortalidade de $57 \%$ sendo $80 \%$ por doenças imunossupressoras. CAAE:15281319.8.0000.0005. Conclusão: UTI’S recebem pacientes com doenças imunossupressoras, na maioria das vezes, crônicas, e talvez, essa tenha sido a razão da influência no Índice de giro.

DESCRITORES: epidemiologia hospitalar, indice de giro de leitos, taxa de mortalidade hospitalar,

\section{REFERÊNCIAS:}

1. BRASIL. Ministério da Saúde. Agencia Nacional de saúde suplementar. Taxa de ocupação operacional UTI Adulto. Janeiro de 2013.

2. PINHEIRO RX, SÁ DLF, SOUZA DA. Oferta de Leitos na Unidade de Terapia Intensiva em Hospital do SUS Utilizando Critérios Clínicos de Gravidade e Prognóstico. Revista Científica Multidisciplinar Núcleo do Conhecimento. Edição 04. Ano 02, Vol. 01. pp 791-802, Julho de 2017. ISSN:2448-0959. 
ANAIS DO I SIMPÓSIO CLÍNICO MULTIPROFISSIONAL DE

INFECTOLOGIA, 2019; 08-78

\title{
RESIDÊNCIA MULTIPROFISSIONAL EM SAÚDE: UM RELATO DE EXPERIÊNCIA
}

\author{
Gabriel Vitor Melo Rocha ${ }^{1}$, Jociani Andrade Reuse ${ }^{2}$, Rodrigo Serrão de Farias ${ }^{3}$, \\ Edigard do Nascimento Menezes ${ }^{4}$
}

\footnotetext{
${ }^{1}$ Psicólogo Residente do Programa de Residência Multiprofissional em Saúde com ênfase em Infectologia. Universidade Nilton Lins/ Fundação de Medicina Tropical - HVD. Manaus, Amazonas, Brasil. E-mail: gabrielvitor.mr@gmail.com.

${ }^{2}$ Psicóloga Residente do Programa de Residência Multiprofissional em Saúde com ênfase em Infectologia. Universidade Nilton Lins/ Fundação de Medicina Tropical - HVD. Manaus, Amazonas, Brasil.

${ }^{3}$ Psicólogo Residente do Programa de Residência Multiprofissional em Saúde com ênfase em Terapia Intensiva. Universidade Nilton Lins/ Fundação de Medicina Tropical - HVD. Manaus, Amazonas, Brasil.

${ }^{4}$ Psicólogo Preceptor do Programa de Residência Multiprofissional em Saúde na modalidade Psicologia. Universidade Nilton Lins/ Fundação de Medicina Tropical - HVD. Manaus, Amazonas, Brasil.
}

\section{RESUMO}

Introdução: A Residência Multiprofissional em Saúde é uma especialização, destinada a capacitação de profissionais para atuarem nas diversas áreas da saúde, dentre eles a psicologia. Essa especialização visa o desenvolvimento de cada profissional, ao mesmo tempo que proporciona a interdisciplinaridade para melhoria do atendimento prestado ao usuário. A psicologia hospitalar foi recentemente reconhecida como especialização, nos últimos anos seus avanços vêm mostrando como o psicólogo tornou-se importante dentro do ambiente hospitalar, a partir da reformulação do conceito de saúde, onde o paciente passa a ser visto sob novas perspectivas, um ser biopsicossocial e espiritual. Objetivos: Descrever as atividades realizadas pelos psicólogos participantes de um Programa de Residência Multiprofissional em Saúde, além de detalhar as atividades dos residentes em sua atuação teórico-prática na Fundação de Medicina Tropical (FMT-HVD). Metodologia: Relato, através de observação participante, sobre nossa prática em serviço no atendimento dos pacientes que se encontram internados, seja nas enfermarias ou UTI's, e aos seus familiares, ou ainda, como facilitador da comunicação entre paciente, família e equipe. Resultados: O ambiente hospitalar permite aos residentes perceber a importância de cada profissional, tornando imprescindível a união dos diversos saberes, pois somente assim é possível definir qual a melhor intervenção para cada situação, nunca deixando de reconhecer que cada paciente possui uma história e essa precisa ser ouvida, antes de realizarmos qualquer intervenção, assim poderemos propiciar a adesão ao cuidado proposto. Conclusão: Verificou-se que a residência nos oferece uma gama de novos conhecimentos, sendo um marco em nossa trajetória profissional. Seja durante nossa prática em campo ou ainda nas aulas, temos oportunidade de realizar a troca de saberes entre os residentes ou com profissionais com anos de experiência, pois existem situações que não vão estar descritas no livro que somente pela troca de saberes será possível a obtenção de novos conhecimentos e aprendizados.

Descritores: Hospital, Psicologia, Saúde. 
Referências:

REIS, B.; FARO, A. A Residência Multiprofissional e a Formação do Psicólogo da Saúde: um Relato de Experiência. Revista Psicologia e Saúde, Alagoas, v. 8, n. 1, p. 62 70, jan/jun. 2016

SILVA, L. Residência Multiprofissional em Saúde no Brasil: alguns aspectos da trajetória histórica. Revista Katál, Florianópolis, v. 21, n. 1, p. 200-209, jan/abr. 2018. 


\title{
SENSIBILIZAÇÃO SOBRE O TEMA "SEXUALIDADE E HIV/AIDS" COM OS DISCENTES DO LABORATÓRIO LECC-UFAM
}

\author{
Jociani Andrade Reuse ${ }^{1}$, Gabriel Vitor Melo Rocha ${ }^{2}$, Thomaz Décio Abdalla Siqueira ${ }^{3}$, \\ Nelzo Ronaldo Cabral Marques Jr ${ }^{4}$
}

\footnotetext{
${ }^{1}$ Psicóloga Residente do Programa de Residência Multiprofissional em Saúde com ênfase em Infectologia. Universidade Nilton Lins/ Fundação de Medicina Tropical - HVD. Manaus, Amazonas, Brasil. E-mail: jocireuse@gmail.com

${ }^{2}$ Psicólogo Residente do Programa de Residência Multiprofissional em Saúde com ênfase em infectologia. Universidade Nilton Lins/ Fundação de Medicina Tropical - HVD. Manaus, Amazonas, Brasil.

3Professor Doutor da Faculdade de Educação Física e Fisioterapia (FEFF) da Universidade Federal do Amazonas (UFAM). Manaus, Amazonas, Brasil.

${ }^{4}$ Acadêmico de Educação Física e Fisioterapia da Universidade Federal do Amazonas (UFAM). Manaus, Amazonas, Brasil.
}

\section{RESUMO}

Introdução: HIV é a sigla para o vírus que pode resultar na síndrome da imunodeficiência adquirida (AIDS), afetando células específicas do sistema imunológico do corpo humano, tornando o organismo incapaz de se proteger. Esta enfermidade é incurável, mas através da terapia antirretroviral, seus sintomas e efeitos no corpo são abrandados. Segundo dados do Ministério da Saúde, houve aumento significativo nos casos de infecções de HIV no Brasil em 2018, principalmente entre os jovens de 15 a 24 anos de idade. A região amazônica apresentou aumento na taxa de mortalidade por HIV/AIDS, registrando 7,8 mortes por 100 mil habitantes, principalmente entre jovens de até 29 anos. O espaço universitário é o principal lugar dos jovens neste conjunto de idades, sendo necessárias campanhas de conscientização acerca do HIV/AIDS na perspectiva da prevenção em saúde. Objetivos: Investigar o conhecimento de estudantes universitários da Universidade Federal do Amazonas (UFAM) sobre os meios de transmissão da infecção por HIV, além de averiguar a aceitação de pessoas que vivem com HIV no círculo social destes mesmos estudantes que participam das atividades do Laboratório de Estudos em Neurologia e Comportamento (LENC). Metodologia: Usamos a observação livre dos relatos e explanações dos acadêmicos do LENC. Resultados: Notamos que havia relações entre baixa instrução acerca do HIV/AIDS e menos aceitação de pessoas vivendo com HIV, entre estudantes universitários que participam das atividades diárias. O LENC dispõe de equipe multidisciplinar que atende pacientes com doenças neurológicas inaptas a praticar exercícios físicos. Conclusão: Foi uma ação curricular de extensão aonde verificamos o nível de conhecimento sobre HIV/AIDS e a partir do resultado programamos palestras com cunho informativo aos alunos vinculados ao laboratório para ajuda-los na compreensão deste conteúdo que provavelmente um dia na vida profissional irão trabalhar efetivamente com pacientes portadores de HIV/AIDS.

Descritores: HIV, Estudantes, Conhecimento.

Referências:

MARTINS, A.; HONORATO, E.; SILVA, T; LEMOS, S; FERREIRA, D.; REIS, M. Percepções de graduando em saúde sobre relacionamentos sorodiscordantes para o HIV/AIDS. Saúde em Redes. 4(2): 71-84. Manaus, 2018. 
ANAIS DO I SIMPÓSIO CLÍNICO MULTIPROFISSIONAL DE

INFECTOLOGIA, 2019; 08-78

MINISTÉRIO DA SAÚDE (BR). Secretaria de Vigilância em Saúde. Departamento de DST, Aids e Hepatites Virais. Boletim Epidemiológico HIV/AIDS. Brasília. 2018. 
ANAIS DO I SIMPÓSIO CLÍNICO MULTIPROFISSIONAL DE INFECTOLOGIA, 2019; 08-78

\title{
IMPORTÂNCIA DA EQUIPE DE ENFERMAGEM NA ACOLHIDA DE GESTANTE COM ISTS: UM RELATO DE EXPERIÊNCIA
}

\author{
Estefany Moreno de Souza ${ }^{1}$, Katia Feitoza Callera ${ }^{2}$, Luan Gabriel Bezerra Pedrosa ${ }^{3}$, \\ Mayllon Matheus Brasil ${ }^{4}$
}

${ }^{1}$ Acadêmica de Enfermagem da Universidade Nilton Lins. Manaus- Amazonas, Brasil.

${ }^{2}$ Acadêmica de Enfermagem da Universidade Nilton Lins. Manaus- Amazonas, Brasil.

${ }^{3}$ Enfermeiro e Docente da Universidade Nilton Lins. Manaus - Amazonas, Brasil.

${ }^{4}$ Acadêmico de Enfermagem da Universidade Nilton Lins. Manaus- Amazonas, Brasil.

\section{RESUMO}

Introdução: A importância de uma boa acolhida, métodos explicativos sobre as ISTs e tratamento em gestantes é um dos principais meios que os profissionais possuem para gerar um vínculo de confiança com esse paciente e assim aumentar os índices de uma gestação e tratamentos bem-sucedidos. Objetivo: descrever experiência do profissional da Enfermagem na saúde obstétrica com relação as ISTs na gestação e a importância de proporcionar conhecimento às pacientes sobre as infecções e possíveis tratamento que podem ser realizados. Método: trata-se de experiências vivenciadas e a percepção do profissional sobre gestações com complicações advindas de ISTs em determinados Institutos localizados na cidade de Manaus-AM. Resultado: a partir das experiências vivenciadas pode-se observar que muitas gestantes não têm conhecimento sobre as infecções sexualmente transmissíveis que possuem, principalmente as mais comuns: sífilis e vírus HIV. O medo deve ser retirado não só com ajuda dos profissionais capacitados como psicólogos, mas também com ajuda do enfermeiro e a sua equipe pois são estes que acompanham diretamente a paciente, gerando um vínculo de confiança e concomitantemente gerando conhecimento sobre as doenças relacionadas e possíveis tratamentos. Deve-se dar ênfase na importância da finalização do tratamento medicamentoso contra as possíveis IST's e explanar sobre o autocuidado e acompanhamento médico durante e pós-tratamento. Conclusão: tendo em vista a postura da equipe de enfermagem realizando acompanhamento físico e psicológico das pacientes, pode-se observar um envolvimento melhorado das gestantes com relação à busca de conhecimento e entendimento sobre as ISTs, aceitação da sua condição patológica e realização do tratamento em questão. Contribuição para enfermagem: a prática educacional dialógica pode ampliar a percepção e a capacidade reflexiva dos profissionais e acadêmicos acerca da realidade dessa determinada população e assim construir uma relação de confiança e conhecimento entre profissional-paciente.

Descritores: Gestação. Enfermagem. Acolhimento. 
ANAIS DO I SIMPÓSIO CLÍNICO MULTIPROFISSIONAL DE INFECTOLOGIA, 2019; 08-78

\title{
RELATO DE EXPERIÊNCIA DOS ACADÊMICOS DE ENFERMAGEM NA ASSISTÊNCIA AO PÊNFIGO FOLIÁCEO
}

\author{
Ana Carolina Moraes Cruz ${ }^{1}$, Ingrid Saraiva da Silva ${ }^{2}$, Jamille da Silva Corrêa ${ }^{3}$, \\ Jeovanna Elizabelly Jean Moraes ${ }^{4}$, Matheus Breno da Silva Gima ${ }^{5}$
}

${ }^{1}$ Enfermeira Mestre em Doenças Infecciosas e Parasitárias pela FMT/HVD, Manaus, Amazonas, Brasil.

${ }^{2}$ Acadêmica de Enfermagem da Universidade Nilton Lins, Manaus, Amazonas, Brasil.

${ }^{3}$ Acadêmica de Enfermagem da Universidade Nilton Lins, Manaus, Amazonas, Brasil.

${ }^{4}$ Acadêmica de Enfermagem da Universidade Nilton Lins, Manaus, Amazonas, Brasil.

${ }^{5}$ Acadêmico de Enfermagem da Universidade Nilton Lins, Manaus, Amazonas, Brasil.

\section{RESUMO}

Introdução: $O$ pênfigo foliáceo, também conhecido como fogo selvagem ou pênfigo brasileiro é uma patologia autoimune e crônica, na qual há formação de bolhas intraepidérmicas de tamanhos diversos que afetam o revestimento da pele e estouram depois de algum tempo. Uma característica relatada pelo paciente é a sensação de "queimação". Pode surgir em ambos os sexos, acomete crianças e jovens, principalmente na faixa etária entre vinte a trinta anos. Objetivo: Relatar a experiência dos acadêmicos de enfermagem na assistência ao paciente com pênfigo foliáceo. Materiais e métodos: trata-se um estudo descritivo, do tipo relato de experiência, elaborado pela vivência no contexto da disciplina enfermagem em doenças transmissíveis e infectocontagiosas ministrada no sexto período de enfermagem da Universidade Nilton Lins, que se objetivou o aprimoramento do conhecimento dos acadêmicos, através do ensino teórico e prático em relação as doenças infectocontagiosas. Resultados: As acadêmicas de enfermagem prestaram assistência ao paciente por meio da realização de uma visita técnica, guiada pelo orientador. $\mathrm{Na}$ qual conheceram a forma de tratamento, medicações administradas, cuidados de enfermagem para o alívio da dor decorrente da patologia e as medidas de CCIH. Conclusão: Concluímos que o pênfigo foliáceo é uma patologia que afeta não somente a integridade física como a psicológica do paciente, e o profissional deve ter conhecimento técnico e científico para auxiliar no alivio do sofrimento deste.

Descritores: doenças autoimunes, pênfigo, cuidados de enfermagem

\section{Referências:}

PINHEIRO, F.G.; FRANCO, A.M.R.

Pênfigo foliáceo endêmico (fogo selvagem) em indígena Yanomami no Município de São Gabriel da Cachoeira, Estado do Amazonas, Brasil. Revista Pan-Amazônica de Saúde, Ananindeua, v.5, n. 2, p. 53-56. Jun. 2014. Disponível em:http://scielo.iec.gov.br/pdf/rpas/v5n2/v5n2a07.pdf. Acessado em: 30 Set. 2019. BEZERRA, O.M.P.A. et al. Pênfigo Foliáceo Endêmico (Fogo Selvagem) e sua associação com fatores ambientais e ocupacionais em Ouro Preto, Minas Gerais, Brasil. Caderno de saúde coletiva, Rio de Janeiro, v. 25, n. 2 p. 225-232, Abr. 2017. Disponível em: http://www.scielo.br/pdf/cadsc/v25n2/1414-462X-cadsc-1414-462X201700020299.pdf.

Acessado em: 30 Set. 2019. 
ANAIS DO I SIMPÓSIO CLÍNICO MULTIPROFISSIONAL DE

INFECTOLOGIA, 2019; 08-78

\title{
PROMOVENDO SAÚDE NO AMBIENTE ESCOLAR - IMUNIZAÇÃO AO PAPILOMA VÍRUS HUMANO (HPV): UM RELATO DE EXPERIÊNCIA
}

\author{
Alice Lima Maceda ${ }^{1}$ Camilla Reane Silva de Souza ${ }^{2}$ Carolinne Amaral de Medeiros ${ }^{3}$ \\ Railton da Silva Miranda ${ }^{4}$ Sirrame Auendy Santarém ${ }^{5}$ \\ ${ }^{1}$ Acadêmica de Graduação em Enfermagem da Universidade Nilton Lins/UNL, Manaus, \\ Amazonas, Brasil \\ ${ }^{2}$ Acadêmica de Graduação em Enfermagem da Universidade Nilton Lins/UNL, Manaus, \\ Amazonas, Brasil. \\ ${ }^{3}$ Acadêmica de Graduação em Enfermagem da Universidade Nilton Lins/UNL. Manaus, \\ Amazonas, Brasil. \\ ${ }^{4}$ Enfermeiro. Mestrando. Docente da Universidade Nilton Lins, Manaus, Amazonas. \\ Brasil.
}

\section{RESUMO}

Introdução: O Papiloma Vírus Humano é um problema de saúde pública, especialmente nos países com socioeconômico baixo, transmitido por via sexual e tendo como público-alvo inicial adolescentes do sexo feminino ${ }^{1}$. A evolução para o câncer de colo de útero se manifesta de forma lenta e para precaução a vacina contra o HPV, é um procedimento de prevenção básica. Objetivo: Promover a educação em saúde ambiente escolar na perspectiva de elucidar a importância da imunização ao papiloma vírus humano. Métodos: Trata-se de um estudo descritivo e exploratório do tipo relato de experiência. Foi desenvolvido em uma escola municipal em Manaus do Amazonas, sendo o público-alvo crianças e adolescentes de 10 a 14 anos. Resultados: A atividade de promoção da saúde ocorreu em 2 estações: 1) Intervenção na escola, com palestras abordando os temas, sobre o câncer do colo do útero, a utilização de preventivos na relação sexual e a imunização preventiva. 2) Prevenção com vacinação contra o HPV. Percebeu-se que nesta idade é muito importante a promoção em saúde; todos os alunos mantiveram uma boa complacência. Durante a atividade, nenhum aluno precisou de algum atendimento emergências sobre a vacinação, sendo monitorada por profissionais especializados na área de saúde. Conclusão: Os acadêmicos de enfermagem como condutores do projeto proporcionaram um diferencial para sua formação profissional, além de contribuir com ações preventivas para as crianças e adolescentes, podendo prestar uma assistência eficaz. Assim observou-se que as instituições educacionais, tanto de saúde, têm papel relevante em relação à prevenção de doenças transmissíveis, a fim de minimizar danos a vítima ou falta de conhecimento, contribuindo para uma saúde efetiva.

\section{Referências:}

1. ALEMIDA, F.L; BEIRAL, J.S; RIBEIRO, K.R.SHI,ODA, E.; SOUZA, C.H.M. A vacina contra o vírus HPV para meninas: um incentivo á vida sexual precoce?. Revista Científica Interdisciplinar $n^{\circ}$ 1, volume 1, artigo $n^{\circ} 3,2014$.

2. BORSATTO, A.Z.; VIDAL, M.L.B.; ROCHA, R.C.N.P.Vacina contra o HPV e a Prevenção do Câncer do Colo do Útero: Subsídios para a Prática HPV. Revista Brasileira de Cancerologia 2011; 57(1): 67-74. Descritores: Adolescentes; Enfermagem e Educação em Saúde. 
ANAIS DO I SIMPÓSIO CLÍNICO MULTIPROFISSIONAL DE

INFECTOLOGIA, 2019; 08-78

\title{
PERCEPÇÃO DE ACOMPANHANTES DE PACIENTES DE UM HOSPITAL SOBRE MEDIDAS DE PREVENÇÃO PARA TUBERCULOSE: RELATO DE EXPERIÊNCIA
}

\author{
Ana Carolina de Oliveira Souza ${ }^{1}$, Rafaela Mariana Pedroso Lopes ${ }^{2}$, Arimatéia Portela \\ de Azevedo ${ }^{3}$ \\ ${ }^{1}$ Acadêmica do curso de Enfermagem da UNINILTON LINS; Manaus, AM, Brasil; \\ ${ }^{2}$ Acadêmica do curso de Enfermagem da UNINILTON LINS; Manaus, AM, Brasil; \\ ${ }^{3}$ Professor MSc. do curso de Enfermagem da UNINILTON LINS; Mestre em Biologia \\ Urbana com ênfase em doenças infectocontagiosas; Atual Coordenador da CCIH da Fundação \\ de Medicina Tropical Dr. Heitor Vieira Dourado; Manaus, AM, Brasil;
}

\section{RESUMO}

Introdução: A tuberculose é uma doença infectocontagiosa que afeta o pulmão ou outros órgãos e sistemas, como cérebro e gânglios, é considerada um dos grandes problemas de saúde pública do Brasil, com altos números de notificações ${ }^{1}$. Atualmente é responsável pelo adoecimento de cerca de dez milhões de pessoas por ano, e leva ao óbito mais de um milhão de pessoas todos os anos. Em 2017, Manaus apresentou mais de 2 mil novos casos de tuberculose. Objetivos: Descrever a percepção de acompanhantes de pacientes em isolamento por aerossóis, sobre as formas e medidas de prevenção para tuberculose. Metodologia: Trata-se de um estudo prospectivo, descritivo tipo relato de experiência desenvolvido por acadêmicos da Universidade Nilton Lins com acompanhantes de pacientes internados em isolamentos por aerossóis na Fundação de Medicina Tropical Dr. Heitor Vieira Dourado em prática pela disciplina de Práticas VIII. A coleta de dados ocorreu durante visitas no mês de agosto/2018, e na oportunidade foi aplicado um questionário para averiguar a percepção dos mesmos sobre a tuberculose e seus riscos de contágio. Resultados: Foram entrevistados 32 acompanhantes de pacientes portadores de tuberculose pulmonar, destes $99 \%$ não sabiam que outras partes do organismo humano também podiam ser acometidas pelo Mycobacterium tuberculosis. Outros $65 \%$ não sabiam as formas de transmissão da doença e $60 \%$ não sabiam como se prevenir contra a tuberculose. Ainda, $45 \%$ demonstraram conhecer os sinais e sintomas da doença, $40 \%$ tinham noção de método utilizado para diagnóstico, $60 \%$ sabia quanto tempo é dispendido para tratamento da Tuberculose e $90 \%$ não sabia informar quais as formas mais eficientes de se proteger desta bactéria. Conclusão: A pesquisa demonstrou a importância de ir a campo e realizar as orientações aos acompanhantes e pacientes para a prevenção de transmissão da tuberculose em ambiente hospitalar.

Descritores: Educação em Saúde, Tuberculose, Estudantes de enfermagem.

\section{Referências:}

1. Tuberculose. Ministério da Saúde. Brasil. Disponível em: http://portalms.saude.gov.br/saude-de-a-z/tuberculose\&gt;. Acesso em: 31/08/2018. 2. Programa Municipal de Controle da Tuberculose. Secretaria Municipal de Saúde de Manaus. Brasil. Disponível em: \&lt;http://semsa.manaus.am.gov.br/programas-desaude/controle-da-tuberculose/\&gt;. Acesso em: 31/08/2018. 
ANAIS DO I SIMPÓSIO CLÍNICO MULTIPROFISSIONAL DE

INFECTOLOGIA, 2019; 08-78

\section{EDUCAÇÃO EM SAUDE: ABORDAGEM DAS IST's ESCOLARES PARA MAIORES DE 18 ANOS - RELATO DE EXPERIÊNCIA}

Niely Miranda Paes ${ }^{1}$ Adriane Castro da Conceição ${ }^{1}$ Railton da Silva Miranda² Regina

Patrícia da Silva Sena ${ }^{1}$ Robson de Oliveira Felix ${ }^{1}$

${ }^{1}$ Acadêmicos do Curso de Enfermagem do Centro Universitário Nilton Lins UNINILTONLINS. Manaus/AM -

Brasil.

${ }^{2}$ Enfermeiro Especialista Docente - Universidade Nilton Lins, Manaus - AM.

\section{RESUMO}

Introdução: As ISTs são um grande problema para a saúde pública, a qual acomete principalmente os jovens devido à falta de conhecimento sobre as mesmas, onde podemos destacar o HIV, a Herpes Genital, Sífilis e Gonorreia como os principais tipos acometidos. Objetivo: Relatar experiência vivenciada em uma escola privada no Amazonas acerca das IST`s e sua educação em saúde. Métodos: Estudo do tipo relato de experiência, de natureza descritiva e narrativa de fato. Onde utilizou - se fotos, vídeos e casos clínicos para uma boa compreensão do tema abordado, foram atingidos 40 escolares. Resultados: A educação em saúde foi feita em dois momentos. No primeiro se trouxe a problematização das IST`s e notou-se uma certa resistência nesses escolares para que eles conseguissem prover soluções em decorrência da descrença dos mesmos. Na Segunda parte não se informou nada aos escolares, apenas colocou em forma de museu interativo digital algumas fotos e esclarecimento sobre as IST`s e jogou-se uma problemática para eles, uma paciente fictícia com diversos problemas de saúde relacionada a IST`s. Na qual eles tinham que resolver esses problemas em conjunto, a partir da resolubilidade desses problemas foi que passaram a entender sobre o tratamento, as medidas preventivas e o diagnóstico, e eles puderam assim responder o questionário para avaliar seus conhecimentos no momento pré e pós. Conclusão: A escola é um espaço importante para se trabalhar a educação em saúde. Orientar os jovens é o melhor caminho para a promoção e prevenção das IST`s tendo em vista que esse público são os mais suscetíveis e que a prevenção se estabelece por meio de ações, sendo as ações educativas a principal delas.

DESCRITORES: Enfermagem; IST’s; Educação em Saúde.

\section{Referências}

BALDOINO, Luciana Stanford; SILVA, Serina Maria do Nascimento; RIBEIRO, Aclênia Maria Nascimento; RIBEIRO, Euclâynne Kassyanne Cardoso. Educação em saúde para adolescentes no contexto escolar: um relato de experiência. Rev enferm, Recife. 2018.

SOUZA, Vânia et al. Conhecimentos, vivências e crenças no campo sexual: um estudo com alunos do ensino médio com perfis socioeconômicos diferenciados. Rev Min Enferm. 2017. 
ANAIS DO I SIMPÓSIO CLÍNICO MULTIPROFISSIONAL DE INFECTOLOGIA, 2019; 08-78

\title{
APRESENTAÇ̃̃O DOS CASOS DE SARAMPO NO ESTADO DO AMAZONAS, NO PERÍODO DE 2018 E 2019
}

\author{
João Victor Rodrigues Carvalho' Brenno Barbosa da Encarnação² Junio Vieira Nunes ${ }^{3}$ \\ Leonardo Barbosa Rolim ${ }^{4}$ Pollyana Mergulhão de Castro ${ }^{5}$ \\ ${ }^{1}$ Acadêmico de enfermagem da Universidade Nilton Lins, Manaus, Amazonas, Brasil. \\ ${ }^{2}$ Acadêmico de enfermagem da Universidade Nilton Lins, Manaus, Amazonas, Brasil. \\ ${ }^{3}$ Acadêmico de enfermagem da Universidade Nilton Lins, Manaus, Amazonas, Brasil. \\ ${ }^{4}$ Enfermeiro Mestre em Ciências, em Saúde da Família - Oswaldo Crus, Manaus, Amazonas, \\ Brasil. \\ ${ }^{5}$ Acadêmica de Enfermagem da Universidade Nilton Lins, Manaus, Amazonas, Brasil.
}

\section{RESUMO}

Introdução: $O$ sarampo é uma doença infectocontagiosa e óbitos. Eliminado das Américas em 2016, o sarampo mantém-se hoje como um problema de saúde publica no estado do Amazonas. Este cenário epidemiológico impõe a necessidade de manutenção de altas e homogêneas coberturas vacinais e constate vigilância epidemiológica. Objetivo: Apresentar o número de casos de sarampo notificados, confirmados, destacados e investigação durante o período de 2018 do $1^{\circ}$ trimestre de 2019 do Estado do Amazonas. Material e métodos: Trata-se de um estudo documental, descritivo, com abordagem quantitativa, onde se utilizou dados secundários do SINAN e da secretaria municipal de saúde de Manaus e da secretaria do Estado do Amazonas. O estudo foi realizado durante os meses de abril e maio de 2019. Para análise e interpretação dos dados, utilizou-se a estatística simples descritiva. Resultados: O boletim epidemiológico de surto de sarampo no Amazonas n ${ }^{\circ} 45$ de 16 de abril de 2019 afirma que na semana epidemiológica 06/2018 a 14/2019: "foram notificadas 11.442 casos suspeitos de sarampo provenientes de 50 municípios no estado. Destes, 85,7\% (9.809) foram confirmados $14,2 \%$ (1.624) foram destacadas e $0,1 \%$ (9) estiveram sob investigação". No $1^{\circ}$ trimestre de 2019, o Amazonas notificou 47 casos de sarampo, sendo 4 casos confirmados, 34 destacados e 9 estiveram em investigação. Dos 9.809 casos confirmados provenientes de 46 municípios do estado, 82,1\% são da capital de Manaus e 17,9\% dos demais municípios. Conclusão: Devido a sua alta infectividade e contagiosidade, a notificação compulsória do sarampo é de fundamental importância, sendo fulcral a comunicação da simples suspeita da ocorrência deste para o inicio da investigação epidemiológica. $\mathrm{O}$ enfrentamento desse problema de saúde publica requer, dos gestores e trabalhadores da saúde, intervenções direcionadas e vacinação em massa da população suscetível, para controle e erradicação do sarampo.

Descritores: Sarampo, vacinação em massa.

\section{Referências:}

FUNDAÇÃO DE VIGILÂNCIA EM SAÚDE DO AMAZONAS. Boletim epidemiológico de surto de sarampo no Amazonas. $n^{\circ}$ 45/2019 - DVE/FVS-AM - assunto: intensificação das ações de monitoramento e controle do sarampo. 30 de maio de 2019

LEMOS, D. R. Q. Epidemia de sarampo no Ceará no período pós-eliminação nas Américas: Enfrentamento, resposta coordenada e avaliação de risco para reintrodução do vírus. $214 f$. Tese (Doutorado em saúde coletiva), Fortaleza. Universidade Estadual do Ceará, 2016. 
ANAIS DO I SIMPÓSIO CLÍNICO MULTIPROFISSIONAL DE

INFECTOLOGIA, 2019; 08-78

\section{PERCEPÇÃO ACADÊMICA DE ENFERMAGEM - ASPECTOS CLÍNICOS DE PACIENTES COM ALOPECIA SIFILÍTICA: RELATO DE EXPERIÊNCIA}

Alice Lima Maceda ${ }^{1}$ Camilla Reane Silva de Souza ${ }^{2}$ Railton da Silva Miranda ${ }^{3}$ Sirrame Auendy Santarém ${ }^{4}$ Tamyres Soares ${ }^{5}$

${ }^{1}$ Acadêmica de Graduação em Enfermagem da Universidade Nilton Lins/UNL, Manaus, Amazonas, Brasil.

${ }^{2}$ Acadêmica de Graduação em Enfermagem da Universidade Nilton Lins/UNL, Manaus, Amazonas, Brasil.

${ }^{3}$ Acadêmica de Graduação em Enfermagem da Universidade Nilton Lins/UNL. Manaus, Amazonas, Brasil.

${ }^{4}$ Enfermeiro. Mestrando. Docente da Universidade Nilton Lins, Manaus, Amazonas.

Brasil.

\section{RESUMO}

Introdução: A alopecia sifilítica é uma doença infecciosa, que acomete os micros vasos sanguíneos invadem a região do cabelo, causando lesões na parede vascular e bloqueio, acomete principalmente os homens e as mulheres. Está relacionado ao estado emocional dos pacientes acometidos, podendo reduzir acentuadamente sua qualidade de vida. Objetivo: Relatar a experiência sobre os aspectos clínicos de pacientes com alopecia sifilítica atendidos em um centro de referência em Manaus Amazonas. Métodos: Tratase de um relato de experiência referente à aspectos clínicos realizada a pacientes submetido com alopecia sifilítica, durante as práticas de campo da disciplina infectologia no centro de referência em Manaus, do curso de enfermagem da universidade Nilton Lins do amazonas. Durante avaliação clínica ocorrida no dia 19 de Abril de 2019, realizou-se uma entrevista voltada à pacientes para identificação e reconhecimento total da sífilis, em seguida de exame físico geral. Resultados: Os aspectos clínicos a um paciente submetido à alopecia sifilítica, proporcionou a vivência de uma situação de ensino- aprendizagem, pois ao prestar a assistência de enfermagem voltada à esses pacientes tivemos conhecimento que pacientes apresentam graves quadros de alopecia, podendo surgir por meio de processo inflamatório que leva a queda dos pelos, afetando mais frequentemente o couro cabeludo, mas pode ocorrer também em outras áreas. Percebeu-se que pacientes alopecia sifilítica requer cuidados e tratamentos específicos. Conclusão: A implementação de estratégias de prevenção e esforços, que visem à melhoria da qualidade assistencial, é altamente relevante. É necessário, portanto, possibilitar ações de educação e saúde sobre as doenças infecciosas, assim ampliando a visão sobre o conhecimento, a fim de evitar a severidade da doença.

Descritores: Enfermagem; perda de pelos e Alopecia.

\section{Referências:}

1. C. BERNÁRDEZ, A.M. MOLINA-RUIZ, L. REQUENA. Histologic Features of Alopecias-Part I: Nonscarring Alopecias. Actas Dermo- Sifiliográficas (English Edition), Volume 106, Issue 3, April 2015, Pages 158-167.

2.TRINDADE, L. C., D’Acr A.M. Alopecia Areata: Revisão Bibliográfica e Relato de

Caso. Cad Bras Med XXVII (3): 1-58, 2014. 
ANAIS DO I SIMPÓSIO CLÍNICO MULTIPROFISSIONAL DE

INFECTOLOGIA, 2019; 08-78

\title{
RELATO DE EXPERIÊNCIA: PERCEPÇÃO DOS ACADÊMICOS DE ENFERMAGEM FRENTE AO PACIENTE TUBERCULOSO NA ATENÇÃO PRIMÁRIA
}

\author{
Railton da Silva Miranda ${ }^{1}$ Fernanda Ellen Pontes Brito ${ }^{2}$ Rayssa Sousa dos Santos ${ }^{3}$ \\ Stheffany da Silva Pinheiro ${ }^{4}$
}

${ }^{1}$ Enfermeiro Especialista. Docente do curso de Graduação em Enfermagem da Universidade Nilton Lins, Manaus-AM

${ }^{2}$ Acadêmica de Enfermagem da Universidade Nilton Lins, Manaus-AM.

${ }^{3}$ Acadêmica de Enfermagem da Universidade Nilton Lins, Manaus-AM.

${ }^{4}$ Acadêmica de Enfermagem da Universidade Nilton Lins, Manaus-AM.

\section{RESUMO}

Introdução: Os indicadores de incidência e mortalidade por tuberculose no Brasil ainda trazem um grande número de óbitos a cada ano, diante disso o Ministério da Saúde escolheu a tuberculose como problema de saúde prioritário a ser pugnado. O enfermeiro apresenta dificuldades ao prestar assistência ao paciente com tuberculose na atenção primária devido à escassez de recursos de materiais, déficit na inserção entre programas para um avanço efetivo das ações de controle e entre outros. Objetivo: Relatar os desafios enfrentados na atenção primária frente ao paciente com tuberculose, na perspectiva de acadêmicos de enfermagem. Materiais e métodos: Trata-se de um relato de experiência de caráter descritivo, onde através de práticas em campo, podemos observar os desafios enfrentados pelo profissional enfermeiro na atenção primária, diante de casos com paciente tuberculoso. Resultados: A participação da enfermagem envolve um desempenho fundamental na atenção primária e no processo de combate à tuberculose, e este profissional está diretamente ligado a assistência e a realização do cuidado com o paciente, principalmente envolvido no tratamento TOD, desenvolvendo também ações educativas e coletivas com a população. É notório o profissional enfermeiro como um agente participativo e decisivo nas ações de organização e assistência ao paciente com TB. Sendo que esta não requer apenas atenção clínica e farmacológica, mas sim integral, social e cultural, ressaltando deste modo a importância da assistência e acompanhamento da enfermagem na continuidade e evolução do tratamento, além da disseminação de informação e notificação da doença, visando sua eliminação. Conclusão: O profissional enfermeiro perante ao paciente com tuberculose encontra pelo caminho muitos obstáculos por conta da carência de matérias, o que consequentemente acaba afetando a forma na qual o mesmo é tratado levando a uma assistência prejudicada.

Descritores: tuberculose, atenção primária, enfermagem.

Referências:

COSTA, Magnania Cristiane Pereira da; MARÍN-LEÓN, Letícia; OLIVEIRA, Helenice Bosco de. As dificuldades dos profissionais no atendimento aos pacientes em tratamento para tuberculose na atenção primária. Revista Eletrônica Gestão \&amp; Saúde ISSN: 1982-4785. V. 8 n. 3 (2017): setembro-dezembro.

RÊGO, Clara Ceci Diógenes; MACÊDO, Sonaly Melo de; ANDRADE, Cíntia Raquel Batista de, et al. Processo de trabalho da enfermeira junto à pessoa com tuberculose na atenção primária à saúde. Revista Baiana de Enfermagem, Salvador, v. 29, n. 3, p. 218-228, jul./set. 2015. 
ANAIS DO I SIMPÓSIO CLÍNICO MULTIPROFISSIONAL DE

INFECTOLOGIA, 2019; 08-78

\title{
MONITORIA ACADÊMICA DE AGENTES INFECTOPARASITÁRIOS PARA OS ACADÊMICOS DE MEDICINA: UM RELATO DE EXPERIÊNCIA
}

\author{
Matheus da Silva Sakamoto ${ }^{1}$, Maria das Graças Vale Barbosa Guerra², Bruna Lopes de \\ Souza $^{3}$ Milena Batista de Oliveira ${ }^{4}$ Roger Dumas Afonso Azulay ${ }^{5}$
}

${ }^{1}$ Acadêmico de Medicina da Universidade do Estado do Amazonas, graduando. Manaus, Amazonas, Brasil.

${ }^{2}$ Doutora em Ciências biológicas pela Universidade Federal do Amazonas, pesquisadora. Manaus, Amazonas, Brasil.

${ }^{3}$ Acadêmico de Medicina da Universidade do Estado do Amazonas, graduando. Manaus, Amazonas, Brasil.

${ }^{4}$ Acadêmica do curso de Enfermagem da Universidade do Estado do Amazonas, graduando. Manaus, Amazonas, Brasil.

${ }^{5}$ Acadêmico de Medicina da Universidade do Estado do Amazonas, graduando. Manaus, Amazonas, Brasil.

\section{RESUMO}

Introdução: A monitoria acadêmica é uma atividade estabelecida pela Lei de Diretrizes e Bases da Educação Nacional No 9.394, de 20 de dezembro de 1996, que tem por finalidade conceder aos acadêmicos experiências em diferentes áreas do ensino e dar apoio aos docentes, possibilitando enriquecimento teórico acadêmico. Objetivo: Esse trabalho tem como objetivo relatar uma experiência vivenciada como monitor na área de Parasitologia humana, que estuda espécies de parasitos dos Reinos Protista e Animália. Metodologia: Trata-se de um estudo descritivo, tipo relato de experiência, realizado na Escola Superior de Ciências da Saúde da Universidade do Estado do Amazonas, de março a junho de 2019, as atividades foram realizadas por discentes do Curso de Medicina na monitoria de Parasitologia, que integra a grade curricular da Universidade. Para isso, ocorreu processo seletivo teórico-prática, após o exame, o aluno selecionado iniciou as atividades de monitoria com a orientação do docente da disciplina. Resultados: Durante as atividades os sete monitores, tiveram a oportunidade de aprofundar seus conhecimentos, na medida em que entre as atividades de monitoria estavam: Auxiliar os docentes tanto nas aulas teóricas quanto práticas para cerca 200 alunos matriculados na disciplina. Especialmente nas práticas as atividades envolveram localização e focalização dos parasitos montados em lâminas. Além disso, o alunomonitor realizou atividades de docência, e segundo relatos, isso despertou em alguns, o interesse para atuação nessa área. Conclusão: $O$ desempenho da monitoria acadêmica demonstra uma atividade de boa prática educativa exercida pelos alunos-monitores na Universidade. Como também, nota-se um relevante crescimento acadêmico e profissional, haja vista ser uma disciplina, cujo conteúdo abrange parte de doenças negligenciadas na saúde pública, e/ou endêmicas da região Amazônica. Conclui-se que essa experiência demandou responsabilidade, comprometimento e dedicação por parte dos monitores, o que contribui para formação de profissionais da saúde capacitados sobre as doenças estudadas.

Descritores: Parasitologia, Educação em Saúde, Estudantes de Medicina. 


\section{REFERENCIAS}

1. Anais do $8^{\circ}$ Salão Internacional de Ensino, Pesquisa e Extensão, 1., 2017, Pampa, Monitoria acadêmica no componente curricular de Semiotécnica em Enfermagem: relato de experiência, Salão de Ensino, Rio Grande do Sul: Universidade Federal do Pampa, 2017.

2. SANTOS, L. M.; LIMA, N. B. Análise da abordagem e conhecimento do tema parasitoses causadas por protozoários em escolas públicas do município de Salinas-MG. Acta BiomedicaBrasiliensia, Minas Gerais, v. 8, n. 2, dez 2017, ISSN: 2236-0867. Disponível em:\&lt; http://dx.doi.org/10.18571/acbm.146\&gt;. Acesso em: 7 mai. 2019. 
ANAIS DO I SIMPÓSIO CLÍNICO MULTIPROFISSIONAL DE

INFECTOLOGIA, 2019; 08-78

\section{DIFICULDADES DO ACADÊMICO DE ENFERMAGEM NA REALIZAÇÃO DO DIAGNÓSTICOS DAS IST'S - RELATO DE EXPERIÊNCIA} Débora Nery Oliveira ${ }^{1}$; Adele Marília de Sousa Vasconcelos ${ }^{1}$; Joice de Souza Ribeiro ${ }^{1}$;
Ana Márcia Lopes dos Santos ${ }^{1}$; Railton da Silva Miranda ${ }^{2}$.

${ }^{1}$ Discentes do curso de Graduação em Enfermagem da Universidade Nilton Lins, Manaus Amazonas, Brasil.

2 1Enfermeiro Especialista. Docente do curso de Graduação em Enfermagem da Universidade Nilton Lins, Manaus-AM.

\section{RESUMO}

Introdução: $O$ diagnóstico é uma ferramenta direcionada e fundamentada no levantamento dos sintomas do paciente durante a anamnese. É um processo imprescindível na graduação de enfermagem, ajudando e auxiliando na detecção de patologias. Sendo clínico, laboratorial e epidemiológicos. Saber diagnosticar Infecções Sexualmente Transmissíveis contribui com a interrupção da cadeia de transmissão e as complicações decorrentes dessas infecções. E promove finalidade curativa e proteção da saúde do paciente. Objetivo: Relatar a vivência de acadêmicos de enfermagem diante a prática do exame do Papanicolau e as dificuldades do mesmo para realizar a identificação e diagnóstico da Infecção Sexualmente Transmissível. Materiais e métodos: Trata-se de um estudo descritivo do tipo relato de experiência, referente a uma visita técnica realizada pelos alunos do $4^{\circ}$ período do curso de enfermagem da Universidade Nilton Lins, em outubro/2018, localizado na UBS Armando Mendes, na cidade de Manaus/AM. Resultados: Durante a visita, cada aluno teve que acompanhar a enfermeira na realização da coleta do Exame do Papanicolau. Ao todo foram observados quatro exames, nos quais duas pacientes apresentaram características suspeitas de IST: uma com corrimento abundante; outra com HPV. No momento da consulta, a enfermeira mencionou que havia presença de verrugas genital e anal na paciente, o acadêmico demorou a associar com o HPV e obteve dificuldade em enxergar as lesões durante a observação, principalmente, na identificação e na diferenciação. Após foi realizado as intervenções necessárias para que cada paciente obtivesse o tratamento adequado. Conclusão: A deficiência de conhecimento prático-científico sobre as IST'S, interferiu no desempenho dos alunos. Sendo necessário, haver aulas práticas internas e externas, contato com as patologias, interesse por leituras e cursos que possam auxiliá-los a obter conhecimento. Para adentrar no ambiente hospitalar sabendo associar os sintomas do cliente com a infecção e assim, realizar o diagnóstico e as intervenções.

Descritores: enfermagem; doenças sexualmente transmissíveis; promoção da saúde; diagnóstico

\section{Referência:}

1. Diagnóstico das IST’S. Ministério da Saúde. Disponível em: \&lt;http://www.aids.gov.br/ptbr/profissionais-de-saude/ist/diagnostico-das-ist\&gt; Acessado em: 27, Set. 2019.

2. SOUZA, Daniel Rubi de, PATO Thaís Rodrigues, LOGULlO Patrícia. Dicionário De Termos Técnicos De Saúde. $2^{\circ}$ ed. São Paulo. Conexão, 2003. 119p. 
ANAIS DO I SIMPÓSIO CLÍNICO MULTIPROFISSIONAL DE

INFECTOLOGIA, 2019; 08-78

\section{ADESÃO A HIGIENE DAS MÃOS ENTRE A EQUIPE DE ENFERMAGEM DAS UTI'S DE UM HOSPITAL}

Arimatéia Portela de Azevedo ${ }^{1}$ Alana Muniz Vieira ${ }^{2}$ Aline Maciel de Souza ${ }^{3}$ Brunna Thays Carvalho de Souza ${ }^{4}$ Sarah Pessoa Rodrigues ${ }^{5}$

${ }^{1}$ Enfermeiro. Mestre. Fundação de Medicina Tropical Dr. Heitor Vieira Dourado. Manaus/AM. Brasil.

${ }^{2}$ Estudante. Curso de Enfermagem do Centro Universitário Nilton Lins - UNINILTONLINS. Manaus/AM.Brasil.

${ }^{3}$ Estudante. Curso de Enfermagem do Centro Universitário Nilton Lins - UNINILTONLINS.

${ }^{4}$ Estudante. Curso de Enfermagem do Centro Universitário Nilton Lins - UNINILTONLINS. Manaus/AM. Brasil.

${ }^{5}$ Estudante. Curso de Enfermagem do Centro Universitário Nilton Lins - UNINILTONLINS. Manaus/AM. Brasil.

\section{RESUMO}

Introdução: A lavagem das mãos é uma das medidas mais eficazes de controle e prevenção de infecções no serviço de saúde. Sabe-se que a adesão do profissional de saúde reduz significativamente a possibilidade de infecções cruzadas. Objetivo: Este estudo objetiva relatar resultados referente a um levantamento técnico sobre Higienização das Mãos em Unidades de Terapia Intensiva de uma Instituição de Saúde referência em Doenças Infecto-parasitárias. Materiais e métodos: Trata-se de um estudo retrospectivo analítico e quantitativo baseado em informações secundárias obtida dos formulários de observação de Higiene das Mãos (HM) arquivados no banco de dados do Serviço de Controle de Infecção Hospitalar (CCIH). Utilizou-se os formulários arquivados durante o ano de 2018. Tal investigação foi realizada com base em variáveis contidas nos formulários de observação de higiene das mãos arquivados na CCIH. Neste, um investigador (membro da equipe executiva da $\mathrm{CCIH}$ ) observou durante o turno diurno no período de duas horas, nas UTI's do presente estudo, selecionando aleatoriamente a cada dia de avaliação um profissional de cada área da equipe multiprofissional para serem observados e anotando se os mesmos estavam realizando a prática de HM nos cinco momentos preconizados e qual produto utilizou. CAAE: 72325617.0.0000.0005 Resultados: Foi realizada a comparação estatística entre os profissionais e a adesão da higienização das mãos dos cinco momentos, entre as Unidades de Terapia Intensivas Adulto e Pediátricas. Logo se pode deduzir que as duas apresentam à adesão similar a higienização das mãos independente do profissional de saúde analisado. Notou-se que momentos onde os profissionais higienizaram as mãos, houve menos adesão antes do paciente $(18,27 \%)$ do que após o mesmo $(35,96 \%)$. Conclusão: Apesar da grande relevância, a lavagem das mãos, ainda é um grande desafio, devido não ser uma prática regular, não só pelos profissionais de saúde, mas de uma forma geral.

DESCRITORES: Unidade de Terapia Intensiva. Higiene das mãos. Serviços de saúde

\section{REFERÊNCIAS:}

1. Silva FM, Porto TP, Rocha PK, Lessmann JC, Cabral PFA., Schneider KLK. Higienização das mãos e a segurança do paciente pediátrico. Ciencia Y Enfermeria XIX 2013;(2):99-109. 2. Santos TCR, Roseira CE, Piai-morais TH, Figueiredo RM. Higienização das mãos em ambiente hospitalar: uso de indicadores de conformidade. Rev Gaúcha Enferm. 2014 mar;35(1):70-77. 


\title{
PROJETO DE EXTENSÃO SOBRE IST'S/AIDS PARA ADOLESCENTES: RELATO DE EXPERIÊNCIA
}

\author{
Aline Maciel de Souza ${ }^{1}$ Brunna Thays Carvalho de Souza ${ }^{2}$ Cheila Maria Lins Bentes ${ }^{3}$ \\ Juliana Girão de Almeida ${ }^{4}$ Sarah Pessoa Rodrigues ${ }^{5}$
}

${ }^{1}$ Estudante. Curso de Enfermagem do Centro Universitário Nilton Lins - UNINILTONLINS. Manaus/AM. Brasil.

${ }^{2}$ Estudante. Curso de Enfermagem do Centro Universitário Nilton Lins - UNINILTONLINS. Manaus/AM. Brasil.

${ }^{3}$ Enfermeira.Doutora. Centro Universitário Nilton - UNINILTONLINS. Manaus/AM. Brasil.

${ }^{4}$ Estudante. Curso de Enfermagem do Centro Universitário Nilton Lins - UNINILTONLINS. Manaus/AM. Brasil.

${ }^{5}$ Estudante. Curso de Enfermagem do Centro Universitário Nilton Lins - UNINILTONLINS. Manaus/AM. Brasil.

\section{RESUMO}

Introdução: As Infecções Sexualmente Transmissíveis (ISTs) configuram um problema de saúde pública, mesmo havendo diversas formas de prevenção e controle da disseminação. Segundo a Organização Mundial da Saúde (OMS) há 1 milhão de casos novos de ISTs por dia no mundo e pelo menos $27,5 \%$ estudantes brasileiros do $9^{\circ}$ ano do ensino fundamental já tiveram relação sexual. Objetivo: Relatar experiência vivenciada no projeto de extensão, dialogando com o adolescente sobre IST's/HIV. Materiais e métodos: Trata-se de um resumo de caráter descritivo qualitativo de relato de experiência, com base em um projeto de extensão com adolescentes de uma escola pública de Manaus/AM. Para execução das atividades propostas pelo projeto utilizaramse ferramentas metodológicas dinâmicas e brincadeiras lúdicas, possibilitando a interação com os adolescentes. As equipes compostas por cinco integrantes, realizaram nas salas de aula orientações sobre sexualidade e IST`s/HIV, demonstrações ilustrativas com slide, vídeo e dinâmica lúdica: o balaio das perguntas, onde eles escreviam e colocavam as suas dúvidas como anônimos, para a timidez não ser mais um obstáculo. Ficou-nos perceptível o interesse dos adolescentes em relação ao conteúdo abordado, demonstrado nas perguntas. Resultados: Foi observado suas expressões faciais e registrado os questionamentos realizados, tais como "durante as relações sexuais, se a mulher ingerir esperma ela pode se infectar com alguma doença?" e "esses vírus contagiam crianças?", sendo possível mencionar: "que para alguns era novidade para outros não era, e outros demonstraram surpresa". A educação sobre a vida sexual não é um assunto que deve ser deixado para depois, é importante ressaltar que as infecções sexualmente transmissíveis não se restringem a idade, raça, cultura e ou situação econômica. Conclusão: Ao finalizar as ações realizadas naquele dia, percebemos a contribuição do projeto de extensão na construção profissional e em nossas trajetórias acadêmicas.

DESCRITORES: Adolescente. Doenças Sexualmente Transmissíveis. Educação em

Saúde. Precaução. 


\section{Referências:}

1. Santos J V O, Araújo L F, Castro J L C, Faro André. Análisis prototípico de las representaciones sociales sobre las infecciones sexualmente transmisibles entre adolescentes. Psicogente, 22(41): pp.1-18. Enero-Junio, 2019. 2.

2. Bermudez B E B V, Fernandes E C, Oliveira H F, Hagel L D, Guimarães P R, Goldberg T B L. Guia Prático de Atualização departamentos científicos de Adolescência e Infectologia. Infecções Sexualmente Transmissíveis na Adolescência. Nº 6, Agosto de 2018. 
ANAIS DO I SIMPÓSIO CLÍNICO MULTIPROFISSIONAL DE INFECTOLOGIA, 2019; 08-78

\title{
A PERCEPÇÃO DOS ACADÊMICOS DE ENFERMAGEM FRENTE AO SURTO DO SARAMPO EM MANAUS - RELATO DE EXPERIÊNCIA
}

\author{
Fabrício de Souza Melo ${ }^{1}$ Helen Suanny Franco de Araujo ${ }^{1}$ Monique Tereza Marinho \\ Medim ${ }^{1}$ Yana dos Santos Maia ${ }^{1}$ Andreza Mendes dos Santos ${ }^{2}$ \\ ${ }^{1}$ Discentes do curso de Graduação em Enfermagem do Centro Universitário-Fametro, Manaus, \\ Amazonas, Brasil. \\ ${ }_{2}^{2}$ Enfermeira Docente Mestre do Centro Universitário Fametro, Manaus, Amazonas, Brasil.
}

\section{RESUMO}

Introdução: O sarampo é uma doença infecciosa aguda, de natureza viral, grave, transmitida pela fala, tosse e espirro, e extremamente contagiosa, pode ser contraída por pessoas de qualquer idade. Desde o início de 2018, até 8 de janeiro deste ano, foram confirmados 10.274 casos no Brasil. Atualmente, o país enfrenta dois surtos de sarampo: no Amazonas com 9.778 casos confirmados e, em Roraima, com 355 casos, os surtos ocorridos no ano passado estão relacionados à importação, com a grande demanda nos hospitais da capital, a secretaria de saúde do estado convocaram alguns voluntários para ajudar nessa grande ação, nos quais foram os acadêmicos de enfermagem para dar o suporte aos funcionários. Objetivo: Descrever as percepções de acadêmicos de enfermagem no desenvolvimento de atividades na campanha de vacinação do sarampo nas escolas de Manaus. Materiais e Métodos: Trata-se de um relato de experiência realizado em uma Instituição de Ensino Superior (IES), na cidade de Manaus-AM. Os acadêmicos participaram de reuniões conduzidas pelas enfermeiras de uma instituição pública de saúde e foram incentivados através do diálogo ou processo dialógico, a participar de forma ativa e reflexiva das programações. Resultados: Ao participarem da ação de vacinação os acadêmicos vivenciaram todo o processo de treinamento e preparo para atender a população alvo e experimentaram as dificuldades existentes para o processo de imunização. A resistência da população alvo deste trabalho perante a vacinação era o principal obstáculo a ser vencido, apesar do recente surto da doença, ainda se verificou resistência e dúvidas no momento da imunização, sendo assim, os acadêmicos exercitaram e compartilharam seus conhecimentos obtidos no treinamento. Conclusão: Portanto, foi uma experiência exitosa para os acadêmicos com a oportunidade de aprofundar conhecimentos sobre a doença e seus agravos, e, contudo, ampliando saberes no campo da imunização e preparando os discentes para serem profissionais competentes.

Descritores: Sarampo; voluntários; imunização.

\section{Referências}

Diagnóstico, notificação e prevenção. Disponível em: \&lt;https://sbim.org.br/images/files/notatecnica-conjunta-sarampo sbimsbisbp20180716.pdf\&gt;. Acesso em: 05 de agos. 2019. MENDES, Amanda. Ministério da saúde atualiza casos de sarampo. Disponível em: \&lt;http://www.saude.gov.br/noticias/agencia-saude/45089-ministerio-da-saude-atualizacasos- de-sarampo-19\&gt;. Acesso em: 25 de jul. 2019. 


\title{
CUIDADOS DE ENFERMAGEM NO TRATAMENTO DE PACIENTES COM HANSENÍASE: RELATO DE EXPERIÊNCIA
}

\author{
Ana Carolina Morais Cruz ${ }^{1}$ Valéria Marreiro Batista ${ }^{2}$ Railton da Silva Miranda ${ }^{3}$ \\ ${ }^{1}$ Enfermeira Mestre em Doenças Infecciosas e Parasitárias pela FMT/HVD, Manaus, \\ Amazonas, Brasil. \\ ${ }^{2}$ Acadêmica de Enfermagem da Universidade Nilton Lins, Manaus, Amazonas, Brasil. \\ ${ }^{3}$ Enfermeiro. Mestrando. Universidade Nilton Lins
}

\section{RESUMO}

Introdução: A hanseníase é uma doença infecciosa, cujo agente causador da doença é o Mycobacterium leprae, que tem afinidade pelas células epiteliais e pelos nervos periféricos. A agressão causada pelo bacilo causa alterações de sensibilidade nas fibras sensitivas, motoras e autonômicas, tornando assim a doença de alto poder incapacitante. Classificada como Paucibacilar e multibacilar. Objetivo: Relatar os cuidados de enfermagem durante o tratamento da hanseníase. Materiais e Métodos: Trata-se de um estudo de natureza descritivo, do tipo relato de experiência, que ocorreu na cidade de Manaus Amazonas, onde a acadêmica participou de um voluntariado voltado aos cuidados de enfermagem na Fundação Alfredo da Mata em um período de 30 dias. Resultados: Realizamos sob supervisão de um enfermeiro as consultas com pacientes hansênicos em curso, durante as consultas ocorriam o exame físico, exame dermato neurológico, onde foi detectado a melhora no estado de saúde dos pacientes que tinham comprometimento com o tratamento, a anamnese acerca do estado de saúde atual do paciente, a dose supervisionada da PQT , as orientações para os pacientes, dos cuidados relacionados com a pele, proteção solar, orientando a atividades físicas, a andar sempre calçados e reforçando a família a importância de realizar o exame e avaliação, prevenindo assim a proliferação da doença, levando segurança ao portador e sua família. Conclusão: Concluímos que a hanseníase ainda é uma doença cercada pelo estigma e preconceito, onde a atenção básica tem papel essencial para ajudar na erradicação da doença, foi notado a necessidade de mais envolvimento por parte do paciente e familiares para entender que a o sucesso do tratamento esta relacionado ao seu comprometimento com o tratamento, a enfermagem fundamental e tem o objetivo de orientar sobre os agravos, cuidados ,e prevenções, fazendo com que haja a promoção da saúde e prevenção de deformidades e incapacidades.

\section{Referências:}

BRASIL. Ministério da Saúde. Secretaria de Vigilância em Saúde. Departamento de Vigilância das Doenças Transmissíveis. Guia prático obre a hanseníase. Brasília: Ministério da Saúde, 2017.

SOUZA, Larissa Ribeiro de Souza et al. Hanseníase: diagnóstico e tratamento. Revista Multidisciplinar: humanidades \&amp; tecnologias, Minas Gerais, p.1809-1628, jan. 2019. 
ANAIS DO I SIMPÓSIO CLÍNICO MULTIPROFISSIONAL DE

INFECTOLOGIA, 2019; 08-78

\section{A IMPORTÂNCIA DA FISIOTERAPIA NO PROCESSO DE DECANULAÇÃO DE PACIENTES HOSPITALIZADOS NO SERVIÇO PÚBLICO DE SAÚDE: RELATO DE EXPERIÊNCIA}

Fernando Hugo Jesus da Fonseca ${ }^{1}$ Josiane Lima Rocha ${ }^{2}$

${ }^{1}$ Fisioterapeuta Residente do Programa de Residência Multiprofissional em Saúde com ênfase em Infectologia, Fundação de Medicina Tropical - HVD / Universidade Nilton Lins.

${ }^{2}$ Fisioterapeuta Especialista da Fundação de Medicina Tropical - HVD.

\section{RESUMO}

Introdução: Para estabelecer o prognóstico e planejar a conduta de desmame da traqueostomia é de fundamental importância o envolvimento da equipe multidisciplinar na interpretação dos aspectos clínicos e laboratoriais. A fisioterapia contribui de maneira significativa no processo de decanulação, sendo necessária cautela para a realização desse processo. Objetivo: Relatar a importância do fisioterapeuta no atendimento ao paciente traqueostomizado com prognóstico de decanulação. Metodologia: Trata-se de um estudo descritivo, com abordagem qualitativa, tipo relato de experiência na área de fisioterapia respiratória, com ênfase na infectologia e reabilitação dos pacientes internados na enfermaria do Hospital e Pronto Socorro Dr. João Lúcio Pereira Machado, na cidade de Manaus-AM. Resultados: A recolocação, troca ou retirada da cânula traqueal não são procedimentos de competência do fisioterapeuta, porém este profissional tem um papel importante no processo de retirada da cânula traqueal, através da reabilitação neuromuscular e da avaliação dos preditores de decanulação, mesmo com a falta de recursos e equipamentos ideais. Conclusão: $O$ fisioterapeuta é um profissional que contribui para a decanulação de forma mais rápida e segura ao paciente, mesmo sem os recursos adequados indisponíveis pelo serviço público de saúde.

Descritores: traqueostomia; serviço hospitalar de fisioterapia; funcionalidade. 
ANAIS DO I SIMPÓSIO CLÍNICO MULTIPROFISSIONAL DE INFECTOLOGIA, 2019; 08-78

\title{
LEVANTAMENTO DA PREVALÊNCIA DA INFECÇÃO PELO PAPILOMA VÍRUS HUMANO (HPV) E O CÂNCER DE COLO DE ÙTERO NO BRASIL: REVISÃO SISTEMÁTICA
}

\author{
Barbara Berse Cutar ${ }^{1}$ Beatriz Ferreira de Araújo ${ }^{2}$ Emile Gervazoni Barroso ${ }^{3}$ Flávia \\ Juliana Rebelo Tenório da Silva ${ }^{4}$ Maria Gracimar Fecury da Gama ${ }^{5}$
}

${ }^{1}$ Acadêmica de Enfermagem da Universidade Nilton Lins, Manaus, Amazonas, Brasil.

2 Acadêmica de Enfermagem da Universidade Nilton Lins, Manaus, Amazonas, Brasil.

${ }^{3}$ Acadêmica de Enfermagem da Universidade Nilton Lins, Manaus, Amazonas, Brasil.

${ }^{4}$ Acadêmica de Enfermagem da Universidade Nilton Lins, Manaus, Amazonas, Brasil.

${ }^{5}$ Graduada em Enfermagem pela Escola de Enfermagem de Manaus / Universidade Federal do Amazonas. Professora da Universidade Nilton Lins. Atualmente no Instituto da Mulher, Manaus, Amazonas, Brasil.

\section{RESUMO}

Introdução: $O$ câncer do colo do útero é o sexto tipo de câncer mais frequente na população em geral e o segundo mais comum entre mulheres. No Brasil, estimam-se 20 mil casos novos de câncer de colo de útero ao ano, uma incidência estimada em 20/100 mil. Objetivo: Considerando a riqueza das informações disponíveis sobre o tema, faz uma revisão para analisar a prevalência de infecção pelo vírus do papiloma humano (HPV) em mulheres no Brasil. Métodos: Revisão sistemática que incluiu artigos recuperados em busca livre nos portais PubMed e Biblioteca Virtual em Saúde, em Out/2019, utilizando se os termos "human papillomavirus", "prevalence" e "Brazil". Dos 150 artigos identificados, 80 permaneceram após leitura de título e resumo e foram submetidos à leitura integral, sendo selecionados 14 artigos. Resultados: Os artigos sobre o tema foram publicados entre 2010 e 2018. Os 14 artigos representaram estudos de quatro regiões brasileiras. Nove artigos relatavam estudos transversais. Em oito utilizaram-se técnicas moleculares para tipagem do HPV e em sete deles utilizou-se captura híbrida para detecção do HPV. As populações estudadas variaram de 49 a 2.329 mulheres. A prevalência geral de infecção do colo do útero pelo HPV variou entre $13,7 \%$ e 54,3\%, e para as mulheres com citologia normal, variou entre 10,4\% e 24,5\%. Quatro estudos relataram os tipos de HPV mais frequentes, segundo resultado de citologia. Conclusão: Este estudo mostrou que existe uma vasta literatura sobre o vírus HPV e o carcinoma cervical, mostrando que alguns aspectos ainda são controversos. Apesar do avanço nos conhecimentos, as taxas de morbimortalidade por câncer de colo de útero continuam altas, por ser uma patologia de evolução lenta, sem manifestação clínica no seu início e, principalmente por se tratar de uma infecção de transmissão sexual.

Descritores: Infecções por Papillomavírus, epidemiologia. Neoplasias do Colo do Útero, prevenção e controle.

\section{Referências}

NAKAGAWA, T.T.J. Vírus HPV e câncer de Colo de Útero. Rev Bras Enferm, nov-jan; 59(2): 176-7, 2015. SCHLMER, J., BARBLERT, M. Prevalência do Vírus HPV . Rev Bras Enferm, mar-abr; 59(3): 183-7, 2010.

AYRE, A. R. G. Prevalência de infecção do colo do útero pelo HPV no Brasil: revisão sistemática. São Paulo: Singular, 2017. 
ANAIS DO I SIMPÓSIO CLÍNICO MULTIPROFISSIONAL DE

INFECTOLOGIA, 2019; 08-78

\title{
OCORRÊNCIA DE RELATOS DE TABAGISMO, ALCOOLISMO E USO DE DROGAS ILÍCITAS ENTRE PACIENTES COM TUBERCULOSE
}

\author{
Arimatéia Portela de Azevedo ${ }^{1}$ Luana Perreira Aguiar ${ }^{2}$ Roberta Lima de Oliveira ${ }^{3}$ Sarah \\ Pessoa Rodrigues ${ }^{4}$
}

${ }^{1}$ Enfermeiro. Mestre. Fundação de Medicina Tropical Dr. Heitor Vieira Dourado. Manaus/AM. Brasil.

${ }^{2}$ Estudante. Curso de Enfermagem do Centro Universitário Nilton Lins - UNINILTONLINS. Manaus/AM. Brasil.

${ }^{3}$ Estudante. Curso de Enfermagem do Centro Universitário Nilton Lins - UNINILTONLINS. Manaus/AM. Brasil.

${ }^{4}$ Estudante. Curso de Enfermagem do Centro Universitário Nilton Lins - UNINILTONLINS. Manaus/AM. Brasil.

\section{RESUMO}

Introdução: Para a preocupação da saúde pública a tuberculose (TB) permanece como um dos principais problemas de saúde na maioria dos países do mundo. Estima-se que um terço da população mundial esteja infectado pelo Mycobacterium tuberculosis. Constituem um dos principais fatores que desencadeiam o abandono do tratamento da tuberculose são sintomas como alcoolismo, drogadição, tabagismo, efeitos adversos do tratamento, baixo nível de escolaridade, baixo nível sócio-econômico, estado geral debilitado e melhora dos sintomas. Objetivo: Este estudo objetiva relatar resultados referentes as ocorrências de relatos de tabagismo, alcoolismo e uso de drogas ilícitas entre pacientes com tuberculose internados em um Hospital da cidade de Manaus/AM referência em doenças infectoparasitárias. Materiais e métodos: Trata-se de um estudo descritivo, prospectivo de registro das atitudes e o comportamento de pacientes quanto ao uso de drogas ilícitas, tabagismo e álcool durante o tratamento de pacientes internados por tuberculose para melhoramento das estratégias de quebra de cadeia de transmissão do Mycobacterium Tuberculosis em um Hospital referência em doenças infecto-parasitárias da cidade de Manaus/AM. Resultados: Foi realizada a entrevista com 11 pacientes, destes, $63,6 \%$ era do gênero masculino, $81,8 \%$ informaram ser divorciado, $636 \%$ tinham filhos e 36,3 se declararam ser os únicos provedores do lar e a idade destes eram entre 23 a 50 anos. Também 18,1\% relataram que não tiveram nenhum tipo de orientação sobre como se comportar em isolamento durante a internação, destes pacientes 54,5\% utilizaram uso de drogas ilícitas e alcoolismo antes do tratamento, e 45,45\% não utilizaram o uso de drogas ilícitas e alcoolismo antes do tratamento. Conclusão: Embora a tuberculose represente riscos para a saúde da humanidade, esforços são realizados para controlar a epidemia da mortalidade e incidência da doença, o intuito é reduzir os fatores que contribuem para a possibilidade de transmissão e infecção da tuberculose.

DESCRITORES: Tuberculose. Transtornos Relacionados ao Uso de Substâncias.

Alcoolismo. Terapia Combinada. 


\section{REFERÊNCIAS:}

1. Silva D R, Torrico M M, Duarte R, Galvão T, Bonini E H, Arbex F F, Arbex M A, Augusto V M, Rabahi M F, Mello F C Q. Fatores de risco para tuberculose: diabetes, tabagismo, álcool e uso de outras drogas. JBrasPneumol. 2018;44(2):145-152.

2. Silveira C S, Passos S P T, Soder T C H, Machado C P H, Fanfa L S, Carneiro M, Valim A R M, Possuelo L G. Perfil epidemiológico dos pacientes que abandonaram o tratamento para Tuberculose em um município prioritário do Rio Grande do Sul.RevEpidemiolControlInfect. 2012;2(2):46-50. 
ANAIS DO I SIMPÓSIO CLÍNICO MULTIPROFISSIONAL DE

INFECTOLOGIA, 2019; 08-78

\title{
SÍNDROME DE GUILLAIN-BARRÉ ASSOCIADA AO HIV SOB OS CUIDADOS DE ENFERMAGEM: RELATO DE EXPERIÊNCIA
}

\author{
Nelisnelson da Silva Oliveira ${ }^{1}$ Victoria Villar Viana ${ }^{1}$ Fernando da S. Mello ${ }^{2}$ Francisco R. B. \\ de Barros ${ }^{2}$ \\ ${ }^{1}$ Academicos de Enfermagem- UNINORTE - \\ ${ }^{2}$ Residentes de Enfermagem da FMT-HVD,
}

\section{RESUMO}

Introdução: O Processo de Enfermagem impõe-se como solução para organização das ações do enfermeiro e tem a Sistematização da Assistência de Enfermagem (SAE) como um instrumento que o normatiza e auxilia. Neste sentido, é de fundamental relevância a aplicação da SAE a um paciente diagnosticado com o Human Immunodeficiency Virus (HIV) que desencadeou a Síndrome de Guillain-Barré (SGB). Objetivos: Relatar a experiência vivenciada por um acadêmico de enfermagem na elaboração da Sistematização da SAE a um paciente diagnosticado com HIV e Síndrome de GuillainBarré em uma Fundação Pública de referência em Manaus/AM. Metodologia: Trata-se de um estudo descritivo do tipo relato de experiência realizado por um acadêmico de enfermagem durante a vivência da prática hospitalar. O estudo foi realizado no período de 21 a 28 de agosto de 2017 em uma Fundação Pública de referência em Manaus/AM, onde foi assistido um paciente diagnosticado com HIV e Síndrome de Guillain-Barré. Resultados: O paciente em questão foi admitido no setor de urgência e emergência do HPS Dr. João Lúcio apresentando um quadro de desconforto respiratório agudo, rigidez na região da nuca e paralisia flácida ascendente, necessitando de ventilação mecânica invasiva e teste rápido com resultado positivo para HIV. Após o diagnóstico foi encaminhado à unidade referência em infectologia, sendo internado na UTI e permanecendo por quatro meses. De acordo com os problemas encontrados, evidenciamos dois Diagnósticos de Enfermagem (DE) prioritários com suas respectivas intervenções. O primeiro DE identificado foi Padrão Respiratório Ineficaz e o segundo foi Mobilidade Física Prejudicada. Visando reestabelecer ou aumentar o nível de mobilidade, intervimos de forma educativa ao informar aos familiares do paciente sobre a doença e a perspectiva de cura. Conclusão: Vivenciar a construção da SAE para um paciente com HIV e Síndrome de Guillain Barré possibilitou compreender a importância desse instrumento do profissional de enfermagem para a aquisição de conhecimento científico.

Descritores: HVI, Síndrome de Guillain-Barré, Processo de Enfermagem. 


\title{
RELATO DE EXPERIÊNCIA: ENFERMAGEM NA PREVENCÃO DAS INFECÇÕES URINARIAS RELACINADO A CATETER VESICAL DE DEMORA
}

\author{
Jesimar Augusto Germano da Cruz ${ }^{1}$ Joao Gorgonha Hipy Neto ${ }^{2}$ Matheus Breno da Silva Gima \\ ${ }^{3}$ Sonaira Daiana Valente de Lira ${ }^{4}$ \\ ${ }^{1}$ Acadêmico de Enfermagem da Universidade Nilton Lins, Manaus, Amazonas, Brasil. \\ ${ }^{2}$ Acadêmico de Enfermagem da Universidade Nilton Lins, Manaus, Amazonas, Brasil. \\ ${ }^{3}$ Acadêmico de Enfermagem da Universidade Nilton Lins, Manaus, Amazonas, Brasil. \\ ${ }^{4}$ Enfermeira Especialista em Auditoria e Metodologia do ensino Superir. Docente do curso de \\ Enfermagem e medicina da Universidade Nilton Lins, Manaus, Amazonas, Brasil.
}

\section{RESUMO}

Introdução: O cateterismo urinário é um procedimento amplamente utilizado, sendo de inestimável valor ao tratamento de processos patológicos. A infecção pode surgir em 1 a $2 \%$ dos pacientes submetidos ao cateterismo urinário intermitente, e em 10 a $20 \%$ dos pacientes submetidos ao cateterismo de demora. Objetivo: Relatar a experiência dos acadêmicos de enfermagem na assistência ao paciente com sonda vesical de demora. Materiais e métodos: trata-se um estudo descritivo, do tipo relato de experiência, elaborado pela vivência no contexto da disciplina de Urgência e emergência ministrada no oitavo período de enfermagem da Universidade Nilton Lins, que objetivou-se no aprimoramento do conhecimento dos acadêmicos, através do ensino teórico e prático no atendimento assistencial no SPA. Resultados: Os acadêmicos de enfermagem prestaram assistência ao paciente por meio da realização de um procedimento técnico, seguindo o protocolo de IRAS guiada pelo orientador. Na qual conheceram a forma de tratamento, medicações administradas, cuidados de enfermagem decorrente da patologia. Conclusão: Concluímos que a Infecção no trato Urinário (ITU), pode ser prevenida se empregado procedimentos adequados, quando necessários e realizados avaliações clínicas e laboratoriais para afastar quadros mais complexos e evitar recidivas. Deve-se investir no conhecimento, para que melhor assistência ao paciente, propiciando à equipe de Enfermagem mais informação, segurança e presteza, tornando possível a diminuição dos índices de infecção do trato urinário relacionados ao cateterismo vesical e suas complicações nos pacientes criticamente enfermos.

Descritores: Infecção urinária, cateterismo urinario, cuidados de enfermagem.

\section{Referências}

MENIN VT, GRAZZIOTIN, NA. Infecções do Trato Urinário Diagnosticadas no Laboratório Universitário da URI - Campus de Erechim/RS. Revista Brasileira de Análises Clínicas. 2010;. Disponível em: https://revista.fagoc.br/index.php/saude/article/view/84/151. Acessado em: 07 Out. 2019.

SOUZA-NETO JL, OLIVEIRA FV, KOBAZ AK, SILVA MNP, LIMA AR, MACIEL LC. Infecção do trato urinário relacionada com a utilização do cateter urinário de demora: resultados da bacteriúria e da microbiota estudadas. Rev Col Bras Cir. 2008;35(1):28-33. 
ANAIS DO I SIMPÓSIO CLÍNICO MULTIPROFISSIONAL DE INFECTOLOGIA, 2019; 08-78

\section{RELATO DE EXPERIÊNCIA NA TERAPIA EMPIRICA DAS INFECÇÕES DO TRATO URINARIO NO IDOSO}

Jesimar Augusto Germano da Cruz Joao Gorgonha Hipy Neto ${ }^{2}$ Matheus Breno da Silva Gima ${ }^{3}$ Sonaira Daiana Valente de Lira ${ }^{4}$

${ }^{1}$ Acadêmico de Enfermagem da Universidade Nilton Lins, Manaus, Amazonas, Brasil.

${ }^{2}$ Acadêmico de Enfermagem da Universidade Nilton Lins, Manaus, Amazonas, Brasil.

${ }^{3}$ Acadêmico de Enfermagem da Universidade Nilton Lins, Manaus, Amazonas, Brasil.

${ }^{4}$ Enfermeira Especialista em Auditoria e Metodologia do ensino Superir. Docente do curso de Enfermagem e medicina da Universidade Nilton Lins, Manaus, Amazonas, Brasil.

\section{RESUMO}

Introdução: A terapia empírica amiúde exige o uso de fármacos de espectro amplo, o que exige critério não só para focar a terapia após o resultado da cultura, como na terapia inicial. O uso de múltiplos agentes antimicrobianos e os de amplo espectro também, nos casos em que apenas uma terapia de menor espectro é suficiente, expõe inevitavelmente o paciente a um risco aumentado de efeitos adversos e propicia a seleção de microrganismos cada vez mais resistentes. A escolha de uma droga para tratamento de ITU deve ser baseada na sua segurança, eficácia, tolerabilidade. Todos os indivíduos com ITU devem receber terapia antibacteriana, mas com esquemas terapêuticos de acordo com os grupos específicos de pacientes e suas manifestações clínicas. Objetivo geral: Relatar a experiência dos acadêmicos de enfermagem na assistência ao paciente com Infecção do trato urinário. Materiais e métodos: trata-se um estudo descritivo, do tipo relato de experiência, elaborado pela vivência no contexto da disciplina de Urgência e emergência ministrada no oitavo período de enfermagem da Universidade Nilton Lins, objetivou-se que no aprimoramento do conhecimento dos acadêmicos, através do ensino teórico e prático no atendimento assistencial no SPA. Resultados: Os acadêmicos de enfermagem prestaram assistência ao paciente por meio da realização de um procedimento técnico, seguindo a Terapia guiada com o uso de antimicrobianos escolhidos, segundo o diagnóstico microbiológico e guiada pelo orientador. Na qual conheceram a forma de tratamento, medicações administradas, cuidados de enfermagem decorrente da patologia. Conclusão: Concluímos que a Infecção no trato Urinario (ITU), deve ser diagnosticada corretamente e empregado antibióticoterapia adequada, e realizados avaliações clínicas e laboratoriais, para afastar quadros mais complexos e evitar recidivas. Deve-se investir no conhecimento, para que melhor assistência ao paciente, tornando possível a diminuição dos índices de infecção do trato urinário e suas complicações nos pacientes criticamente enfermos.

Descritores: Infecção urinária, Idoso, cuidados de enfermagem.

\section{Referências}

MENIN VT, GRAZZIOTIN, NA. Infecções do Trato Urinário Diagnosticadas no Laboratório Universitário da URI - Campus de Erechim/RS. Revista Brasileira de Análises Clínicas. 2010;. Disponível em: https://revista.fagoc.br/index.php/saude/article/view/84/151. Acessado em: 07 Out. 2019.

MENEZES RL, BACHION MM, SOUZA JT, NAKATANI AYK. Estudo longitudinal dos aspectos multidimensionais da saúde de idosos institucionalizados. Rev Bras Geriatr Gerontol [Internet]. 2011 [cited 2016 Aug 18];14(3):485-96. Disponivel em: http://www.scielo.br/pdf/rbgg/v14n3/v14n3a09 Acessado em: 07 Out. 2019. 
ANAIS DO I SIMPÓSIO CLÍNICO MULTIPROFISSIONAL DE

INFECTOLOGIA, 2019; 08-78

\section{PERFIL SOCIODEMOGRÁFICO DE PACIENTES COM LESÃO POR PRESSÃO DE UM HOSPITAL REFERÊNCIA EM INFECTOLOGIA/AM.}

Arimatéia Portela de Azevedo ${ }^{1}$ Jesimar Augusto Germano da $\mathrm{Cruz}^{2}$ João Gorgonha Hipy Neto $^{3}$ Jones dos Anjos Muniz ${ }^{4}$ Lucely Damasceno de Jesus ${ }^{5}$

${ }^{1}$ Enfermeiro, Mestre Fundação de Medicina Tropical Dr. Heitor Vieira Dourado, Manaus-AM. Brasil

${ }^{2}$ Acadêmico de Enfermagem da Universidade Nilton Lins, Manaus-AM, Brasil.

${ }^{3}$ Acadêmico de Enfermagem da Universidade Nilton Lins, Manaus-AM, Brasil.

${ }^{4}$ Acadêmico de Enfermagem da Universidade Nilton Lins Manaus-AM, Brasil.

${ }^{5}$ Acadêmica de Enfermagem da Universidade Nilton Lins, Manaus, Amazonas, Brasil.

\section{RESUMO}

Introdução: Tratar ferida é uma atividade cotidiana do enfermeiro, porém esse cuidado confronta a autonomia das atividades desse profissional frente aos pacientes portadores de feridas. Por muito séculos, o tratamento de feridas pretendia alcançar resultado cicatriciais em menos tempo possível. Na pré-história eram utilizados agentes como: extrato de plantas, água, neve, gelo, frutas e lama que eram colocados nas feridas. Objetivo: Descrever o perfil sociodemográfico e patológico dos pacientes atendidos pela de feridas da Fundação de Medicina Tropical Dr. Heitor Vieira dourado. Materiais e métodos: Baseado nas informações secundárias obtidas dos formulários de observação (LPP) tratou de um estudo do tipo retrospectivo, descritivo e quantitativo onde as informações existentes no banco de dados da CCIH. Este trabalho foi apreciado é aprovado pelo CEP da FMT/HVD conforme CAAE: 67728317.5.0000.0005. Resultado: Em dez meses foi avaliado o perfil de 51 pacientes com idade entre 16 a 73 anos, tinham entre um mês e dois anos de acamados, 60,7\% eram do gênero masculino, 52,9\% moravam com familiares, 72,5\%residiam em Manaus 15,6\%em outros Municípios do Amazonas e 9,8\% eram oriundos de outros Estados. Conclusão: Concluímos que o fato de a maioria dos pacientes acamados e com lesões já instaladas serem do gênero masculino $(60,7 \%)$, provavelmente é em virtude da grande resistência dos homens em procurar a ajuda médica e quando procuram, estão em estado grave. Também o fato termos registrado pacientes com 16 anos de idade, acamado, portador do vírus HIV e com lesão já em curso e às vezes sem acompanhantes, nos leva a refletir sobre a exposição do vírus ainda na juventude e o descaso e às vezes ate abandono familiar.

Descritores: Lesão por pressão, Perfil de saúde, Cuidados de Enfermagem.

\section{Referências}

SANDERS LSC, PINTO FJM. Ocorrência de ulcera por pressão em pacientes internados em um hospital público de Fortaleza-CE, Reme-Rev. Min. Enf.;16(2); 166170,abri.jun., 2012: Disponível em: www.reme.org.br/artigo /detalhes/515. Acessado em 10/04/2018 ás 10:30.

FAVRETO F J L BETIOLLI S E, SILVA F B CAMPA A. O papel do enfermeiro na prevenção, avaliação e tratamento das lesões por pressão. Revista Gestão \&amp; Saúde (ISSN 1984-8153): 
ANAIS DO I SIMPÓSIO CLÍNICO MULTIPROFISSIONAL DE

INFECTOLOGIA, 2019; 08-78

\section{CUIDADOS AO NEONATO COM MÃE PORTADORA DE SÍFILIS: UM RELATO DE EXPERIÊNCIA}

Ana Carolina de Moraes Cruz ${ }^{\mathrm{I}}$ Julie Bianca Matos dos Anjos ${ }^{\mathrm{II}}$ Karina Mendonça da Silva ${ }^{\text {III }}$ Kemelly Oriente de Matos ${ }^{\text {IV }}$ Liandra da Costa Saraiva ${ }^{\mathrm{V}}$

1Enfermeira Mestre em Doenças Infecciosas e Parasitárias, docente do curso de Graduação em Enfermagem da Universidade Nilton Lins, Manaus-AM, Brasil.

${ }^{2}$ Acadêmica de enfermagem na Universidade Nilton Lins, Manaus-AM;

${ }^{3}$ cadêmica de enfermagem na Universidade Nilton Lins, Manaus-AM;

${ }^{4}$ Acadêmica de enfermagem na Universidade Nilton Lins, Manaus-AM, Brasil.

${ }^{5}$ Acadêmica de enfermagem na Universidade Nilton Lins, Manaus-AM

\section{RESUMO}

Introdução: $O$ aumento progressivo de doenças infectocontagiosas tem causado inquietação na maior parte da população. Estima-se que 1 milhão de casos de infecções sexualmente transmissíveis são notificadas diariamente, por ano 357 milhões dessas infecções equivalem a clamídia, gonorreia, sífilis e tricomoníase, e dentre esses casos 11 milhões tem prevalência em adultos de 15 a 40 anos de idade com diagnóstico de sífilis. Objetivo: Relatar os cuidados de enfermagem ao neonato com mãe portadora de sífilis. Metodologia: Trata-se de um estudo descritivo, do tipo relato de experiência. Elaborado pela vivência no contexto de uma maternidade pública, na assistência de enfermagem a um neonato com mãe portadora de sífilis no mês de setembro de 2019. Resultado: Percebeu-se que os enfermeiros reforçavam as ações de prevenção e diagnóstico precocemente no pré-natal. Foram identificados fatores de risco relacionados à transmissão vertical da sífilis como mães menores de 18 anos, que desconhecem o uso do preservativo, multíparas, que quebram a continuidade do tratamento da sífilis. Os cuidados ao neonato exposto ao Treponema pallidum reduzem a mortalidade neonatal e evitam sequelas que possam prejudicar a qualidade de vida do RN. Conclusão: Os cuidados da assistência em enfermagem consistem em conscientizar e incentivar a prevenção da sífilis durante o pré-natal. O enfermeiro deve oferecer uma assistência humanizada ao bebê e a mãe, promover atenção integral a saúde, reduzindo agravos e o índice de mortalidade neonatal.

Descritores: Sífilis Congênita, doenças urogenitais femininas e complicações na gravidez, transmissão vertical e doença infecciosa.

\section{Referências}

BRASIL. Ministério da Saúde. Secretaria de Vigilância em Saúde. Programa Nacional de DST/AIDS. Diretrizes para controle da sífilis congênita: manual de bolso. 2. ed. Brasília, 2006.

NUNES J. T., MARINHO A. C. V., DAVIM R. M. B., et al. Sífilis na gestação: perspectivas e condutas do enfermeiro. Revista de enfermagem UFPE on line, Recife, 2017. 


\title{
ANAIS DO I SIMPÓSIO CLÍNICO MULTIPROFISSIONAL DE
}

INFECTOLOGIA, 2019; 08-78

\section{ASPECTOS CLÍNICOS DA MALÁRIA EM UMA UNIDADE HOSPITALAR DA ZONA OESTE DE MANAUS}

\author{
Elaine Carolina Obando Parreira ${ }^{1}$, Jani Kenta Iwata ${ }^{2}$, Patrícia Soares De Lima ${ }^{3}$, \\ Regislane Ribeiro Rodrigues ${ }^{4}$, Suellem Tello Barbosa ${ }^{5}$. \\ ${ }^{1}$ Graduanda. Enfermeira. Universidade Nilton Lins. \\ ${ }^{2}$ Doutorando. Enfermeiro. Universidade Nilton Lins. \\ ${ }^{3}$ Graduanda. Enfermeira. Universidade Nilton Lins. \\ ${ }^{4}$ Graduanda. Enfermeira. Universidade Nilton Lins. \\ ${ }^{5}$ Graduanda. Enfermeira. Universidade Nilton Lins.
}

\begin{abstract}
RESUMO
Introdução: Malária é uma enfermidade infecciosa transmitida por mosquitos e ocasionada pelos protozoários parasitários do gênero Plasmodium (SOUSA et al., 2015). No Brasil, mais de $99 \%$ dos acontecimentos de malária são registrados na região amazônica, que engloba os estados do Acre, Amazonas, Amapá, Maranhão, Mato Grosso, Pará, Rondônia, Roraima e Tocantins (COSTA et al., 2017). Objetivo: Relatar os aspectos clínicos dos pacientes infectados pelo vetor da malária. Metodologia: O estudo é um relato de experiência, vivenciado na unidade hospitalar da zona oeste, referência em doenças tropicais. Resultados: A doença é sintomatologia básica da malária foi observada nos indivíduos aonde, as queixas mais frequentes mialgia, fraqueza, cefaleia, calafrio e febre. Entretanto, esses sintomas são idênticos com outras patologias, como dengue, febre de Chikungunya e febre por Zika vírus. Contudo, o acesso a unidade é livre para todos os pacientes que chegarem com os sinais e sintomas para realização dos exames. Conclusão: A pesquisa apontou baixo nível econômico entre os pacientes. O acesso a unidade é fácil e os problemas de saúde são, sobretudo, solucionados na própria unidade hospitalar.
\end{abstract}

DESCRITORES: Malária Vivax; Malária Falciparum; Prevenção \& Controle. REFERÊNCIA:

SOUSA, Jonata Ribeiro de et al. Situação da malária na Região do Baixo Amazonas, Estado do Pará, Brasil, de 2009 a 2013: um enfoque epidemiológico. Revista PanAmazônica de Saúde, v. 6, n. 4, p. 39-47, 2015. 


\title{
DIFICULDADES QUANTO A ABORDAGEM DE ENFERMAGEM SOBRE IST'S AO PÚBLICO ADOLESCENTE - RELATO DE EXPERIÊNCIA
}

\author{
Adele Marilia Sousa Vasconcelos ${ }^{1} ;$ Débora Nery Oliveira $^{1} ;$ Brena Tavares Rocha $^{2}$; \\ Clarice Rosa de Souza Gomes ${ }^{2}$, Leila Cristina Oliveira Rodrigues ${ }^{3}$.
}

1- Acadêmicas do $6^{\circ}$ período do curso de Bacharelado em Enfermagem da Universidade Nilton Lins, Manaus, Amazonas:

2- Acadêmicas do $6^{\circ}$ período do curso de Bacharelado em Enfermagem da Faculdade Estácio do Amazonas.

3- Enfermeira atuando como Gerente da Enfermagem do Hospital e Maternidade Santo Alberto. Especialista em Enfermagem Obstétrica, Auditoria em Enfermagem.

\section{RESUMO}

Introdução: As IST'S correspondem a um grupo de infecções transmitidas principalmente por meio do contato sexual sem o uso de preservativo, com uma pessoa infectada. A adolescência compreende um período de grande vulnerabilidade, devido o início precoce da vida sexual sem o conhecimento básico sobre IST'S. Sendo que, ainda existe um tabu em relação a educação sexual no âmbito familiar e no âmbito escolar, tendo como conseqüência a dificuldade em abordar o assunto com os mais jovem. Objetivo: Relatar a dificuldade dos acadêmicos de enfermagem na abordagem sobre Infecções Sexualmente Transmissíveis com adolescentes. Materiais e métodos: Trata-se de um estudo descritivo do tipo relato de experiência, referente a uma palestra desenvolvida por acadêmicos de enfermagem do $4^{\circ}$ período, em setembro de 2018, numa escola de rede pública na cidade de Manaus/AM. Resultados: Durante a palestra, cada acadêmico ficou responsável por apresentar um tipo de IST. Foram expostas as que têm maior índice de ocorrência como: Herpes Genital, HIV, Gonorréia, Clamídia e HPV. Enfatizando os sintomas, os riscos, e a importância do uso do preservativo. Houve orientações de como agir em caso de suspeita. A dificuldade na interação com os alunos foi perceptível, muitos se sentiram constrangidos ao falar sobre o assunto ou tirar dúvidas com os acadêmicos. Durante a explicação foi difícil ter a atenção de alguns alunos, pois não levaram a temática a sério e não tiveram a conscientização da importância das informações fornecidas. Conclusão: A falta de conscientização por parte dos adolescentes e o início precoce da atividade sexual associada à baixa adesão ao uso do preservativo contribui para o aumento da incidência. Políticas públicas de saúde sexual e reprodutiva, que incluem educação em saúde e acompanhamento psicológico são de extrema importância no combate de IST'S nesta faixa etária.

Descritores: doenças sexualmente transmissíveis; adolescente; promoção da saúde

\section{Referências:}

Doenças de Condições Crônicas e Infecções Sexualmente Transmissíveis, Ministério da Sáude. Disponível em: aids.gov.br/pt-br/publico-geral/o-que-são-ist. Acessado em: 7, Out. 2019.

Infecções Sexualmente Transmissíveis na Adolescência, Residência Pediátrica. Disponível em: residenciapediatrica.com.br/detalhes/170/infecções-sexualmentetransmissiveis-na-adolescencia. Acessado em: 7, Out. 2019. 


\section{LIGA ACADÊMICA DE DOENÇAS TRANSMISSÍVEIS: A IMPORTÂNCIA DA EXTENSÃO UNIVERSITẢRIA NA FORMAÇÃO DO ENFERMEIRO}

$\underline{\text { Karoline Costa de Souza }}{ }^{1}$ Albert Einstein Tavares de Seixas ${ }^{2}$ Carlos Rafael Lopes de Azevedo $_{\text {- }}$ Suellen Oliveira de Sousa ${ }^{2}$ Alaidistânia Aparecida Ferreira ${ }^{3}$

1 Discente de Graduação em Enfermagem pela Universidade Federal do Amazonas (UFAM), Manaus, Amazonas, Brasil.

${ }^{2}$ Discentes de Graduação em Enfermagem pela Universidade Federal do Amazonas (UFAM), Manaus, Amazonas, Brasil.

2 Professora Doutora da Escola de Enfermagem de Manaus (EEM/UFAM), Manaus, Amazonas, Brasil.

\section{RESUMO}

Introdução: A inserção do discente de graduação em atividades de extensão na universidade possibilita que o aluno desenvolva habilidades para sua prática profissional. Conforme Biscarde (2014), o reconhecimento da cidadania é fundamental no enfrentamento da realidade socioeconômica e sanitária para a reflexão em relação à formação em saúde. Objetivo: Descrever a experiência de discentes durante as atividades de extensão universitária de aproximação ao cuidado em doenças transmissíveis. Materiais E Métodos: Trata-se de um relato de experiência sobre a atuação da Liga Acadêmica de Doenças Transmissíveis do Amazonas (LADTAM). No período de prática, os alunos realizaram ações de Educação em Saúde e na campanha de vacinação em Unidade Básica de Saúde. Atuaram também em uma Unidade de Referência no Atendimento em Dermatologia na cidade de Manaus. Onde é oferecido à população atendimento especializado em Hanseníase, Leishmaniose, Infecções Sexualmente Transmissíveis, incluindo Serviço de Atendimento Especializado (SAE) para pessoas vivendo com HIV/AIDS. Outra oportunidade de atuação foi a vivência na gestão do serviço, ao acompanharem o trabalho da equipe multiprofissional no contexto administrativo. Resultados: Como contribuição, pode-se destacar o contato com profissionais capacitados que incentivaram à busca pela excelência na formação acadêmica. Os alunos puderam acompanhar a atuação da equipe nos setores de triagem dermatológica, prevenção de incapacidades em hanseníase, distribuição de medicamentos onde são realizados atendimentos clínicos com farmacêutico ou consulta de Enfermagem com enfermeiro. Conclusão: A participação na LADTAM foi de suma importância devido ao contato com usuários do Sistema Único de Saúde (SUS) em diversas situações, nos preparando assim para a realidade como profissional de saúde. No campo das doenças transmissíveis, é possível refletir sobre aspectos que vão muito além do estudo das doenças e epidemiologia; é dada a possibilidade de conhecer o papel de cada profissional nas linhas de cuidado às pessoas vivendo com essas condições.

Descritores: Doenças Transmissíveis; Comunicação Interdisciplinar; Relações Comunidade-Instituição.

\section{REFERÊNCIAS:}

BISCARDE, Daniela Gomes dos Santos; PEREIRA-SANTOS, Marcos; SILVA, Lília Bittencourt. Formação em saúde, extensão universitária e Sistema Único de Saúde (SUS): conexões necessárias entre conhecimento e intervenção centradas na realidade e repercussões no processo formativo. Interface (Botucatu), Botucatu , v. 18, n. 48, p. 177-186, 2014. 


\title{
DIALOGANDO COM O ADOLESCENTE SOBRE IST'S-AIDS EM ESCOLAS PUBLICAS EM MANAUS: RELATO DE EXPERIÊNCIA
}

\author{
Cheila Maria Lins Bentes ${ }^{6}$ Lana Maria Libânio Fernandes ${ }^{7}$ Maria Luana Pereira \\ Aguiar ${ }^{8}$ Maria lucivane felix da silva ${ }^{4}$ Roberta lima de oliveira ${ }^{5}$
}

\begin{abstract}
RESUMO
Introdução: Neste contexto, destacam-se a temática das Infecções Sexualmente Transmissíveis (IST`s) e a importância da sua discussão junto a grupos de adolescentes ${ }^{1}$. Pensa-se que ações educativas podem cumprir um papel importante nesta faixa etária, uma vez que trazem informações e trocas de experiência acerca da atividade sexual. ${ }^{2}$ objetivo: Realizar palestras educativas visando a prevenção de IST's/AIDS com adolescentes das escolas publica na cidade de Manaus/AM. Materiais E Métodos: Tratase de um resumo descritivo qualitativo de relato de experiência, onde foram utilizadas metodologias dinâmicas participativas ente acadêmicos e ouvintes na realização do projeto de extensão da Universidade Nilton Lins. Resultados: Foi notório o interesse dos adolescentes que encontravam-se em sala de aula, participando com perguntas e respostas de forma aberta, despertando nestes participantes a importância da prevenção das IST's/AIDS. A criação de um clima lúdico e de liberdade para o desenvolvimento das estratégias educativas utilizadas na realização do projeto, através de perguntas como: “ HIV pode ser transmitido através do beijo?", "uso de camisinha previne a AIDS?", "sexo oral transmite AIDS?", "uma pessoa pode ser afetada por mais de uma doença?", "qual forma o Vírus é transmitido?". A temática foi apresentada por slides e brincadeiras educativas. Percebemos que vários adolescentes já possuíam algum conhecimento sobre assunto e outros totais desconhecimentos. Ao término das atividades alguns adolescentes procuraram os acadêmicos em particular para tirar suas dúvidas em relação das IST's/AIDS. Devemos prover aos adolescentes informações e principalmente para que estes consigam dialogar dentro da estrutura familiar. CONCLUSÃO: As ações realizadas pelos acadêmicos no proposto dia, revelou-nos uma necessidade de incentivar os adolescentes sobre a educação sexual, onde destaca-se a importância de promover, espaços para discussões acerca da temática no contexto escolar.
\end{abstract}

Descritores: Adolescente. Infecções Sexualmente Transmissíveis. Prevenção. Educação sexual nas escolas.

\footnotetext{
${ }^{6}$ Enfermeira.Mestre. Centro Universitário Nilton Lins - UNINILTONLINS. Manaus/AM. Brasil. Email: cheilabentes@hotmail.com

${ }^{7}$ Estudante. Curso de Enfermagem do Centro Universitário Nilton Lins - UNINILTONLINS.

Manaus/AM. Brasil. E-mail: lanalibanio@ hotmail.com

${ }^{8}$ Estudante. Curso de Enfermagem do centro Universitário Nilton - UNINILTONLINS. Manaus/AM. Brasil. E-mail: luanaaguiar28@ gmail.com

${ }^{4}$ Estudante. Curso de Enfermagem do centro Universitário Nilton - UNINILTONLINS. Manaus/AM. Brasil. E-mail: lucyfelix-1@ hotmail.com

${ }^{5}$ Estudante. Curso de Enfermagem do centro Universitário Nilton - UNINILTONLINS. Manaus/AM.

Brasil. E-mail: roberta.enf1@ outlook.com
} 


\section{REFERÊNCIAS:}

1. CAMARGO BV, Botelho LJ. Aids, sexualidade e atitudes de adolescentes sobre proteção contra o HIV. Rev Saúde Pública [Internet]. 2007 [cited 2014 Out 13]; 41(1):61-8. 
ANAIS DO I SIMPÓSIO CLÍNICO MULTIPROFISSIONAL DE

INFECTOLOGIA, 2019; 08-78

\title{
RELATO DE EXPERIÊNCIA DE ACADÊMICOS DE ENFERMAGEM NA ASSISTÊNCIA DE ENFERMAGEM NA LEISMANIOSE VISCERAL
}

\author{
Ana Carolina Moraes Cruz¹. Ana Beatriz Fonseca Lima² \\ ${ }^{1}$ Enfermeira Mestre em Doenças Infecciosas e Parasitárias pela Fundação Medicina \\ Tropical Doutor-HVD, Manaus, Amazonas, Brasil. \\ ${ }^{2}$ Acadêmica de Enfermagem da Universidade Nilton Lins, Manaus, Amazonas, Brasil.
}

RESUMO
INTRODUÇÃO: A Leishmaniose Visceral é uma doença infecciosa e de evolução
cronológica, seu acometimento é de maneira sistêmica. É transmitida ao Homo sapiens
pela picada de um vetor infectado do sexo feminino, denominado flebotomíneo que é
conhecido popularmente na região amazônica como mosquito palha. No Brasil como
um todo, a principal espécie responsável pela transmissão é a Lutzomyia longipalpis. OBJETIVO GERAL: Mostrar a importância de promover educação em saúde à pacientes com diagnóstico de LTA cutâneo-mucosa. MATERIAIS E MÉTODOS: Se trata de um estudo descritivo, na qual é relatado experiências vivenciadas no contexto do I Simpósio Clínico Multiprofissional de Infectologia da Universidade Nilton Lins que objetivou-se o conhecimento dos acadêmicos aprimorando o ensino teórico e prático em vinculação as Doenças Infectocontagiosas. RESULTADOS E DISCUSSÃO: Durante a realização do Processo de Enfermagem, foi avaliado que um grupo de pessoas adoecidas consideram de grande importância a participar de ações de cuidado que envolvam a enfermagem por abordar novos meios de conhecimentos e benefícios para esse grupo de pessoas, pois essa é uma doença de muita importância e de grande perspicácia para os acadêmicos de enfermagem, foi prestada a assistência ao paciente por meio de uma visita técnica, junto ao orientador. Na qual foram apresentadas as formas de prevenção, tratamento, medicações administradas e os cuidados de enfermagem no decorrente da patologia. CONCLUSÃO: Consideramos que os profissionais de enfermagem que atuam na assistência de doenças infectocontagiosas, têm uma grande importância educativa como multiplicadores, atuando na promoção somando a prevenção de agravos de possíveis reinfecções, além de promover educação em saúde, não somente para os indivíduos já infectados, mas para familiares e pessoas que tem contato diretamente no ambiente infectado e para pessoas que possam a vim a se infectar indiretamente.

Descritores: Leishmaniose, assistência, enfermagem.

\section{REFERÊNCIAS:}

Portal do Governo Brasileiro, disponível em: http://www.saude.gov.br/saude-de-az/leishmaniose-visceral/. Acessado em 06 Out. 2019. Agência Fiocruz de Notícias, disponível em: https://agencia.fiocruz.br/leishmaniose. Acessado em 06 Out. 2019. Revista Científica Eletrônica De Medicina Veterinária, disponível em: http://faef.revista.inf.br/imagens_arquivos/arquivos_destaque/fA4b0h8gC5IQUuu_2013 -6-27-15-48-34.pdf. Acessado em 06 Out. 


\title{
ESTIGMAS EM PACIENTES COM HANSENÍASE: A MELHOR SOLUÇÃO É A INFORMAÇÃO - RELATO DE EXPERIÊNCIA
}

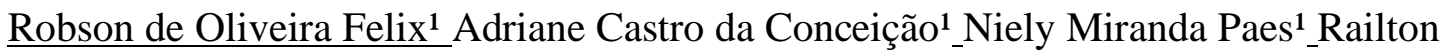 \\ da Silva Miranda ${ }^{2}$ Regina Patricia da Silva Sena ${ }^{1}$
}

1 Acadêmicos do Curso de Enfermagem do Centro Universitário Nilton Lins UNINILTONLINS. Manaus/AM - Brasil.

${ }^{2}$ Enfermeiro Esp. -Docente da Universidade Nilton Lins. Manaus/AM. Brasil.

\begin{abstract}
RESUMO
Introdução: A hanseníase é uma doença historicamente antiga de caráter infeccioso, crônico e incapacitante. A prevalência e o grande impacto social perduram por muito tempo e dessa forma tornou-se um problema de saúde pública no Brasil em decorrência de sua incidência. Os estigmas sociais caminham concomitantes o desenvolvimento sociocultural da doença, uma vez que o preconceito e a exclusão social marcaram o passado e ainda resistem nos dias atuais. Objetivo: Relatar a experiência vivenciada por acadêmicos de enfermagem durante uma oficina realizada no mês de maio sobre a escala de estigmas sociais na hanseníase. Materiais e métodos: Trata-se de um estudo descritivo, observacional do tipo relato experiência, desenvolvido a partir da vivência de alunos durante a execução de uma oficina sobre a escala de estigmas na hanseníase em uma Universidade privada de Manaus. Resultados: foi realizada uma oficina para a escala de estigma dividida em duas partes. Na primeira os acadêmicos vivem na pele o que é ser estigmatizado e na segunda há apresentação dos questionários e como aplicálos. Os participantes recebem também problemas corriqueiros e precisam achar soluções em saúde para a problemática. O resultado no final da oficina foi satisfatório, pois ao ser finalizada a atividade observou-se através da aplicação de um questionário o conhecimento dos alunos sobre a doença e a sua relação com os estigmas sociais, obtevese uma satisfação positiva de mais de $90 \%$ das repostas dos envolvidos. Conclusão: O estigma social na hanseníase ainda é um grande desafio para o país, tendo em vista que a falta de conhecimento, de informação e conscientização ainda é a principal falha na luta por essa causa social. Dessa forma, trabalhar a informação ainda é o melhor caminho a ser trilhado.
\end{abstract}

Descritores: Enfermagem; Hanseníase; estigma social.

\section{Referencias bibliográficas}

Barreto J, Gasparoni JM, Politani AL, Rezende LM, Edilon TS, Fernandes VG, Lima VM. Hanseníase e Estigma. Hansen. Int. 2013; 38 (1-2): p. 14-25.

Secr. de Vigilância em Saúde-Ministério da Saúde-Brasil. Boletim epidemiológicoHanseníase. Volume $49 \mathrm{~N}^{\circ} 4-2018$.

Nunes JM; Oliveira EM;Vieira NFC. Hanseníase: conhecimentos e mudanças na vida das pessoas acometidas. Ciência \& Saúde Coletiva, 16(Supl. 1):1311-1318, 2011. 


\title{
ASSISTÊNCIA DE ENFERMAGEM A PACIENTES PORTADORES DE HIV/AIDS INTERNADOS NA UNIDADE DE TERAPIA INTENSIVA (UTI).
}

\author{
$\underline{\text { Lenilson Alves de Souza }}^{9}$; Aine Lorenna Araújo Bié ${ }^{10}$; Diorges Boone da Silva ${ }^{11}$; \\ Heriederson Sávio Dias Moura ${ }^{12}$; Rayanne da Silva Souza ${ }^{5}$.
}

\begin{abstract}
RESUMO
Introdução: Estima-se que no mundo cerca 37,9 milhões de pessoas estejam vivendo com o Vírus da Imunodeficiência Humana e Síndrome da Imunodeficiência Adquirida (HIV/AIDS). Em 2018, foram diagnosticados 1,7 milhões de novos casos mundialmente, cerca de 770 mil relacionados à AIDS $^{1}$. A solicitação de vagas para UTI para esse público é grande, mesmo com o avanço das terapêuticas, o principal fator que leva a isso é a falta de adesão ao tratamento ${ }^{2}$. Objetivo: Identificar as condutas da assistência de enfermagem a pacientes com HIV internados na UTI. Metodologia: Revisão bibliográfica descritiva, foram consultadas as bases Scielo, LILACS e UNAIDS, utilizando critérios para inclusão e exclusão das publicações. Resultados: As principais causas que levam a admissão dos pacientes com HIV/AIDS estão restritas aos casos de doenças oportunistas, como: tuberculose, insuficiência respiratória aguda, rebaixamento da consciência e $\operatorname{sepse}^{2}$. $\mathrm{O}$ Enfermeiro deve propor intervenções que visem aliviar a dor do paciente, bem como melhorar o conforto e prevenir eventuais complicações, aumentando assim a qualidade de vida do mesmo. Este profissional torna-se o elo de comunicação entre paciente e familiar, assim, faz-se necessário agir com ética, buscando preservar a integridade do paciente ${ }^{3}$. Conclusão: Inúmeras são as comorbidades que levam a internação na UTI, sendo assim, o enfermeiro precisa atuar de forma humanizada e ética, preservando a privacidade e integridade do paciente. Desta forma, faz-se necessário profissional qualificado, que forneça uma assistência humanizada, com equidade e de forma integral, visando à melhora do quadro clínico, bem como a alta hospitalar.
\end{abstract}

Descritores: Assistência de Enfermagem, UTI, HIV.

\section{Referências}

1. UNAIDS. Estatísticas globais sobre HIV de 2019 - 2019. Disponível em: <https://unaids.org.br/estatisticas/>. Acesso em: 09 Out 2019.

2. SOUZA, P. N.; MIRANDA, E. J. P.; CRUZ, R.; FORTE, D. N. 2016. Cuidados paliativos no paciente com HIV/AIDS internado na unidade de terapia intensiva. Rev. bras. ter. intensiva; vol.28, n.3, pp.301-309.

${ }^{9}$ Graduando em Bacharelado em Enfermagem, CEUNI-FAMETRO, ManausAmazonas-Brasil. E-mail: lenilson.1990.25@gmail.com.

${ }^{10}$ Graduanda em Bacharelado em Enfermagem, CEUNI-FAMETRO, Manaus-

Amazonas-Brasil.

${ }^{11}$ Graduando em Bacharelado em Enfermagem, CEUNI-FAMETRO, Manaus-

Amazonas-Brasil.

${ }^{12}$ Graduando em Bacharelado em Enfermagem, CEUNI-FAMETRO, Manaus-

Amazonas-Brasil.

${ }^{5}$ Mestre em Ciências Farmacêuticas, SUSAM, Manaus-Amazonas-Brasil. 
3. VASCONCELOS, M. F.; COSTA, S. F. G.; BATISTA, P. S. S.; LOPES, M. E. L. 2016. Cuidados paliativos para pacientes com HIV/AIDS, Rev enferm UERJ, Rio de Janeiro; 24(2): e26409. 


\title{
RELATO DE EXPERIÊNCIA: A IMPORTÂNCIA DO CCIH FRENTE AO PACIENTE COM DOENÇAS INFECTOCONTAGIOSAS
}

\author{
Railton da Silva Miranda ${ }^{1}$ Fernanda Ellen Pontes Brito ${ }^{2}$ Rayssa Sousa dos Santos ${ }^{3}$ \\ Stheffany da Silva Pinheiro ${ }^{4}$
}

${ }^{1}$ Enfermeiro Especialista. Docente do curso de Graduação em Enfermagem da Universidade Nilton Lins, Manaus-AM.

${ }^{2}$ Acadêmica de Enfermagem da Universidade Nilton Lins, Manaus-AM.

${ }^{3}$ Acadêmica de Enfermagem da Universidade Nilton Lins, Manaus-AM.

${ }^{4}$ Acadêmica de Enfermagem da Universidade Nilton Lins, Manaus-AM.

\section{RESUMO}

Introdução: As doenças infectocontagiosas são as grandes fontes de transmissão para pacientes e profissionais da saúde. Diante disso, houve a exigência da criação CCIH nos hospitais para manter o controle e prevenção de infecções hospitalares de pacientes e profissionais da área de saúde. Objetivo geral: Relatar a importância do CCIH frente ao paciente com doenças infectocontagiosas, baseado na perspectiva vivenciada em hospital de referência na cidade de Manaus. Materiais e Métodos: Trata-se de um relato de experiência do tipo narrativo descritivo, onde por meio de vivência em um hospital de referência na cidade de Manaus, Amazonas, podemos observar a importância do CCIH em relação ao paciente infectocontagioso, o ambiente hospitalar que é necessário a este indivíduo. Resultados: Os Pacientes com doenças infectocontagiosas são muito mais susceptíveis de se obter novas infecções e disseminar a já presente. Nos hospitais, as principais fontes de infecção ocorrem por causas ligadas ao ambiente, pessoal, equipamento, material e muitos outros. A CCIH é atualmente uma necessidade sentida por muitos hospitais, já que está é responsável pela elaboração de medidas efetivas visando a redução e eliminação das infecções. Conclusão: É através da CCIH que é possível identificar possíveis focos de infecções e buscar alternativas para contorná-las visando o bem-estar do paciente quanto do profissional que está presente no meio hospitalar. Vale ressaltar que o $\mathrm{CCIH}$ tem o compromisso de visar a biossegurança de cada integrante no meio hospitalar.

Descritores: transmissão, biossegurança, controle de infecções.

\section{Referências:}

FERNANDES AT, Fernandes MOV, Ribeiro Filho R. Infecção hospitalar e suas Interfaces na área da saúde. São Paulo: Atheneu; 2000. HOEFEL HHK, Sheneider LO. O profissional de saúde na cadeia epidemiológica In: Rodrigues EAC. Infecções hospitalares: prevenção e controle. São Paulo: Savier; p.78-86, 1997. HORR, Lidvin et al. Comissão de Controle de Infecção Hospitalar. Rev. Bras. Enferm., Brasília, v.31, n.2, p.182-192, 1978. 


\section{IMPACTO DO TABACO AOS MORADORES DA ÁREA RIBEIRINHA DE MANAUS RELACIONADO À TUBERCULOSE}

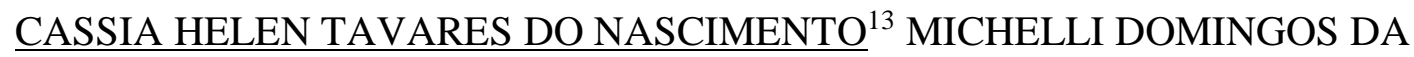 SILVA $^{14}$.}

\section{RESUMO}

Introdução: A incidência de tuberculose no Brasil aumenta cada dia mais, principalmente por causa da grande quantidade de fumantes que vem tendo um vasto crescimento tanto nas cidades em desenvolvimento quanto também nas cidades e comunidades afastadas das metrópoles (GARRIDO et al., 2015; SILVA et al., (2018). Objetivo: Relatar o aumento da tuberculose em áreas ribeirinhas no Estado do Amazonas. Metodologia: Estudo do tipo relato de experiência narrativo descritivo, caracterizado pelos casos de tuberculose relacionada ao tabagismo no interior do Amazonas. Resultado: A tuberculose está relacionada a diversos problemas de saúde, é uma doença crônica, o seu diagnóstico e tratamento precoce acontecem no ambulatório. Entretanto, esses resultados mostram que a taxa de tuberculose é significativamente maior em fumantes, e estudos revelam que não só a exposição ativa é maléfica, mas também a passiva, como em crianças que tem pais fumantes e consequentemente inalam a fumaça do cigarro. A probabilidade de abandono do tratamento aumenta quando o paciente continua fazendo uso do cigarro, nas comunidades ribeirinhas o índice de não adesão ao tratamento é maior, concernente muitas vezes ao vicio, a cultura ou a dificuldade da localização residencial, no caso os ribeirinhos são os mais afetados. Conclusão: A incidência da tuberculose no interior do Estado do Amazonas supera a média nacional e por alguns períodos a do Estado, associada as drogas ilícitas elas se tornam um problema de saúde pública.

Descritores de Saúde: Tuberculose; Tabagismo; Exposição

\section{REFERÊNCIA}

1. SILVA, Denise Rossato et al. Fatores de risco para tuberculose: diabetes, tabagismo, álcool e uso de outras drogas. Jornal Brasileiro de Pneumologia, v. 44, n. 2, p. 145 152, 2018. GARRIDO, Marlucia da Silva et al. Temporal distribution of tuberculosis in the State of Amazonas, Brazil. Revista da Sociedade Brasileira de Medicina Tropical, v. 48, p. 63-69, 2015.

\footnotetext{
${ }^{13}$ Graduanda. Enfermagem. Universidade Nilton Lins. Manaus/AM. Brasil. cassiahelen38@gmail.com

${ }^{14}$ Enfermeira. Doutoranda. Universidade Nilton Lins. Manaus/AM. Brasil.
} 
ANAIS DO I SIMPÓSIO CLÍNICO MULTIPROFISSIONAL DE INFECTOLOGIA, 2019; 08-78

\title{
BIOSSEGURANÇA E O USO DO JALECO EM AMBIENTE NÃO HOSPITALAR: RELATO DE EXPERIÊNCIA
}

\author{
Brunno da Silva Siqueira ${ }^{1}$ Fabiane Veloso Soares $^{2}$ \\ ${ }^{1}$ Estudante. Curso de Enfermagem. Universidade Nilton Lins Manaus/AM. \\ ${ }^{2}$ Enfermeira. Doutora. Docente da Faculdade Mauricio de Nassau- Manaus/AM.
}

\begin{abstract}
RESUMO
Introdução: Na prevenção de contaminação por agentes infecciosos recomendam que os profissionais de saúde adotem medidas de biossegurança especificamente aqueles que trabalham em áreas insalubres, com risco variável de infecção para a saúde. O jaleco é um dos equipamentos de biossegurança que protege tanto o profissional quanto o paciente, além disso, os jalecos são contaminados durante os atendimentos clínicos e em outros procedimentos, passando a ser o primeiro sítio de contato em termos de indumentária com a pele, líquidos e secreções dos pacientes, tornando-se com isto um verdadeiro fômite ${ }^{1}$. As bactérias multirresistentes, que podem provocar doenças como faringites, otites, pneumonia, tuberculose e até mesmo a morte, são carregadas para lugares públicos e retornam das ruas para consultórios médicos odontológicos, enfermarias e salas de cirurgia nos jalecos dos mais diversos profissionais de saúde. Freqüentemente, a seriedade da questão é negligenciada por arrogância ou desconhecimento de alguns conceitos básicos de microbiologia ${ }^{2}$. Objetivo: Relatar a respeito dos aspectos da biossegurança relacionados ao uso do jaleco em ambiente não hospitalar e seus riscos. Metodologia: Trata-se de um estudo descritivo do tipo relato de experiência a respeito das observações realizadas durante o estágio supervisionado em um Serviço de Pronto Atendimento (SPA). Discussão: Observou-se que alguns profissionais usam de forma inadequada o jaleco fora do ambiente hospitalar do SPA, fato que ocorre devido ao desconhecimento microbilógico ${ }^{1}$ e/ou por status na sociedade. O jaleco é abordado como fonte de contaminação e como equipamento de proteção individual na prevenção das infecções, fato observado ao longo do estágio, com ressalvas para o uso fora das dependências do SPA. Conclusão: É fundamental o conhecimento microbiológico e da educação continuada em biossegurança para estes profissionais, uma vez que estudos comprovam a existência de Staphylococcus aureus nos equipamento de proteção individual, que poderiam causar pneumonia, infecções no trato urinário, septicemia $^{3}$, havendo a necessidade de campanhas educativas no sentido de orientar os profissionais de saúde sobre o uso adequado do jaleco.
\end{abstract}

Descritores: Biossegurança, Contaminação, Equipamento de proteção individual.

\section{Referências:}

1. ${ }^{1}$ CARVALHO, Carmem Milena Rodrigues Siqueira et al. Aspectos de biossegurança relacionados ao uso do jaleco pelos profissionais de saúde: uma revisão da literatura. Texto \& Contexto Enfermagem, v. 18, n. 2, p. 355-360, 2009.; ${ }^{2}$ DIAS Júnior, P.P. Jaleco: uso correto na hora certa, em local apropriado. Rev Eletrônica Ciências [online]. 2008 (43); ${ }^{3}$ GASPARD, P. et al. Meticillin-resistant Staphylococcus aureus contamination of healthcare workers' uniforms in long-term care facilities. Journal of Hospital Infection, v. 71, n. 2, p. 170-175, 2009. 


\title{
VIVÊNCIA NO CAMPO DE ESTÁGIO EM DOENÇAS INFECTOCONTAGIOSAS: RELATO DE EXPERIÊNCIA
}

\author{
Ana Carolina Moraes Cruz ${ }^{1} \underline{\text { Kalíssia Moraes de Araújo }}{ }^{2}$
}

${ }^{1}$ Enfermeira Mestre em Doenças Infecciosas e Parasitárias pela Fundação de Medicina Tropical Doutor- HVD, Manaus, Amazonas, Brasil.

${ }^{2}$ Acadêmica de Enfermagem da Universidade Nilton Lins, Manaus, Amazonas, Brasil.

\begin{abstract}
RESUMO
Introdução: A vivência no campo de estágio é um momento importante e de muita expectativa para os acadêmicos e estudantes de enfermagem, pois é uma oportunidade de interligar os conhecimentos científicos com a prática dentro de um hospital e com isso, o envolvimento com os pacientes com doenças infectocontagiosas. Objetivo geral: Relatar a experiência dos acadêmicos de enfermagem no campo de estágio em doenças infectocontagiosas. Materiais e métodos: Trata-se de um estudo descritivo, do tipo relato de experiência, elaborado pela vivência em estágio no contexto da disciplina de enfermagem em doenças infectocontagiosas ministrada no sexto período do curso de enfermagem, da Universidade Nilton Lins. Resultados: Foram prestados assistência de enfermagem aos pacientes com doenças infectocontagiosas, tais como: Tuberculose, HIV e Raiva Humana, por meio de uma visita técnica realizada e guiada com o preceptor e docente da Universidade. Foram desenvolvidas atividades para o conhecimento e embasamento das patologias, e no decorrer entramos em contato com os pacientes. Conhecer e compreender a natureza das doenças infectocontagiosas, seus condicionantes e formas de tratamento se fazem através da educação em saúde. É importante que o acadêmico tenha vínculo com os pacientes, para além do conhecimento, saber que os mesmos sofrem diariamente por conta das emoções que são negativas. Conclusão: Diante do que foi relatado, conclui-se que os estágios são de suma importância quando unidas as disciplinas ofertadas no curso, para que os acadêmicos tenham contato com os pacientes e além disso, a experiência nos proporciona aprofundamento do conhecimento acerca do quadro clínico e a evolução do paciente.
\end{abstract}

Descritores: Educação em saúde, doenças transmissíveis, cuidados de enfermagem.

\section{Referências}

PERBONE, J.G.; CARVALHO, E. C. Sentimentos do estudante de enfermagem em seu primeiro contato com pacientes. Ver. Bras. Enferm., Brasília, v.64, n2, p.343-347, mar/abr., 2011. Disponível em: www.scielo.br/scielo.php?script=sci_arttext\&pid=S0034-71672011000200019. Acessado em: 02 de Out de 2019. 


\title{
RELATO DE EXPERIÊNCIA DOS ACADÊMICOS DE ENFERMAGEM FRENTE AO PACIENTE COM DOENÇA DE CHAGAS
}

\author{
Ana Carolina Moraes Cruz ${ }^{1}$ Jamille da Silva Correa ${ }^{2}$ Kalíssia Moraes de Araújo $^{3}$ \\ Michelli Domingos da Silva ${ }^{4}$ Railton da Silva Miranda ${ }^{5}$
}

\begin{abstract}
${ }^{1}$ Enfermeira Mestre em Doenças Infecciosas e Parasitárias pela Fundação de Medicina Tropical Doutor- HVD, Manaus, Amazonas, Brasil.

${ }_{2}^{2}$ Acadêmica de Enfermagem da Universidade Nilton Lins, Manaus, Amazonas, Brasil. ${ }^{3}$ Acadêmica de Enfermagem da Universidade Nilton Lins, Manaus, Amazonas, Brasil. ${ }^{4}$ Enfermeira Especialista em UTI e Urgência e Emergência da Universidade Nilton Lins, Manaus, Amazonas, Brasil.

${ }^{5}$ Enfermeiro Mestrando em Ciências Aplicadas à Saúde, Universidade Nilton Lins, Manaus, Amazonas, Brasil.
\end{abstract}

\begin{abstract}
RESUMO
Introdução: A doença de Chagas é uma parasitose que tem como agente etiológico o Tripanossoma Cruzi, um protozoário flagelado da família Trypanossomatidae e possui curso clínico bifásico: fase aguda e crônica, apresentando diversas manifestações. Classicamente, a doença é transmitida através da passagem do protozoário através da pele lesada ou mucosas do ser humano. Objetivo geral: Relatar a experiência dos acadêmicos de enfermagem frente ao paciente com doença de Chagas. Materiais e métodos: Tratase de um estudo descritivo, em forma de relato de experiência desenvolvida acerca da assistência ao paciente com a patologia, elaborado através da disciplina ministrada no curso, no segundo período em parasitologia humana. Resultados: Na ocasião da visita, as acadêmicas de enfermagem junto ao paciente portador da doença de Chagas, foi possível observar a progressão dos sinais e sintomas que afetam fisicamente o indivíduo, com o auxílio do orientador prestaram assistência ao mesmo. Estima-se que até maio deste ano foram 12 casos notificados e 89 casos em 2019 no Amazonas. Conclusão: Considerada uma doença tropical negligenciada, a doença de Chagas está sendo estudada atualmente com investimento de tecnologia para detecção de triatomíneos. O grande número de pessoas afetadas nos indica a falta de informações sobre o contágio e desenvolvimento da patologia.
\end{abstract}

Descritores: Doença de Chagas, doenças negligenciadas, parasitas.

\section{Referências}

1. Coura JR, Viñas PA, Junqueira AC. Epidemiologia, história curta e controle da doença de Chagas endêmicos e o novo desafio para os países não endêmicos. Mem Inst Oswaldo Cruz. 2014 Nov; 109 (7): 856-62. Disponível em: http://scielo.iec.gov.br/scielo.php?script=sci arttext\&pid=S167949742016000500007. Acessadoem 05 Out de 2019.

2. Sangenis LHC, Nielebock MAP, Santos CS, Silva MCC, Bento GMR. Transmissão da doença de Chagas por consumo de carne de caça: revisão sistemática.

3. Rev Bras Epidemiol. OUT-DEZ 2016; 19(4): 803-811. Disponível em: https://www.scielosp.org/pdf/rbepid/2016.v19n4/803-811/pt. Acessado em 05 Out de 2019. 
ANAIS DO I SIMPÓSIO CLÍNICO MULTIPROFISSIONAL DE

INFECTOLOGIA, 2019; 08-78

\title{
MEDIDAS DE CONTROLE APLICADAS PARA A PREVENÇÃO DA TRANSMISSÃO DO MYCOBACTERIUM TUBERCULOSIS: RELATO DE EXPERIÊNCIA
}

\author{
Regina Patricia da Silva Sena ${ }^{1}$._Adriane Castro da Conceição ${ }^{1}$ Arimatéia Portela de \\ Azevedo ${ }^{2}$. Niely Miranda Paes ${ }^{1}$. Robson de Oliveira Felix ${ }^{1}$
}

${ }^{1}$ Acadêmicos do Curso de Enfermagem do Centro Universitário Nilton Lins UNINILTONLINS. Manaus/AM - Brasil. E-mail: regina-patricia2011@ @otmail.com 2 Enfermeiro Mestre - Fundação de Medicina Tropical Dr. Heitor Vieira Dourado. Manaus/AM. Brasil. E-mail: arimateia@fmt.am.gov.br

\section{RESUMO}

Introdução: A Tuberculose e uma doença infecciosa e contagiosa, causada pelo Mycobacterium tuberculosis. Sendo transmitida de indivíduo para indivíduo por meio de aerossóis infectantes eliminados no ar através da tosse ou da fala. Sabe-se que o elevado risco de exposição à $\mathrm{TB}$ em ambiente hospitalar relaciona-se com falhas no reconhecimento, isolamento e manejo de pacientes com TB pulmonar. Objetivo: Este estudo objetiva registrar o conhecimento dos pacientes e seus acompanhantes sobre medidas de controle e prevenção da doença. Materiais E Métodos: Tratou-se de um estudo prospectivo de caráter descritivo com abordagem quantitativa, baseado em informações obtidas por meio de uma entrevistas no local de internação do paciente (beira-leito). Durante a visita nas enfermarias, foi apresentado o objetivo do estudo e em seguida foi realizado o preenchimento de um questionário que nos permitiu mensurar o conhecimento dos mesmos acerca do tema. Em seguida, foram realizados orientações para os acompanhantes e pacientes sobre o comportamento em ambiente de isolamento, sobre não conformidades referentes aos ambientes onde ficam os pacientes em isolamento, sobre o uso de EPi's e sobre a identificação adequada das salas de isolamento por aerossóis. Resultados: Foi realizada a comparação estatística entre as Clinicas daquela unidade, observou-se que 57\% dos internados com TB eram do sexo masculino, com faixa etária entre 21 a 62 anos e $43 \%$ eram feminino com faixa etária entre 25 a 50 anos. Notou-se que dos 21 entrevistados somente 03 acompanhantes estavam devidamente aparamentado com EPI's apropriados para isolamentos por aerossóis conforme preconiza as diretrizes de biossegurança. Conclusão: A eficiência do conjunto para medidas de controle da tuberculose depende de múltiplas tarefas como: manejo correto dos pacientes com tuberculose, uso da máscaras tipo N95, treinamento dos profissionais em biossegurança entre outros.

Descritores: Tuberculose, Doenças Transmissíveis, Biosegurança.

\section{REFERÊNCIAS}

1. PIRES NETO R J, COSTA C O, BASTOS FILHO J B B, LINS J M M, FEITOSA R G F, LEITÃO T M J S, FAÇANHA M C, PINHEIRO V G F. Tuberculose em ambiente hospitalar: Perfil clínico em hospital terciário do Ceará e grau de conhecimento dos Profissionais de saúde acerca das Medidas de controle. RBPS, Fortaleza, 23(3): 260-267, jul./set., 2010. Visto em Outubro de 2019. Visualizado em: https://periodicos.unifor.br/RBPS/article/view/2025/2320 
2. SILVA E A, SILVA G A. O sentido de vivenciar a tuberculose: um estudo sobre representações sociais das pessoas em tratamento. Physis Revista de Saúde Coletiva, Rio de Janeiro, 26 [4]: 1233-1247, 2016. Visto em Outubro de 2019. Visualizado em: https://www.scielosp.org/article/physis/2016.v26n4/1233-1247/ 
INFECTOLOGIA, 2019; 08-78

\title{
RELATO DE EXPERIÊNCIA SOBRE DOENÇAS INFECTOCONTAGIOSAS: PROMOÇÃO E PREVENÇÃO A SAÚDE EM NO CENTRO SOCIOEDUCATIVO
}

\author{
Carolinne Amaral ${ }^{1}$; Camilla Reane Silva ${ }^{1}$ Claubia Reane ${ }^{1}$ Railton Miranda ${ }^{2}$; Tamyres \\ Soares ${ }^{1}$ \\ ${ }^{1}$ Acadêmicas do $8^{\circ}$ período do curso de Graduação em Enfermagem da Universidade \\ Nilton Lins/UNL Manaus-AM. \\ ${ }^{2}$ Enfermeiro Especialista. Docente do curso de Graduação em Enfermagem da \\ Universidade Nilton Lins/UNL. Manaus-AM.
}

\begin{abstract}
RESUMO
Introdução: A educação em saúde consiste em um processo de ensino-aprendizagem que visa à promoção da saúde, e o profissional dessa área é o principal mediador para que isso ocorra. Destaca-se que o mesmo é um educador preparado para propor estratégias no intuito de oferecer caminhos que possibilitem mudanças positivas nas pessoas/comunidades. Nota-se que a prática educativa em saúde não deve estar apenas centrada em escolas, mas também, nas instituições de apoio ao menor. Objetivos: Relatar a experiência do projeto de educação em saúde sobre doenças infectocontagiosas: promoção e prevenção. Métodos: relato de experiência com ênfase na educação em saúde, ao tema que se refere infecções sexualmente transmissíveis como: hiv, aids, hpv, sifilis. Este projeto foi implementado para jovens rapazes entre 14 a 17 anos, onde de início fizemos uma pergunta para saber o nível de conhecimento deles sobre o assunto e notamos que a maioria dos jovens tiveram dificuldade de responder e outros não responderam, após isso fizemos uma breve apresentação das doenças com: conceito, transmissão, diagnóstico, tratamento e prevenção, em formato de slide com imagens ilustrativas e alguns vídeos. Resultados: Após a apresentação retornamos com a questão do começo e logo podemos perceber a evolução das respostas em relação ao início evidenciando assim que a educação em saúde é uma base para muito dos jovens que entram para o mundo do crime e não tem base escolar, acabam sendo levados para instituições de apoio. Conclusão: Este projeto surte com eficiência não apenas no cuidar do enfermeiro, mas também passar conhecimentos de prevenção a doenças para diminuir o índice de jovens com patologias infectocontagiosas.
\end{abstract}

Descritores: Cuidado, saúde, infectologia.

Referências

AZEVEDO, Arimatéia Portela et al. Health education for companions of hospitalized patients. Journal of Nursing UFPE on line, [S.1.], v. 12, n. 4, p. 1168-1173, apr. 2018. ISSN 1981-8963. 
ANAIS DO I SIMPÓSIO CLÍNICO MULTIPROFISSIONAL DE INFECTOLOGIA, 2019; 08-78

\title{
AÇÕES DE EDUCAÇÃO EM SAÚDE NO COMBATE AO ZIKA VÍRUS EM UMA ESCOLA DE MANAUS
}

Cleiciane Granjeiro da Silva Batista ${ }^{1}$ Ana Carolina Moraes Cruz ${ }^{2}$ Andson Lima de Melo $^{3}$ Elessandra Ramos Pedrosa ${ }^{4}$ Railton da Silva Miranda ${ }^{5}$

\section{RESUMO}

Introdução: $\mathrm{O}$ vírus Zika é a mais recente das doenças virais transmitidas por artrópodes, é um arbovírus da família Flaviviridae, composto de ácido ribonucleico. Trata-se de uma doença febril aguda que causa manchas avermelhadas na pele, mas que, na maioria dos casos, evolui para cura. Sua transmissão em mulheres gravidas pode ocorre a presença de microcefalia e outras anormalidades cerebrais que têm sido observadas em muitos bebês, são consistentes com infecção ocorrendo no primeiro trimestre ou no início do segundo trimestre de gestação. Objetivo geral: Relatar a experiência de ações de educação em saúde no combate ao Zika vírus em uma escola de Manaus. Materiais e métodos: Tratase de um estudo de campo descritivo em relato de experiência, da qual foi realizado ações em saúde por acadêmicos de enfermagem, tendo como objetivo de explicar orientar e prevenir doenças contra o vetor do Zika Vírus através de palestras na escola Municipal Nazira Chamma Daou com alunos do ensino fundamental da quinta série. Resultados: $\mathrm{Na}$ escola foi aplicado slides criativos, despertando curiosidades dos alunos e dinamismos educativos, direcionando as orientações integradas de vigilância no controle de doenças causadas por vetores, inserindo medidas preventivas pessoais e populacionais. Conclusão: concluímos que para prevenção e as reduções de consequências causadas pelo vírus permanecem em desafios importantes para se obter o controle da infecção no Brasil, a cada ano ocorre um declínio da curva epidêmica dos casos de microcefalia relacionado pelo Virus Zika durante a gestação, a propagação do vírus são situações de emergência em saúde pública nacional e internacional.

Descritores: Zika Vírus, microcefalia, educação em saúde.

\begin{abstract}
Referências
RIBEIRO, F.N, B. et al. Artigo de revisão: Síndrome congênita pelo vírus Zika e achados de neuroimagem, o que sabemos o momento. Rio de janeiro, setembro de 2017. Disponível em: http://www.scielo.br/pdf/rb/v50n5/pt_0100-3984-rb-50-05-0314.pdf. Acesso em:04/10/2019.

RODRIGUES, N.R.R.; GRISOTTI, M. Comunicando sobre Zika: recomendações de prevenção em contexto de incertezas. Interface (Botucatu). 2019; 23: e190140. Disponível em: www. Scielo.br/Scielo.php/script=sci abstracti=s1414.pdf. Acesso em:04/10/2019. GRAUL, T.E. C. et al. Políticas públicas para doenças transmitidas por vetores: situação atual e educação como alternativa. Revista de políticas públicas. Rio de janeiro, maio de 2018. Disponível em: www.periodicoseletronicos.ufma.br9840.pdf. Acesso em:04/10/2019.
\end{abstract}

\footnotetext{
${ }^{1}$ Acadêmica de Enfermagem da Universidade Nilton Lins, Manaus, Amazonas, Brasil 2Enfermeira Mestre em Doenças Infecciosas e Parasitária pela Fundação Medicina Tropical Doutor- HD.

${ }^{3}$ Acadêmico de Enfermagem da Universidade Nilton Lins.

${ }^{4}$ Acadêmica de Enfermagem da Universidade Nilton Lins.

${ }^{5}$ Enfermeiro. Especialista. Universidade Nilton Lins.
} 


\title{
IDENTIFICAÇÃO DOS RISCOS DE INFECÇÃO DO VÍRUS HIV POR ACIDENTES DE TRABALHO ENTRE PROFISSIONAIS DE SAÚDE.
}

\author{
Diorges Boone da Silva ${ }^{15}$ Anderson Lima Cordeiro da Silva ${ }^{15}$ Heriederson Sávio Dias
} Moura $^{15}$. Daniella Souza Gama ${ }^{15}$. Erika Oliveira da Silva ${ }^{16}$

\begin{abstract}
RESUMO
Introdução: O Vírus da Imunodeficiência Humana (HIV) tem sido um dos principais problemas de saúde pública, estima-se que o risco de contaminação seja de 0,3\% em acidentes com perfuro cortantes em ambiente hospitalar ${ }^{1}$. Estando os profissionais de saúde na zona de risco, uma vez que se encontram expostos a contaminação por materiais com fluidos do vírus ${ }^{2}$. Objetivo: Identificar os riscos ocupacionais que levam a infecção do HIV entre profissionais da Saúde. Metodologia: Trata-se de um estudo bibliográfico, com levantamento de dados nas bases Biblioteca Virtual em Saúde (BVS), Biblioteca Científica Eletrônica Online (SciELO), Literatura Latino-Americano e do Caribe (LILACS), utilizando critérios de inclusão e exclusão das publicações. Resultado: Frequentemente, os trabalhadores de saúde estão em contato com material perfuro cortante em grande parte das atividades assistenciais, como também durante auxílio em atendimento de outros profissionais ${ }^{3}$. O primeiro caso de transmissão ocupacional da infecção pelo HIV foi documentado em 1984, na Inglaterra, quando uma enfermeira sofreu acidente ocupacional ${ }^{4}$. Estudos mostram que o modo de contágio com maior ocorrência envolve dedos e mãos, falta do uso de EPI's, carga horária exaustiva, sobrecarga de trabalho, sendo agulha e sangue os maiores veiculadores. $\mathrm{O}$ grupo com maiores registros de exposição, bem como contaminação pelo vírus está na categoria da enfermagem. Conclusão: Independente de qual for o perfil epidemiológico do país, fazse necessário a cautela, principalmente os profissionais de saúde durante a prestação do cuidado. Portanto, prover um ambiente de trabalho adequado, treinar e fiscalizar torna-se essencial para uma assistência de qualidade.
\end{abstract}

Descritores: Infecção hospitalar, HIV/AIDS, Acidentes ocupacionais.

\section{Referências}

1. BRASIL, Ministério da Saúde. AIDS. 2017. Disponível em: <http://portalms.saude.gov.br/saúde-de-a-z/aids>. Acesso em: 04/10/2019.

2. MACHADO, K. Medidas preventivas da equipe de Enfermagem frente aos riscos biológicos no ambiente hospitalar. Revista Científica do ITPAC, Araguaína, v.6, n.3, Pub.1, Julho 2013.

3. MAGAGNINI, M.A.M.; AYRES, J. A. Acidentes com material biológico: a Realidade de uma Instituição Hospitalar do Interior Paulista. REME -Rev. Min. Enfermagem. v.13, n.1, p.115-122, Jan./Mar., 2009.

4. CANALLI, R. T. C. Acidentes com materiais biológicos entre estudantes de enfermagem de um munícipio paulista. Ribeirão Preto 2008. Dissertação (Mestrado em Enfermagem). Escola de Enfermagem da Universidade de São Paulo - Ribeirão Preto, 2008.

${ }^{15}$ Graduando em Bacharelado em Enfermagem, CEUNI-FAMETRO, ManausAmazonas-Brasil.

${ }^{16}$ Enfermeira, Doutoranda, PPGIBA, UFAM, INPA, Manaus-Amazonas-Brasil. 


\title{
ESTRATÉGIAS DE AÇÃO PARA CONTENÇÃO DO SURTO DE SARAMPO EM MANAUS: UM RELATO DE EXPERIÊNCIA
}

\author{
Pollyana Mergulhão de Castro ${ }^{1}$ Ana Carolina de Moraes Crus² . João Victor Rodrigues \\ Carvalho ${ }^{3}$ Junio Vieira Nunes ${ }^{4}$ Leonardo Barbosa Rolim ${ }^{5}$
}

${ }^{1}$ Acadêmica de Enfermagem da Universidade Nilton Lins, Manaus, Amazonas, Brasil. 2Enfermeira Mestre em Doenças Infecciosas e Parasitárias - FMT/HDV, Manaus, Amazonas, Brasil. ${ }^{3}$ Acadêmico de enfermagem da Universidade Nilton Lins, Manaus, Amazonas, Brasil.

${ }^{4}$ Acadêmico de enfermagem da Universidade Nilton Lins, Manaus, Amazonas, Brasil.

${ }^{5}$ Enfermeiro Mestre em Ciências, em Saúde da Família - Oswaldo Crus, Manaus, Amazonas, Brasil.

\section{RESUMO}

Introdução: O sarampo é uma doença infecciosa exantemática aguda, transmissível e extremamente contagiosa. Pode ser grave e evoluir com complicações infecciosas e óbito, particularmente em crianças desnutridas e menores de um ano de idade. Em 2018, Manaus enfrentou um surto de sarampo, o qual foi necessário realizar atividades extremas para controlar o mesmo. Através do estágio realizado pela Secretária Municipal de Saúde (SEMSA) pelos acadêmicos de Enfermagem, permitiu que os mesmos estivessem atuando nas práticas para o controle do surto de Sarampo. Objetivo: O presente relato tem propósito descrever as estratégias e ações para contenção do surto de sarampo em Manaus sob a ótica de acadêmicos de enfermagem. Materiais e métodos: Trata-se de um estudo descritivo, do tipo relato de experiência elaborado pela vivência durante o estágio realizado no Distrito de Saúde Norte, no período de março a maio de 2018. O acompanhamento dos casos foi realizado através de boletim eletrônico epidemiológico pela secretária de vigilância em saúde do município. Resultados: As estratégias utilizadas nas quais os acadêmicos tiveram participação ativa para combater o surto foram: Busca ativa de contatos, bloqueio vacinal, investigação dos casos suspeitos, participação da campanha vacinal e intensificação vacinal em escolas, creches e comércios. Foram notificados 8.985 casos de sarampo em 2018, destes, 8.055 foram confirmados e 922 descartados. Conclusão: De acordo com os dados aqui relatados, podemos concluir a importância de um atendimento educacional e preventivo para que surtos como esse possam ser evitados, essas medidas devem ser mantidas de forma deliberada e permanente para um controle efetivo do agravo.

Descritores em Saúde: doenças transmissíveis, sarampo, vacinação.

\section{Referência}

Brasil. Ministério da Saúde. Secretaria de Vigilância em Saúde. Coordenação Geral de Desenvolvimento de Epidemiologia em Serviços. Guia de Vigilância em Saúde: volume 1/ Ministério da Saúde, Secretaria de Vigilância em Saúde, Coordenação-Geral de Desenvolvimento da Epidemiologia e Serviços. -1. Ed. Atual. - Brasília: Ministério da Saúde, 2017. 


\title{
CUIDADOS DE ENFERMAGEM EM UM AMBULATÓRIO DE PÉ DIABÉTICO: RELATO DE EXPERIÊNCIA
}

\author{
Daniel Araújo Freire ${ }^{17}$ Rosiane Sales Melo $^{18}$ Arimatéia Portela de Azevedo ${ }^{3}$
}

${ }^{1}$ Estudante. Curso de Enfermagem do Centro Universitário Nilton Lins UNINILTONLINS. Manaus/AM. Brasil.

${ }^{2}$ Estudante. Curso de Enfermagem do Centro Universitário Nilton Lins UNINILTONLINS. Manaus/AM.

Brasil.

${ }^{3}$ Enfermeiro. Mestre. Centro Universitário Nilton - UNINILTONLINS. Manaus/AM. Brasil.

\section{RESUMO}

Introdução: O Pé Diabético causa principalmente a amputação do membro inferior, e é considerada como um caso clínico bastante complexo, que pode acometer membros inferiores até os tornozelos de portadores de Diabetes Mellitus. Tem como principal fator, a neuropatia periférica ${ }^{1}$. A ferida do pé diabético deve ser analisada em conjunto com infectologista, que vai cuidar da infecção; endocrinologista, que controla a diabetes; o vascular, para melhorar a circulação no local; o estomaterapeuta, que é especialista em curativos $^{2}$. Objetivo: $O$ presente trabalho descreve a experiência vivenciada por um acadêmico de enfermagem, sendo executado um trabalho de monitorização de feridas recorrentes a pacientes com Diabetes em uma policlínica de Manaus-AM. Materiais E Métodos: Trata-se de um relato de experiência de um acadêmico do curso de enfermagem da Universidade Nilton Lins, após vivências anteriores em um estágio em policlínicas, no período de fevereiro à julho de 2018, com carga horária de 30 horas semanais, o trabalho no ambulatório era composto por um enfermeiro e uma técnica de enfermagem, a qual faziam curativos e o estagiário fazia as anotações no prontuário e as fotos para analisar a evolução das feridas. Resultados: Durante o estágio atendíamos cerca de 40 pacientes diários, com uma ou mais feridas em seus membros inferiores. As feridas na sua maioria eram infectadas, e o enfermeiro limpava tirando os esfacelos até a ferida ficar limpa. A causa das feridas eram dos mais variados motivos, mas o avanço se decorria por conta da diabetes. Lá tínhamos os mais variados tamanhos e formas de feridas, as infectadas tinha odor muito fétido e até necrose, fotografamos de como o paciente fez a admissão até sua alta. Conclusão: Ao finalizar o estágio percebeu-se que foram muito importantes as experiências de poder acompanhar cada paciente e sua evolução em relação a diminuição de suas feridas.

Descritores: Pé Diabético. Infecção dos Ferimentos. Infectologia. 


\section{REFERÊNCIAS:}

1. CAIAFA, Jackson Silveira, et al. Atenção integral ao portador de pé diabético. J. vasc. bras. Porto Alegre, v. 10, n. 4, supl. 2, p.1 32, 2011. Visto em: http://ref.scielo.org/yvfbch em 08 de outubro de 2019.

2. MELO, Elizabeth Mesquita et al. Evaluation of interfering factors in treatment adherence of patients with diabetic foot conditions. Rev. Enf. Ref., Coimbra, v. serIII, n. 5, p. 3744, dez. 2011. http://www.scielo.mec.pt/scielo.php?pid=S087402832011000300004\&script=sci_arttext\&tl ng=en em 08 de outubro 2019. 


\section{COBERTURA VACINAL DE H1N1 POR GRUPOS PRIORITÁRIOS EM MANAUS - AM}

$\underline{\text { Junio Vieira Nunes }^{1}}$ Alex Araújo Rodrigues ${ }^{2}$ Ana Carolina de Moraes Cruz ${ }^{3}$ Leonardo Barbosa Rolim ${ }^{4}$ Pollyana Mergulhão de Castro ${ }^{5}$

${ }^{1}$ Acadêmico de enfermagem da Universidade Nilton Lins, Manaus, Amazonas, Brasil. ${ }^{2}$ Enfermeiro especialista em Saúde da família - Faculdade Integrada de Patos, Campina Grande, Paraíba, Brasil

${ }^{3}$ Enfermeira Mestre em Doenças Infecciosas e Parasitárias - FMT/HDV, Manaus, Amazonas, Brasil. ${ }^{4}$ Enfermeiro Mestre em Ciências, em Saúde da Família - Oswaldo Crus, Manaus, Amazonas, Brasil. ${ }^{5}$ Acadêmica de Enfermagem da Universidade Nilton Lins, Manaus, Amazonas, Brasil.

\section{RESUMO}

Introdução: O H1N1 se configura como um grave problema de saúde publica de relevância local e nacional. Desta feita, o Ministério da Saúde e gestores locais tem empreendido esforços para o alcance da cobertura vacinal por grupos prioritários no combate a esta doença. Objetivo: $O$ objetivo do presente estudo foi apresentar a distribuição da cobertura vacinal de $\mathrm{H} 1 \mathrm{~N} 1$ por grupos prioritários, na cidade de Manaus - AM. Material e métodos: Trata-se de pesquisa, exploratória, descritiva, onde os dados foram extraídos do boletim epidemiológico da SEMSA de março de 2019. A coleta de dados se deu no mês de setembro de 2019. A descrição e analises dos dados foi feita por meio da estatística simples descritiva, com posterior discussão a luz da literatura. Resultados: Os resultados apontam que no período supracitado, no município de Manaus foram notificados 751 casos, destes, 255 foram confirmados, sendo: 100 casos de influenza, 144 casos sincicial respiratório (VRS) e 11 casos de outros vírus respiratórios. Já os casos em investigação restaram 496. No que se referem no grupo prioritário, as principais estatísticas de grupos vacinados foram para o grupo de professores, idosos e o grupo que apresentava algumas comorbidade, o que representou respectivamente: $95,94 \%, 81,01 \%, 96,09 \%$. Já o grupo prioritário de gestantes obtiveram um percentual de $48,06 \%$, o que representa um total de 14.274 gestantes vacinadas. Considerações finais: Os menores índices de imunização contra H1N1 foram às crianças, gestantes e trabalhadores da saúde, em sequencia. Acredita-se que as informações aqui divulgadas possam ser empregadas na fundamentação de estratégias de controle e prevenção da infecção pelo subtipo viral junto a população como crianças de 5 meses a 6 meses, gestantes, trabalhadores da saúde, puérperas, idosos, professores e morbidades.

Descritores em saúde: Influenza humana, vacinação em massa;

\section{Referências:}

1. FUNDAÇÃO DE VIGILÂNCIA EM SAÚDE DO ESTADO DO AMAZONAS. Situação Epidemiológica da Síndrome Respiratória Aguda Grave no Estado do Amazonas. ANO 7 | Nº 08, Pág. 1,17 de abril de 2019. 


\section{ATUAÇÃO DA ENFERMAGEM NO SERVIÇO DE ASSISTÊNCIA ESPECIALIZADA EM HIV/AIDS SOB A PERSPECTIVA DISCENTE}

Carlos Rafael Lopes de Azevedo ${ }^{1 \cdot}$ Karoline Costa de Souza ${ }^{2}{ }_{S}$ Suellen Oliveira de Sousa ${ }^{2}$ Albert Einstein Tavares de Seixas ${ }^{2}$ Alaidistânia Aparecida Ferreira ${ }^{3}$

1 Discente de Graduação em Enfermagem pela Universidade Federal do Amazonas (UFAM), Manaus, Amazonas, Brasil.

2 Discentes de Graduação em Enfermagem pela Universidade Federal do Amazonas (UFAM), Manaus, Amazonas, Brasil.

${ }^{3}$ Professora Doutora da Escola de Enfermagem de Manaus (EEM/UFAM), Manaus, Amazonas, Brasil.

\section{RESUMO}

Introdução: O Serviço de Assistência Especializada (SAE) é uma unidade assistencial de caráter ambulatorial que desenvolve ações multidisciplinar e contínua, como forma de garantir um atendimento integral às pessoas vivendo com HIV/AIDS (BRASIL, 2018). Nesse contexto, de acordo com Rocha et al. (2015), o enfermeiro deve promover uma assistência equânime e integral para promover aumento da expectativa e qualidade de vida desses indivíduos. Objetivo: Relatar a vivência de acadêmicos de enfermagem, a partir de práticas vivenciadas em um SAE na cidade de Manaus. Materiais E Métodos: Trata-se de um relato de experiência sobre a perspectiva de discentes de enfermagem que integram a Liga Acadêmica de Doenças Transmissíveis do Amazonas (LADTAM) quanto à atuação do enfermeiro no SAE. Resultados: A partir do contato com o SAE surgiram reflexões a cerca da importância do enfermeiro para a assistência ao cliente. Por conseguinte, a LADTAM possibilitou que os ligantes acompanhassem as consultas de enfermagem, onde eram realizadas ações educativas em saúde; que é uma habilidade fundamental para o profissional. Dessa forma, ocorreu um aprofundamento referente aos conteúdos teóricos vistos durante a formação. Verificou-se a atuação da equipe multiprofissional, desde a triagem até o atendimento com o infectologista. Conclusão: $E$ ́ necessário incentivar a criação de atividades de extensão que possibilitem ao graduando o conhecimento sobre o atendimento para as pessoas vivendo com HIV/AIDS, fortalecendo a formação de profissionais com capacidade de reconhecer seu papel no cuidado.

Descritores: Doenças Transmissíveis; Papel do Profissional de Enfermagem; Relações Comunidade-Instituição.

\section{REFERÊNCIAS:}

1. BRASIL. Ministério da Saúde. Secretaria de Vigilância em Saúde. Protocolo clínico e diretrizes terapêuticas para o manejo da infecção pelo HIV em adultos. Brasília (DF): Ministério da Saúde, 2018. [Acessado 3 Outubro 2019]. Disponível em: <http://www.aids.gov.br/pt-br/pub/2013/protocolo-clinico-e-diretrizes-terapeuticaspara-manejo-da-infeccao-pelo-hiv-em-adultos $>$ 
ANAIS DO I SIMPÓSIO CLÍNICO MULTIPROFISSIONAL DE

INFECTOLOGIA, 2019; 08-78

\section{PROJETO "INFECTO NA ESCOLA" - O USO NA DISCIPLINA ENFERMAGEM EM DOENÇAS INFECTOCONTAGIOSAS - RELATO DE EXPERIÊNCIA.}

Alice Lima Maceda ${ }^{1}$; Camilla Reane Silva ${ }^{2}{ }_{-}$Cézar Augusto ${ }^{3}$; Claubia Reane ${ }^{4}$; Railton Miranda $^{5}$

${ }^{1}$ Acadêmica do $8^{\circ}$ período do curso de Graduação em Enfermagem da Universidade Nilton Lins/UNL Manaus-AM.XVP

${ }^{2}$ Acadêmica do $8^{\circ}$ período do curso de Graduação em Enfermagem da Universidade Nilton Lins/UNL. Manaus-AM

${ }^{3}$ Acadêmico do $8^{\circ}$ período do curso de Graduação em Farmácia da Universidade Nilton Lins/UNL. Manaus-AM

${ }^{4}$ Acadêmica do $9^{\circ}$ período do curso de Graduação em Enfermagem da Universidade Nilton Lins/UNL. Manaus-AM

${ }^{5}$ Enfermeiro Especialista. Docente do curso de Graduação em Enfermagem da Universidade Nilton Lins/UNL. Manaus-AM

\section{RESUMO}

Introdução: O programa de saúde na escola contribui diretamente nas práticas em construção compartilhada de saberes sustentado pelas histórias individuais e coletivas e fazer com que os escolares tenham emponderamento para a mudança do estado que se encontram em relação a endemias, doenças negligenciadas, prevenção de ISTs, estado nutricional, entre outros. objetivos: Relatar a experiência do projeto infecto na escola como base funcional da disciplina Enfermagem em infectologia. Métodos: relato de experiência com ênfase na educação em saúde, aonde temas importantes acorda das infecções sexualmente transmissíveis e HIV/AIDS são realizadas. O projeto se deu com escolares superiores a 17 anos e os mesmos no responderam um quiz online sobre prevenção, transmissão e diagnóstico e avaliou-se primariamente o grau de entendimento, em seguida estudos de casos simplificados foram realizados e os alunos procuraram pelos problemas em saúde, finalizando a abordagem, os profissionais expõem os problemas e buscam soluções de saúde aos alunos. Como fase final, eles respondem o mesmo quiz online e verifica-se as respostas para aumento ou diminuição do conhecimento. Resultados: Os resultados foram considerados positivo e nas infecções como sífilis, gonorreia e cranco mole, o índice de respostas corretas chegou a $100 \%$, evidenciando assim que a educação em saúde é mais eficiente quando o conhecimento pode ser produzido a partir de problemas. Conclusão: O projeto teve como finalidade educar em saúde e transformar os modos de resolução de problemas de saúde público diário, isto é, os que podem ser resolvidos conjuntamente entre profissionais - sociedade, a enfermagem como grande precursora do cuidado se torna a porta de entrada para que a prevenção continue como base para que as doenças diminuam sua incidência/prevalência ou não ocorram.

Descritores: Enfermagem, saúde, infectologia. 
INFECTOLOGIA, 2019; 08-78

\section{Referência:}

TANAKA, Luana Fiengo; Latorre, Maria do Rosário Dias de Oliveira; Silva, Aline Medeiros da; Konstantyner, Thais Claudia Roma de Oliveira; Peres, Stela Verzinhasse; Marques, Heloisa Helena de Sousa. Alta prevalência de sedentarismo em adolescentes que vivem com HIV/Aids / High prevalence of physical inactivity among adolescents living with HIV/AIDS $\underline{\text { Rev. paul. }}$ pediatr; 33(3): 326-331, jul.-set. 2015. Tab Artigo em Português| LILACS | ID: lil-761143. BESERRA Eveline Pinheiro, ARAÚJO Márcio Flávio Moura de, BARROSO Maria Grasiela Teixeira; Promoção da saúde em doenças transmissíveis - uma investigação entre adolescentes. Acta Paul Enferm 2006;19(4):402-7. 


\section{LEISHMANIOSE MUCOSA: ASPECTOS CLÍNICOS, EPIDEMIOLÓGICOS E EVOLUTIVOS DE PACIENTES ATENDIDOS EM UM CENTRO DE REFERÊNCIA EM MANAUS DE JANEIRO DE 2007 A DEZEMBRO DE 2016.}

Lottar Matheus de Souza Costa ${ }^{1}$; Luciana Mendes dos Santos ${ }^{2}$; Nicolle Tayná Brandão dos Santos ${ }^{3}$; Bleno Leonam Golçalves da Costa ${ }^{4}$; Jorge Augusto de Oliveira Guerra ${ }^{5}$.

Introdução: As leishmanioses são antropozoonoses consideradas um grande problema de saúde pública e representam um complexo grupo de doenças. A Organização Mundial da Saúde (OMS) estima que 350 milhões de pessoas estejam expostas ao risco. É uma doença infecciosa, não contagiosa, causada por diferentes espécies de protozoários do gênero Leishmania, que acomete pele e mucosas. A leishmaniose tegumentar (LT) tem ampla distribuição mundial e no Continente Americanoo e o envolvimento mucoso é freqüente. Objetivos: Avaliar os aspectos clínicos, epidemiologicos e evolutivos de pacientes portadores de Leishmaniose Mucosa (LM) atendidos na Fundação de Medicina Tropical Doutor Heitor Vieira Dourado no periodo de 2007 a 2016. Métodos: Avaliouse registro, sexo, faixa etária, atividade, registro de Leishmaniose cutãnea (LC) anterior, apresentacão clinica, tempo de entre LC e LM, tempo de LM e desfecho dos casos. Resultados: Avaliou-se dados de 138 pacientes, 117 (85\%) do sexo masculino, média de idade: 51,8 anos. 99 (72\%) apresentavam história prévia de leishmaniose cutânea. Lesões nasais foram observadas em 121 (87\%) casos, 13 (9\%) obtiveram envolvimento extra nasal. 92 (67\%) desenvolviam atividades extrativistas na época da LC. O tempo médio entre ocorrência, lesões de pele aos sintomas de LC foi de 2,1 anos em 92 (67\%) pacientes, 11(8\%) apresentavam concomitancia de lesoes. No desfecho final do tratamento observou-se uma taxa de cura de $75 \%$ (104) com uma perda de seguimento de 25\% (34 pacientes). Conclusão: Foi observado que há predominancia dos casos do sexo masculino sendo a exposição relacionada a atividades extrativistas e predominância da L.(V) braziliensis entre as espécies caracterizadas, logo diagnostico precoce da LM e acesso ao tratamento e monitoramento de longo prazo é crucial, dada a complexidade, gravidade e as possíveis complicações da doença.

Palavra-chave: LTA, Diagnóstico, Leishmaniose cutânea.

Referênicas

BRASIL M da saúde. Manual De Vigilância Da Leishmaniose Tegumentar. Secretaria de Vigilância em Saúde. 2017. 159 p.

\footnotetext{
19 Graduando em Enfermagem, Acadêmico da Universidade Nilton Lins, PAIC da Fundação de Medicina Tropical Heitor Vieira Dourado, Manaus, Amazonas, Brasil, E-mail: 15100183@uniniltonlins.edu.br 2 Graduada em Medicina pela Universidade Federal do Amazonas, Doutorando em Doenças Tropicais e Infecciosas, Fundação de Medicina Tropical Heitor Vieira Dourado e UEA, Manaus, Amazonas, Brasil. ${ }^{3}$ Graduação em Biomedicina pela Fametro, Programa de pós graduação em Ciências aplicadas a dermatologia pela UEA em convênio com a Fundação Alfredo da Matta . ${ }^{4}$ Graduado em Enfermagem pela Uninorte, Mestrando no programa de pós graduação em Ciências da Saúde pela Ufam. ${ }^{5}$ Graduação em Medicina pela UFAM, Doutorado em Doenças Tropicais e infecciosas, Docente, e pesquisador pela FMTDHVD, Manaus, Amazonas.

Patrocínio: Universidade Federal da Bahia. ${ }^{3}$
} 


\section{ASSISTÊNCIA À SAÚDE DA MULHER TRANSGÊNERO PORTADORA DE HIV/AIDS NO BRASIL}

$\underline{\text { Heriederson Sávio Dias Moura }}^{20}$; Anderson Lima Cordeiro da Silva ${ }^{21}$; Diorges Boone da Silva ${ }^{22}$; Marinara de Mendonça Bezerra ${ }^{23}$; Erika Oliveira da Silva ${ }^{24}$.

Introdução: Transexualidade é movimento social ligado a uma questão de identidade e de modo de viver ${ }^{1}$. As mulheres transgênero buscam a possibilidade de pertencimento social, para isso, utilizam da prostituição como modo de sobrevivência financeira, porém esse exercício acarreta o aumento dos riscos de contrair HIV/Aids ${ }^{2}$. Objetivo: Identificar publicações científicas inerentes à assistência à saúde da mulher transgênero portadora de HIV/AIDS no Brasil. Método: Revisão bibliográfica descritiva, foram consultadas as bases Scielo e PubMed, utilizando critérios para inclusão e exclusão das publicações. Resultados: Inúmeros fatores levam as mulhers transgêneros ao trabalho sexual como sua principal atividade econômica, podendo citar a exclusão social e marginalização, levando a uma alta vulnerabilidade à infecção pelo HIV $^{2}$. A discriminação e a falta de conhecimento do status de HIV faz com que as mulheres transexuais não utilizem o tratamento precoce, que é disponibilizado no Sistema de Saúde Pública para indivíduos infectados pelo HIV no Brasil ${ }^{3}$. Conclusão: Essa abordagem trás um olhar crítico e reflexivo quanto à necessidade de prestar uma assistência humanizada a população transgênero, como também identificar a necessidade de implementar ações de prevenção especificas. Torna-se fundamental, também, a ampliação do conhecimento quanto à assistência prestada a mulheres transgênero, uma vez que esta população enfrenta discriminação nos ambientes de saúde, assim como a transfobia. Além do mais, essa pesquisa pode instigar posteriores estudos quanto à prática profissional de enfermagem a este público.

Descritores: Mulher Transgênero; HIV; Assistência Integral à Saúde.

\section{Referências}

BRASIL. Política nacional de saúde integral de lésbicas, gays, bissexuais, travestis e transexuais. $1^{\mathrm{a}}$ ed. Brasília, DF : Ministério da Saúde, 2013.

SILVA-SANTISTEBAN, A. et al. HIV prevention among transgender women in Latin America: implementation, gaps and challenges. Journal of the international aids society; 19 (3Suppl 2) : 20799, 2016.

GRINSZTEJN, B.; JALIL, E. M.; MONTEIRO, L. et al. Unveiling HIV dynamics among transgender women: a respondent driven sampling study in Rio de Janeiro, Brazil. HHS Public Access; Lancet HIV: Apr; 4(4) : e169-e176, 2017.

\footnotetext{
${ }^{20}$ Graduando em Bacharelado em Enfermagem, CEUNI-FAMETRO, Manaus-AmazonasBrasil. E-mail: heriederson@gmail.com

${ }^{21}$ Graduando em Bacharelado em Enfermagem, CEUNI-FAMETRO, Manaus-AmazonasBrasil.

${ }^{22}$ Graduando em Bacharelado em Enfermagem, CEUNI-FAMETRO, Manaus-AmazonasBrasil.

${ }^{23}$ Graduanda em Bacharelado em Enfermagem, CEUNI-FAMETRO, Manaus-AmazonasBrasil.

${ }^{24}$ Enfermeira, Doutoranda, PPGIBA, UFAM, INPA, Manaus-Amazonas-Brasil.
} 


\title{
COINFECÇÃO DE CRIPTOCOCOSE E HISTOPLASMOSE EM IMUNOCOMPETENTES - REVISÃO DE LITERATURA
}

\author{
ROOSEVELT GUIMARÃES SOARES JÚNIOR ${ }^{1}$ GABRIEL OLIVEIRA SOUZA $^{2}$
}

1 Acadêmico do Curso de Graduação em Farmácia na Universidade Nilton Lins, Manaus (AM), Brasil.

2 Farmacêutico; Especialista em Farmácia Clínica em Cirurgia, Emergência e Trauma; Docente na Graduação de Farmácia da Universidade Nilton Lins, Manaus (AM), Brasil. Autor correspondente: Roosevelt Guimarães Soares Júnior - e-mail: junioroosevelt@gmail.com

\section{RESUMO}

Introdução: Coinfecção por criptococoses e histoplasmoses são frequentemente encontradas em pacientes imunocomprometidos, sendo esta, considerada rara neste grupo de indivíduos. Todavia, existem relatos da coinfecção em pacientes imunocompetentes. Objetivo: Revisar a coinfecção de criptococose e histoplasmose em pacientes imunocompetentes, através de achados clínicos, bem como elucidar o melhor modelo de tratamento com fármacos antifúngicos. Material e Métodos: Através das bases de dados PUBMED, Elselvier e Scielo, foi realizado levantamento bibliográfico usando os descritores: coinfections, histoplasmosis e cryptococosis. Resultados: Dos 10 artigos obtidos, apenas 2 foram selecionados, após análise, para compor essa revisão cientifica. O primeiro caso, paciente 69 anos, fumante, com doença pulmonar obstrutiva crônica (DPOC) e diabetes mellitus tipo 2 (DM), apresenta tosse, chiado e dispneia durante 5 meses. Após os exames, o resultado foi negativo para câncer. Com paciente reinternado, onde a avaliação do líquido cefalorraquidiano (LCR) revelou o sorotipo de $C$. neoformans, isolado em cultura. O esfregaço sanguíneo com coloração May-GrunwaldGiemsa apresentou levedura de Histoplasma sp. Tratamento realizado com: anfotericina B e administração intravenosa de fluconazol. O segundo caso, paciente de 71 anos, HIV negativo, diagnosticado com miastenia gravis (MG). Apresentava quadro de dor no peito com dispneia, leucocitose, além de infiltrados multifocais nos lobos pulmonares. Tratamento realizado com: prednisona e micofenolato (para a MG); antibióticos de amplo espectro: vancomicina, piperacilina, ciprofloxacina e levofloxacina. Apresentou posteriormente quadro de insuficiência respiratória hipoxêmica aguda. Exames anteriores foram revisados e retornaram positivos para histoplasma e criptococose. Discussão: Alguns fatores foram semelhantes nos dois casos, sendo eles: dispneia, presença de neutrofilia, além do pré-estabelecimento da diabetes mellitus tipo 2. Conclusão: Fármacos imunossupressores como os corticoides, podem colaborar para a instalação de infecções fúngicas em pacientes imunocompetentes. Visando avaliar os benefícios desses fármacos no manejo farmacológico em imunossuprimidos, deve-se proporcionar maior vigilância a esses pacientes, visto maior comprometimento imunológico.

Descritores: Coinfecção, Criptococose, Histoplasmose.

\section{REFERÊNCIAS:}

ASIF, S; BENNETT, J; PAULY, R. A Unique Case of Cryptococcus and Histoplasmosis Co-infection in na HIV-Negative Male on Chronic Steroid Therapy. Cureus: 2019. Disponível em: $<$ https://www.cureus.com/articles/20005-a-unique-case-of-cryptococcus-and-histoplasmosis-co-infectionin-an-hiv-negative-male-on-chronic-steroid-therapy>. Acesso em 18 de setembro de 2019.

NUNES, J. et. al. The Simultaneos Occurrence of Histoplasmosis and Cryptococcal Fungemia: A Case Report and Review of the Literature. Mycopathologia: 2016. Disponível em: <https://www.ncbi.nlm.nih.gov/pubmed/27423433>. Acesso em: 18 de setembro de 2019. 


\title{
ATUAÇÃO DE ACADÊMICOS DE ENFERMAGEM NA CAMPANHA NACIONAL DE VACINAÇÃO CONTRA O SARAMPO
}

\author{
$\underline{\text { Suellen Oliveira de Sousa }}{ }^{1}$. Albert Einstein Tavares de Seixas ${ }^{2}$. Karoline Costa de \\ Souza $^{2}$ Carlos Rafael Lopes de Azevedo² Alaidistânia Aparecida Ferreira ${ }^{3}$ \\ 1 Discente de Graduação em Enfermagem da Universidade Federal do Amazonas \\ (UFAM), Manaus, Amazonas, Brasil. E-mail: suellen.o.sousa97@ gmail.com \\ 2 Discentes de Graduação em Enfermagem da Universidade Federal do Amazonas, \\ Manaus, Amazonas, Brasil. \\ 3 Professora Doutora da Escola de Enfermagem de Manaus (EEM/UFAM), Manaus, \\ Amazonas, Brasil.
}

INTRODUÇÃO: O sarampo é uma doença febril exantematosa aguda que apresenta alta transmissibilidade, causada por um vírus. Sua transmissão é direta, através de secreções nasofaríngeas. A medida profilática adotada mundialmente é a vacinação, que, no Brasil, é oferecida pelo Sistema Único de Saúde através da Tríplice Viral (XAVIER et al., 2019). Em 2019, o Ministério da Saúde interrompeu a transmissão do vírus do sarampo na região norte do país, após um surto relacionado à transmissibilidade de casos oriundos da Venezuela em 2018 (BRASIL, 2019; XAVIER et al., 2019). OBJETIVO: Relatar a experiência de acadêmicos de enfermagem em ações de controle do surto de Sarampo. METODOLOGIA: A experiência foi viabilizada pela Liga Acadêmica de Doenças Transmissíveis do Amazonas da Universidade Federal do Amazonas (UFAM), nos meses de agosto, outubro e novembro de 2018. Os acadêmicos atuaram na vacinação, orientação, sensibilização e atualização da situação vacinal dos grupos de risco da Campanha Nacional de Vacinação contra o sarampo. As atividades foram realizadas em unidades da UFAM, igreja e escolas do município de Manaus. RESULTADOS: Através da vivência, foi observada deficiência da situação vacinal no Amazonas, a carência de informação da população acerca da importância da imunização para sua própria saúde e controle de surtos, como o ocorrido em 2018. Constatou-se também como a educação em saúde é uma ferramenta necessária para a perpetuação de informações, uma vez que, depois das orientações, a demanda dos grupos de risco - principalmente familiares de indivíduos já vacinados pelos acadêmicos- aumentou bastante. CONCLUSÃO: A extensão como um dos eixos da formação universitária em saúde proporciona ao acadêmico o contato direto com as necessidades da população, suas principais problemáticas e a possibilidade de intervenção. A experiência descrita reafirma a vantagem, tanto para o acadêmico, como para a comunidade, da universidade estar inserida diretamente no controle de doenças infectocontagiosas.

DESCRITORES: Sarampo; Doenças Transmissíveis; Imunização.

\section{REFERÊNCIAS:}

BRASIL. Ministério da Saúde. Secretaria de Vigilância em Saúde. SARAMPO Boletim Epidemiológico, v.50, n.19, Jun./Ago, 2019.

XAVIER, Analucia R. et al. Diagnóstico clínico, laboratorial e profilático do sarampo no Brasil. Jornal Brasileiro de Patologia e Medicina Laboratorial, v. 55, n. 4, p. 390-401, 2019. 


\section{ATUAÇÃo DE ACADÊMICOS NA PROMOÇÃO DA SAÚDE A MULHERES ATRAVÉS DA EDUCAÇÃO EM SAÚDE}

$\underline{\text { Suellen Oliveira de Sousa }}{ }^{1}$ Albert Einstein Tavares de Seixas ${ }^{2}$ Carlos Rafael Lopes de Azevedo $^{2}$. Karoline Costa de Souza ${ }^{2}$. Sibele Naiara Ferreira Germano ${ }^{3}$

1 Discente de Graduação em Enfermagem da Universidade Federal do Amazonas (UFAM), Manaus, Amazonas, Brasil. E-mail: suellen.o.sousa97@ gmail.com

2 Discentes de Graduação em Enfermagem da Universidade Federal do Amazonas, Manaus, Amazonas, Brasil.

${ }^{3}$ Enfermeira, Mestranda da Universidade Federal do Amazonas, Manaus, Amazonas, Brasil.

INTRODUÇÃO: As mulheres, através do seu mecanismo fisiológico vaginal, apresentam secreções que variam de acordo com alterações hormonais e comumente são confundidas com infecções. O corrimento vaginal pode ser indicativo de Infecção Sexualmente Transmissível (IST's) ou não; pode estar associado a outros sintomas e precisa de tratamento correto, quando necessário. A orientação adequada é a melhor forma de prevenção e identificação do corrimento patológico (TABILE, et al., 2016). OBJETIVO: Relatar a experiência de acadêmicos de enfermagem na promoção da saúde da mulher através da educação em saúde. METODOLOGIA: A experiência ocorreu no segundo semestre de 2018, em uma Unidade Básica de Saúde na zona norte de Manaus, durante as atividades do projeto de extensão da Universidade Federal do Amazonas intitulado "O reconhecimento do corpo feminino nas diferentes fases da vida para a promoção da saúde, prevenção e tratamento das ISTs". Na ocasião, foram confeccionados folders para distribuição às mulheres presentes nas rodas de conversa, após as discussões sobre o autocuidado, autoconhecimento, prevenção de IST's e direitos da mulher no Sistema Único de Saúde, foram realizadas dinâmicas para a avaliação de aprendizado. RESULTADOS: Observou-se que ainda há muitas dúvidas a respeito do corrimento fisiológico e patológico, que muitas vezes impedem a prevenção de agravos. As rodas de conversa possuíam instrumentos de avaliação da comunidade, nos quais foram registrados agradecimentos aos acadêmicos sobre a relevância do tema abordado, a forma como foi debatido e o impacto da atividade para a saúde das mulheres. CONCLUSÃO: A educação em saúde é a estratégia mais eficaz na promoção da saúde pelo enfermeiro. Percebe-se a importância de os acadêmicos estarem atuando na disseminação de conhecimento para estimular o autocuidado nas mulheres, visto que, até os dias atuais essa temática é tratada como um tabu e acarreta sérios problemas de saúde pública.

DESCRITORES: Saúde da Mulher; Educação em Saúde; Doenças Sexualmente Transmissíveis.

\section{REFERÊNCIAS:}

TABILE, Patrícia Micheli et al. Características clínicas, prevalência e diagnóstico de vulvovaginites em ambulatório do interior do Rio Grande do Sul. Journal of Health \& Biological Sciences, v. 4, n. 3, p. 160-165, 2016. 


\title{
ADMISSÃO DA PACIENTE NO PRÉ- PARTO E AVALIAÇÃO SINTOMATOLÓGICA DE DOENÇAS INFECCIOSAS: RELATO DE EXPERIÊNCIA
}

\author{
Diana Claúdia de Paiva dos Santos ${ }^{\mathrm{I}}$ Julie Bianca Matos dos Anjos ${ }^{\mathrm{II}}$ Karina Mendonça \\ da Silva ${ }^{\text {III. Kemelly Oriente de Matos }}{ }^{\text {IV }}$ Liandra da Costa Saraiva ${ }^{\mathrm{V}}$ \\ 'Enfermeira Especialista em Unidade de Terapia Intensiva (UTI), Urgência e emergência, obstetrícia, \\ docente do curso de Graduação em Enfermagem da Universidade Nilton Lins, Manaus-AM, Brasil. \\ ${ }^{\mathrm{II}}$ Acadêmica de enfermagem na Universidade Nilton Lins, Manaus-AM; \\ III Acadêmica de enfermagem na Universidade Nilton Lins, Manaus-AM; \\ IV Acadêmica de enfermagem na Universidade Nilton Lins, Manaus-AM, Brasil. \\ kemellyoriente19@hotmail.com \\ ${ }^{\mathrm{V}}$ Acadêmica de enfermagem na Universidade Nilton Lins, Manaus-AM;
}

Introdução: $\mathrm{O}$ teste rápido na maternidade é fundamental, mesmo que a gestante tenha realizado exames no $3^{\circ}$ trimestre, existe a possibilidade de infecção e transmissão pela via hematogênica transplacentária, tornando-se indispensável a avaliação clínicalaboratorial das gestantes para identificação de doenças transmissíveis durante todo período da gestação até o puerpério. Objetivo: Relatar a importância da avaliação sintomatológica de doenças infecciosas no momento do pré-parto, baseado na perspectiva vivenciada em uma maternidade de referência localizada em Manaus. Metodologia: Foi realizado um estudo descritivo, do tipo relato de experiência, realizado em maio de 2019. Consiste em avaliar prontuários e diagnósticos de mulheres no momento do pré-parto, conscientizando pacientes quanto à prevenção da transmissão vertical, e identificando sintomas relacionados a doenças infecciosas, para uma assistência adequada. Resultados: Através da análise foi possível observar a importância da confirmação do diagnóstico das doenças infecciosas na admissão para o parto, almejando prevenir o acometimento de doenças que podem ser transmitidas verticalmente. Conclusão: A sensibilidade e conhecimento técnico-científico dos profissionais de saúde na avaliação da mulher no momento do pré-parto é importante na adoção de medidas para prevenir e reduzir a transmissão vertical de doenças infecciosas, ressaltando os testes rápidos feitos na maternidade, contribuindo para reversão dos indicadores perinatais.

Descritores: Doenças infecciosas, transmissão vertical, admissão do paciente.

\section{Referências}

OLIVEIRA, M, I, C. SILVA, K, S. GOMES, D, M, Fatores associados á submissão ao teste rápido anti-HIV na assistência ao parto. Ciênc. saúde coletiva online. São Paulo, vol.23, n.2, (2018): fevereiro. BRASIL. Ministério da Saúde (MS). Transmissão vertical do HIV e sífilis: estratégias para redução e eliminação. Brasília: MS, 2014. 


\section{ATITUDES E PRÁTICAS DOS SERVIDORES DE UNIDADE DE PROCESSAMENTO DE ROUPAS DE SERVIÇOS DE SAÚDE SOBRE COMPORTAMENTO EM AMBIENTE DE LAVANDERIA HOSPITAR DE MANAUS/AM}

\section{Arimatéia Portela de Azevedo ${ }^{1}$ Geissa Paula Trindade Nobre ${ }^{2}$ Lucely Damasceno de Jesus $^{3}$ Maria Lucivane Félix da Silva ${ }^{4}$}

INTRODUÇÃO: A lavanderia hospitalar (LH) é o setor responsável pela lavagem e desinfecção de roupas de uso hospitalares na tentativa de diminuir infecções. Um ambiente complexo, que apresentam diferentes riscos aos trabalhadores da saúde, e os acidentes de trabalho, constituem a serem um problema quanto a infecção por material biológico. OBJETIVOS: Este estudo tem como objetivo registrar a percepção dos servidores da lavanderia da FMT/HVD sobre biossegurança e comportamento em ambiente hospitalar. MATERIAIS E MÉTODOS: Trata-se de um estudo prospectivo descritivo analítico. RESULTADOS: Os responsável pelo processamento de roupas da FMT/HVD que receberam orientações sobre biossegurança e comportamento em ambiente crítico, 66,6\% eram do gênero feminino com idade entre 23 a 32 anos e $76 \%$ tinha apenas o ensino fundamental incompleto e $70 \%$ destes nunca havia trabalhado em lavanderia hospitalar antes e $75 \%$ deles não tinham conhecimento de como se comportar em ambiente crítico. CONCLUSÃO: Dessa forma, a lavanderia hospitalar de um hospital precisa promover a qualidade de vida de seus colaboradores através do uso adequados dos EPI`s, para a segurança e prática do dia a dia.

DESCRITORES: Processamento de roupas, serviços de saúde

\section{REFERÊNCIAS:}

DONATELLI, S; VILELA, R.A.G; ALEMIIDA, L. M; LOPES, M.G.R. Acidente com material biológico: uma abordagem a partir de análise das atividades de trabalho. Artigos. Saúde soc. 24 nº São Paulo, Out/Dez, 2015.

FERNANDES, D.M, FERNANDES, S.B, FERRAZZA, C.A.C. Gestação para a segurança e a qualidade de vida no trabalho em uma lavanderia hospitalar. RAS- VOL $15, \mathrm{~N}^{\mathrm{a}} 61$ - Out-Dez,2013. 


\section{RELATO DE EXPERIÊNCIA: PERCEPÇÃO E CONHECIMENTO DOS ACADÊMICOS DE ENFERMAGEM QUANTO À EXPOSIÇÃO AOS RISCOS BIOLÓGICOS.}

MICHELLI DOMINGOS DA SILVA $^{25}$, TEZEU BOMFIM MACHADO ${ }^{26}$, RAILTON MIRANDA DA SILVA ${ }^{27}$.

INTRODUÇÃO: Biossegurança é o conjunto de ações voltadas para a prevenção, minimização ou eliminação dos riscos inerentes ás atividades (ALBUQUERQUE et al., 2016). Ainda assim, é de extrema importância relacionar a biossegurança a legalização no Brasil que está vinculada a Lei $\mathrm{N}^{\circ} 11.105$ de 25 de março de 2005, que dispõe sobre a Política Nacional de Biossegurança (SILVA et al., 2017). OBJETIVO: Relatar o processo de contaminação por material biológico em acadêmicos de enfermagem. METODOLOGIA: Estudo do tipo de relato de experiência narrativo descritivo, onde o cenário foi a Unidade de Pronto Atendimento da Zona Oeste, Manaus - AM. A população alvo do estudo foram 35 graduandos do curso de enfermagem do $5^{\circ}$ período e $8^{\circ}$. RESULTADOS E DISCUSSÕES: Os acidentes de trabalho estão presentes no dia-adia de todos os profissionais de saúde, e de certa forma está vinculada a outra atividade. Embora esses episódios de exposições ocupacionais aos instrumentos evidentemente contaminados ainda é um fator preocupante entre os acadêmicos de enfermagem no ambiente hospitalar. Durante as aulas práticas hospitalar, expliquei sobre as precauções que incluem a utilização de Equipamento de Proteção Individual (EPI), higienização das mãos, vacina contra a hepatite B e cuidados singulares para a manipulação e descarte de materiais contaminados por sangue, o que inclui a recomendação de "não reencapar agulhas". Entretanto, isso não aconteceu, eles estavam reencapando as agulhas. CONCLUSÃO: Com este relato de experiência, foi possível constatar a vulnerabilidade dos discentes quanto aos riscos inerentes ao ambiente de ensino-prático.

Descritores de Saúde: Enfermagem; Risco Biológico; Exposição

\section{REFERÊNCIA}

\footnotetext{
${ }^{25}$ Enfermeira. Doutoranda. Universidade Nilton Lins.

${ }^{26}$ Enfermeiro. Mestrando. Universidade Nilton Lins.

${ }^{27}$ Enfermeiro. Especialista. Universidade Nilton Lins.
} 
ALBUQUERQUE SGE et al. Fatores de risco à segurança do enfermeiro na unidade de terapia intensiva de um hospital geral. Revista Brasileira de Ciências da Saúde, v. 19, n. 2, p. 135-142, 2016. 


\title{
ATENÇÃO FARMACÊUTICA NA DISPENSAÇÃO DA PROFILAXIA PÓS- EXPOSIÇÃO NUMA FUNDAÇÃO DE REFERÊNICA - RELATO DE EXPERIẾNCIA
}

\author{
Eron Barbosa Fonseca $^{28}$
}

\begin{abstract}
RESUMO
Introdução: A Profilaxia Pós-Exposição (PEP) de risco à infecção pelo HIV, consiste no uso de medicamentos para reduzir o risco de adquirir a infecção. E deve ser utilizada após qualquer situação em que exista risco de contágio, tais como: violência sexual, relação sexual desprotegida e acidente ocupacional com instrumentos perfurocortantes ou contato direto com material biológico. É uma emergência que deve ser iniciada preferencialmente após a exposição ou no máximo até 72 horas. Além do esquema antirretroviral (ARV) usado os pacientes recebem orientação quanto ao uso de outros meios de prevenção. $O$ farmacêutico no ato da dispensação dos medicamentos realiza a orientação acerca dos riscos da exposição e as reações adversas que os medicamentos podem causar, assim como suas interações medicamentosas. Objetivo: Relatar a importância da orientação farmacêutica aos pacientes que realizam com frequência a PEP. Metodologia: Trata-se de um estudo descritivo com abordagem qualitativa, tipo relato de experiência na área de farmácia, durante a atenção farmacêutica na dispensação dos ARV em ambiente hospitalar de uma Fundação de Referência em Infectologia na cidade de Manaus-AM. Resultados: Os pacientes recorrentes no uso da PEP, eram orientados quanto ao programa de Profilaxia Pré-exposição (PREP), uma estratégia eficaz e segura para pessoas com risco aumentado de adquirir a infecção, como as pessoas recorrentes de exposição. Assim como reforçar o uso de preservativos e uso de Equipamento de Proteção Individual (EPI) no trabalho. Conclusão: A orientação farmacêutica possibilita uma melhor adesão a prevenção, ao autocuidado e a conhecimentos acerca dos efeitos adversos pelo uso dos medicamentos, assim como na orientação de prevenções combinadas eficazes.
\end{abstract}

Descritores: Atenção Farmacêutica, Antirretrovirais, Hiv.

${ }^{28}$ Farmacêutico Especialista em Farmácia Clínica e Hospitalar, Residente do Programa de Residência Multiprofissional em Saúde de Apoio Diagnóstico e Terapêutico, Fundação de Medicina Tropical - HVD / Universidade Nilton Lins. Manaus. Amazonas. Brasil. E-mail: eron.ebf@gmail.com 


\title{
SOFRIMENTO MORAL DURANTE A RESIDÊNCIA EM ENFERMAGEM NUMA UNIDADE DE SAÚDE - RELATO DE EXPERIÊNCIA
}

\author{
Kalry Miranda Oliveira Queiroz ${ }^{1}$
}

Introdução: o sofrimento moral começou a ser descrito na década de oitenta do último século (BARLEM, 2012), segundo Pereira et al (2017) é o produto de situações em que por meio de pressão o profissional é obrigado a agir de uma forma errada do ponto de vista ético. Franco et al (2005) em um trabalho prévio evidenciaram comprometimento nos aspectos mentais e emocionais entre residentes de enfermagem, prevalecendo disforia e depressão em 27,9\% dos participantes. Objetivo: relatar o sofrimento moral durante a residência de enfermagem numa unidade de saúde da cidade de Manaus. Método estudo qualitativo de abordagem exploratório-descritiva, realizado numa unidade de saúde considerada como referência no atendimento em doenças infectoparasitárias na cidade de Manaus. O relator é o próprio autor deste trabalho, residente do programa de Terapia Intensiva. Relato: a pressão psicológica e estressora por parte da preceptora de campo desencadeou no participante do estudo um mau desempenho no decorrer da assistência (dificuldade de tomada de decisão, ansiedade e psicossomatização) atrelada ao impedimento de relacionamento com os demais colegas que compõem a equipe multiprofissional. Tal vivência descumpre totalmente o princípio da residência multiprofissional, uma vez que o programa propõe uma inserção e atuação do profissional na equipe multiprofissional de modo integral e humanizado, qualificando-o para uma assistência resolutiva, eficaz e transformadora da sociedade. Conclusão: a residência em enfermagem consiste numa oportunidade ímpar ao pós-graduando para potencializar a sua formação em determinada área. Fatores individuais, institucionais e sociais interferem nesse processo de modo positivo ou negativo, nesse caso, o sofrimento moral emerge como uma preocupação sobre o bem estar biopsicossocial do residente. As vivências relacionadas principalmente aos estressores de relacionamento foram as evidências encontradas neste trabalho. Como limitação para o seu desenvolvimento encontra-se a baixa disponibilidade de artigos nos bancos de dados.

Descritores: sofrimento moral. Residência. Enfermagem.

\section{Referências:}

BARLEM, E.L.D. Vivência do sofrimento moral na enfermagem: percepção da enfermeira. Rev. Esc. Enferm. USP, v. 46, n. 3, p. 681-688, 2012.

FRANCO, G.P. et al. Qualidade de vida e sintomas depressivos em residentes de enfermagem. Rev. Latino-Am. Enferm., v. 13, n. 2, p. 139-144, mar.-abr., 2005. PEREIRA, V.T. et al Vivências de sofrimento moral pela equipe de enfermagem no centro cirúrgico. Convibra [Internet]. Acesso em 10/06/019. 2017. Disponível em: http://www.convibra.com.br/upload/paper/2017/156/2017_156_14283.pdf. 